STRUGTURAL ASPEGTS OF NEUROSEGRETORY AND GORPUS ALLATUM AGTiVity in THE ADULT GOLORADO BEETLE, LEPTINOTARSA DECEMLINEATA SAY, AS A FUNGTION OF DAYLENGTH 



\section{STELLINGEN}

\section{I}

Gezien de uiterst gecompliceerde structuur van het neurosecretorische systeem van insekten dient het gebruik van een term als "brain hormone" vermeden te worden.

Dit proefschrift

\section{II}

Zonder inzicht te hebben in de dynamiek van productie, axonaal transport en afgifte van neurosecreet, is het niet mogelijk de activiteitstoestand van een neurosecretorisch systeem af te leiden uit de hoeveelheid neurosecreet die dit systeem bevat.

Dit proefschrift

K. C. Highnam, 1965. Zool. Jb., Physiol. 71: 558-582

\section{III}

BERN's karakterisering van neuronen in termen als "possibly", "probably", of "definitely neurosecretory" leidt tot vergroting van de spraakverwarring en bewijst geen dienst aan het onderzoek.

H. A. Bern , 1962. Gen. comp. Endocr. Suppl. 1: 117-132

\section{IV}

De conclusie van Thomsen en LeA dat het corpus allatum van Calliphora erythrocephala de activiteit van de neurosecretorische cellen rechtstreeks reguleert, is aanvechtbaar.

E. Thomsen \& A. O. Lea, 1968. Gen. comp. Endocr. 12: 51-57

A. O. Lea \& E. Thomsen, 1969. J. Insect Physiol. 15: 477-482

\section{V}

In het kader van de Geïntegreerde Bestrijding van Plagen is het van belang, de onderzoekingen naar de effecten van planten-groeiregulatoren op insekten nauwkeurig te volgen en waar mogelijk te stimuleren. 


\section{I}

Methoden zoals die welke MrLler en medewerkers ontwikkeld hebben voor het onder controle krijgen van door het autonome zenuwstelsel gereguleerde processen in ratten, kunnen van groot belang worden bij de therapie van psychosomatische storingen bij de mens.

N. E. Miller, 1969. Science 163: 434-445.

\section{VII}

Het plastisch worden van plantecelwanden bij breedtegroei onder invloed van indolazijnzuur berust waarschijnlijk op een interactie van cellulosevormende en -afbrekende mechanismen.

\section{VIII}

Tegen de wijze waarop SiEw de duur van de "turnover" van ${ }^{35} \mathrm{~S}-$ cystine in neurosecretorische cellen interpreteert zijn ernstige bedenkingen aan te voeren.

Y. C. SiEw, 1965. J. Insect Physiol. 11 : 973-981

\section{IX}

De publicatie van Cannata en Tramezzani betreffende het voorkomen van een viertal typen van zenuwuiteinden in de neurohypophyse van de rat vormt geen bijdrage tot de kennis van neuroendocriene regulaties.

M. A. v. Cannata \& J. H. Tramezzani, 1969.Experientia 25: 1281-1282

$$
\mathrm{X}
$$

Het van de zijde van de Bond van Nederlandse Architecten opgestelde reglement betreffende de relatie opdrachtgever-architect dient in diè zin te worden gewijzigd dat de opdrachtgever de architect met recht kan beschouwen als vertrouwensman.

\section{$\mathrm{XI}$}

Als het al komt tot de instelling van "muziek" als eindexamenvak op middelbare scholen, verdient het aanbeveling, meer dan nu het geval is bij de vaststelling van het examenprogramma op de z.g. experimenteerscholen rekening te houden met de belangstelling van de leerlingen. 


\title{
STRUCTURAL ASPEGTS OF
} NEUROSEGRETORY AND

CORPUS ALLATUM ACTIVITY

IN THE ADULT COLORADO BEETLE, LEPTINOTARSA DEGEMLINEATA SAY, AS A FUNGTION OF DAYLENGTH

\author{
PROEFSGHRIFT \\ TER VERKRIJGING VAN HET DOGTORAAT IN \\ DE WISKUNDE EN NATUURWETENSGHAPPEN AAN DE \\ RIJKSUNIVERSITEIT TE GRONINGEN OP GEZAG VAN \\ DE REGTOR MAGNIFIGUS DR. W. F. DANKBAAR \\ IN HET OPENBAAR TE VERDEDIGEN \\ OP VRIJDAG 8 MEI I 970 DES NAMIDDAGS \\ TE I4.45 UUR PRECIES \\ DOOR

\section{HUGO SCHOONEVELD} \\ geboren te Koog a/d Zaan
}

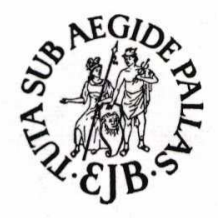

E. J. BRILL LEIDEN I970 
Promotor:

Prof. Dr. J. DE WILdE 
Aan mijn Moeder Aan Bonnie 
Dit proefschrift verschijnt tevens in

Netherlands Fournal of Zoology 20 (2) : 151-237 (1970) 


\title{
STRUCTURAL ASPEGTS OF NEUROSEGRETORY AND GORPUS ALLATUM ACTIVITY \\ IN THE ADULT GOLORADO BEETLE, LEPTINOTARSA DEGEMLINEATA SAY, AS A FUNGTION OF DAYLENGTH
}

by

\author{
H. SCHOONEVELD
}

(Department of Entomology, Agricultural University, Wageningen, The Netherlands)

\section{CONTENTS}

1. General introduction

2. Materials and methods

2.1. Breeding conditions

2.2. Histological procedures . . . . . . . . . . 154

3. General structure of the neurosecretory system and the corpus allatum . 155

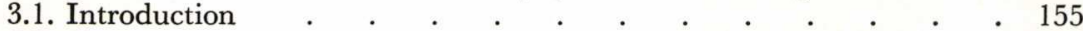

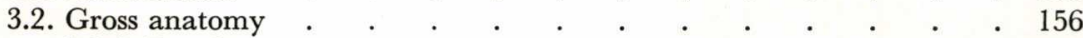

3.2.1. Results . . . . . . . . . . . . . . . 156

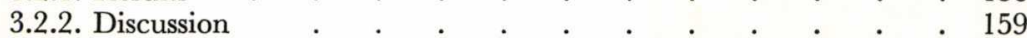

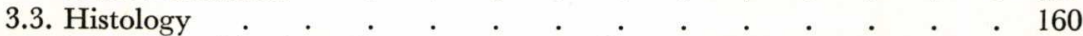

3.3.1. Classification of neurosecretory cells _ . . . . . . . . . $\quad$. 160

3.3.1.1. Definition of neurosecretory cells . . . . . . . . 160

3.3.1.2. Terminology . . . . . . . . . . . . . . 162

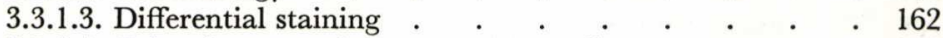

3.3.1.4. Other features of neurosecretory cells _ . . . . . 164

3.3.2. Neurosecretory pathways . . . . . . . . . . . 165

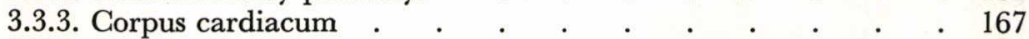

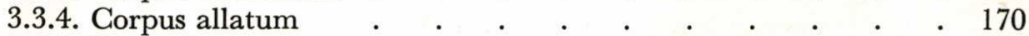

3.3.5. Discussion . . . . . . . . . . . . . . 171

4. Estimates of neurosecretory activity: introduction _ . . . . . 173

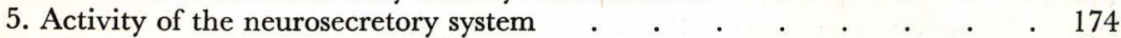

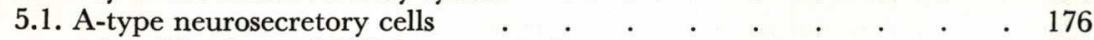

5.1.1. Histology of NSM accumulation . . . . . . . . . . 176

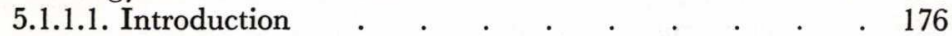

5.1.1.2. Scoring-systems . . . . . . . . . . . . . . . 176

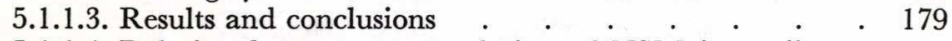

5.1.1.4. Relation between accumulation of NSM in perikarya and axon-terminals $. \quad . \quad . \quad . \quad . \quad . \quad . \quad . \quad . \quad 182$

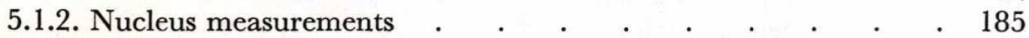

5.1.3. Rates of incorporation of ${ }^{35} \mathrm{~S}$-cysteine into neurosecretory material: autoradiographic experiments . . . . . . . 186 5.1.3.1. Introduction . . . . . . . . . . . . . . . 186 5.1.3.2. Methods . . . . . . . . . . . . . . 187

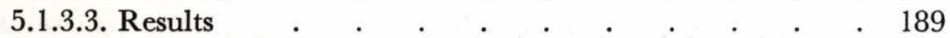

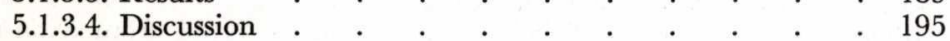

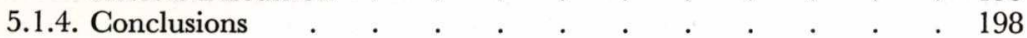


5.2. $A_{1}$-type neurosecretory cells _ . . . . . . . . . . 200

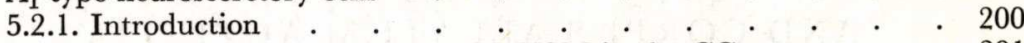

5.2.2. Histology of accumulation of A-NSM in the CC . . . . 201

5.2.3. Relation between accumulation phenomena in $\mathrm{A}_{1^{-}}$and A-NSC 202

5.3. C-type neurosecretory cells _. . . . . . . . . . . .

5.4. E-type neurosecretory cells _ . . . . . . . . . . . 207

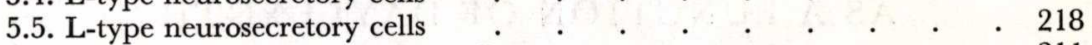

5.6. SOG-A-type neurosecretory cells . . . . . . . . . . . . 211

5.7. Secretory cells of the corpus cardiacum . . . . . . . . . $\quad$. 212

6. Activity of the corpus allatum _ . . . . . . . . . . . . $\quad$. 213

7. General discussion . . . . . . . . . . . . . . . . $\quad$. 217

7.1. The composite picture of neurosecretory and corpus allatum activity 217

7.2. Control of neurosecretory activity . . . . . . . . . . 219

7.3. Photoperiodic induction of neurosecretory activity $\quad . \quad$. $\quad$. $\quad$. 222

7.4. Control of corpus allatum activity . . . . . . . . . $\quad . \quad 223$

7.5. Involvement of the neurosecretory system in long-day development . 224

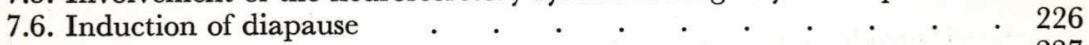

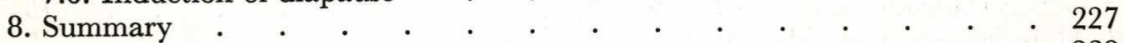

Acknowledgements . . . . . . . . . . . . . . . 229

References . . . . . . . . . . . . . . . 230

\section{ABBREVIATIONS}

(Singular or plural)

$\begin{array}{ll}\text { AT } & \text { axon-terminal } \\ \text { CA } & \text { corpus allatum } \\ \text { CG } & \text { corpus cardiacum } \\ \text { CNS } & \text { central nervous system } \\ \text { EG } & \text { elementary neurosecretory granule } \\ \text { ESC } & \text { extrinsic secretory cell of the corpus cardiacum } \\ \text { FP-factor } & \text { female protein factor } \\ \text { ISC } & \text { intrinsic secretory cell of the corpus cardiacum } \\ \text { LD } & \text { (under) long-day (breeding conditions) } \\ \text { NCA } & \text { nervus corporis allati } \\ \text { NCG } & \text { nervus corporis cardiaci } \\ \text { NCSO } & \text { nervus cardiaco-suboesophagealis } \\ \text { NSC } & \text { neurosecretory cell } \\ \text { NSM } & \text { neurosecretory material } \\ \text { NSS } & \text { neurosecretory system } \\ \text { PAF } & \text { paraldehyde-fuchsin } \\ \text { PI } & \text { pars intercerebralis } \\ \text { SD } & \text { (under) short-day (breeding conditions) } \\ \text { SOG } & \text { suboesophageal ganglion }\end{array}$

The word "discharge" has been used in the meaning of movement of NSM from cellbody to axon; "release", as the movement of NSM from axon-terminals to haemolymph. 


\section{GENERAL INTRODUGTION}

Over a period of twelve years much information has been collected concerning the role of the corpora allata in reproduction and diapause in the Colorado beetle (Leptinotarsa decemlineata Say; Coleoptera: Chrysomelidae), as induced by long-day and short-day breeding conditions, respectively (DE WILDE, 1959, 1960, 1964, 1965, 1969; DE WILDE et al., 1958, 1961, 1969). In physiological experiments much evidence has been obtained indicating that the activity of the corpora allata is, in turn, controlled by a higher centre, i.e., the neurosecretory system (DE Wilde, 1965; de Wilde \& DE BoeR, 1969).

The histological investigations reported about in this paper have been undertaken to clarify some problems, dealt with in the General Discussion and emerging from the above-mentioned physiological experiments. As a first step, studies were focussed on the structure of the neurosecretory system and corpus allatum of female Colorado beetles, and on the differences in neurosecretory and corpus allatum activity patterns found between females bred under long-day and short-day conditions.

The author is aware that a histological approach of physiological problems does not by itself provide definite clues. The combination of both types of approach is, however, a necessity as structure and function are two inseparable aspects of living matter. Moreover, as will appear in this paper, in the neurosecretory system a number of highly interesting phenomena are detected by histological observation, which may stimulate physiological work. For instance, the fact that in the brain seven different types of neurosecretory cells occur renders a revision of the word "brain hormone" necessary, and should initiate detailed studies on the physiological action of the substances (hormones?) produced by these cells.

This paper is divided into two major parts. In the first part (Chapter 3 ) a detailed description is given of the structure of the neurosecretory system. In the second part, an analysis is presented of the patterns of activity of the various components of the neurosecretory system (Chapter 5) and of the corpora allata (Chapter 6) throughout the normal adult life cycle. Some of the problems underlying the interpretation of histological signs of secretory activity have been dealt with in Chapter 4. In the General Discussion (Chapter 7) an attempt is made to integrate the information obtained in our knowledge of the physiology of Leptinotarsa and in some current concepts of neurosecretory principles in general. 


\section{MATERIALS AND METHODS}

\subsection{BREEDING GONDITIONS}

The beetles used in these studies were obtained from a stock that has been bred in our laboratory for over 13 years. As compared with the ancestors of these beetles and the present-day field populations the response to photoperiod has slightly changed. As a consequence of continuous selection $100 \%$ of the female beetles bred under long-day (LD) conditions (18 hours photoperiod) start oviposition. On the other hand, the critical photoperiod inducing diapause has been lengthened (HoDEK \& DE WILDE, 1969) as compared with data obtained earlier (DE WILDE et al., 1959). Under standard breeding conditions $\left(25^{\circ} \mathrm{C}, 60 \%\right.$ R.H. $)$ the life cycle of the beetle is as follows. Eggs develop in about four days. Nine days later, in the fourth larval instar, prepupae enter the soil (moist sand). Adult development is accomplished in eleven days. After ecdysis the initially yellow-coloured and soft adults remain in the soil for another day before they emerge.

Long-day beetles were collected within twelve hours after adult emergence, between 08.00 and 10.00 a.m., and transferred to a climatized room illuminated with high pressure mercury bulbs and $4300^{\circ} \mathrm{K}$ fluorescent tubes. They were kept in cages as described by DE WILDE (1957). Mating occurred within four days; males were usually removed a few days later. Oviposition started at about the fifth day and lasted 2-3 months. Three days before ovipositing females had to be taken for investigation, they were placed in 3 in. wide glass jars. Daily, fresh food was supplied and the eggs deposited were counted. For these studies only females were used that produced 60-80 eggs a day, on the average.

Short-day beetles were bred as follows. Eggs from stock beetles were transported to a $\mathrm{SD}$ room, illuminated in the same manner as described above but during only 10 hours a day. The larvae hatched, developed and pupated quite normally but females did not produce eggs under these conditions. Two weeks after emergencei.e., a few days after pre-diapause behaviour was initiated-the adults were transferred to a metal box containing moist sand. In spite of the availability of food the beetles moved downwards within a few hours. Under these conditions and left untouched, the beetles remained in diapause for several months. Kept in diapause for a month or more they could be reactivated by exposing them to light. When food was supplied oviposition took place within 7 days.

Adults were fed with young and fresh potato foliage placed in pots with water or moist sand. It was replaced at least daily. Potato plants were raised for this purpose in greenhouses, under controlled conditions.

\subsection{HISTOLOGIGAL PROGEDURES}

After one minute of ether narcosis the heads of the beetles were separated from the body and immersed immediately in the fixation fluid under reduced pressure. A variety of fixatives has been tested, i.e., Carnoy \& Lebrun, Bouin, Stieve-A and -B, susa, Zenker, $10 \%$ neutral formol- $0.9 \% \mathrm{NaCl}$, Helly, and Champy (GrAy, 1954). Alcohol containing fixatives had to be omitted because of the supposed solubility of neurosecretory material after alcohol treatment (ScHreINER, 1965). Only Heidenhain's susa gave satisfactory results with respect to the preservation of nervous structures. Heads were therefore routinely fixed in susa, for 12 to 24 hours at room temperature. The total content of the head capsule was dissected out in water and transferred to alcohol $96 \%$. Via methylbenzoate, $2 \%$ celloidin in methylbenzoate and benzene, it was embedded in "Paraplast" (Brunswick, England). Serial sections 
were routinely cut at $5 \mu$. In some cases, alternate sections of the paraffin ribbons were distributed over 2 or more slides; this enabled the study of staining reactions of separate cells towards more than one staining procedure.

The following staining procedures have been used for revealing the various components of the neurosecretory system: $a$, chrome-alum haematoxylin-phloxin (Gomori, 1941); $b$, paraldehyde-fuchsin after HALMI (1952); $c$, paraldehyde-fuchsin after GABE (1953), and $d$, paraldehyde-thionin (HuBER, 1963). All procedures were preceded by $\mathrm{KMnO}_{4}-\mathrm{H}_{2} \mathrm{SO}_{4}$ oxidation; sections stained by $b, c$ and $d$ were counterstained by chromotrope $2 \mathrm{R}$, orange $\mathrm{G}$, and light green. In the second part of this work procedure $c$ has been used routinely. The best staining results were obtained by using "Diamant Fuchsin" (Chroma Gesellschaft).

For the demonstration of -S-S- linkages in the neurosecretory material the following techniques were used: 1, performic acid-alcian blue (Adams \& Sloper, 1956); 2, performic acid-alcian blue-alcian yellow (Peute \& VAN DE KAMER, 1967) and $3, \mathrm{~N}, \mathrm{~N}^{\prime}$-diethylpseudoisocyaninchloride after Coalson (1966) with the use of a fluorescence microscope. (The stain was kindly supplied by Dr. H. Harms, Leverkusen, B.R.D.)

Other methods and procedures will be given at the appropriate places in the text.

\section{GENERAL STRUGTURE OF THE NEUROSEGRETORY SYSTEM AND THE CORPUS ALLATUM}

\subsection{INTRODUGTION}

In all ganglia of the central nervous system of insects neurosecretory cells (NSG) may be found (see GABE, 1966, for references). In contrast, the presence of NSC in the visceral nervous system has up till now not generally been accepted. Recently, Finlayson \& Osborne (1968) demonstrated the secretory nature of neurons situated in peripheral abdominal regions of a blowfly and a stick insect.

Primarily due to the fact that NSC in other parts of the body cannot readily be identified as such by using the histological techniques generally adopted to that purpose, in the present work attention has been paid exclusively to NSC in the brain and suboesophageal ganglion and to the adjacent retrocerebral gland complexes. The corpora allata, in fact not forming part of the nervous system are included because of their close functional relationships with the latter. Light and electron microscopic observations went hand in hand. In this paper the light microscopic features will be stressed especially; papers on the ultrastructure of the neurosecretory system (NSS) are in preparation (Schooneveld, 1970).

Previous neuro-anatomical investigations on the Colorado beetle are of a rather fragmentary nature. Bounhiol (1927) and BRUNETEAU (1928) gave descriptions of the general anatomy of the central nervous system of larvae and adults, respectively. A close examination of the architecture of the brain in relation to the role of the various areas was 
performed by GieRyng (1959). CAzAL (1948) studied the gross anatomy of the NSS in fifth stage larvae, whereas ARVY \& GABE (1954) and Belyaeva (1967) investigated the microscopic structure of this system in adult beetles.

\subsection{GROSS ANATOMY}

In natural position the head is orthognatous. For dissection, the head was separated from the partly enveloping thorax and pinned down with the mouthparts in front. This involves a rotation of about $45^{\circ}$. For convenience, terms like 'dorsal' will refer to this new position.

\subsubsection{RESULTS}

The main centres where neurosecretory material (NSM) is produced are situated in the dorso-caudal part of the protocerebrum (see Fig. 1 and Pl. I figs. 1 and 2). A medial group-in the pars intercerebralis (PI) - and two lateral groups can be distinguished (Fig. 2).

The medial group can ontogenetically be divided into a right and left half. This is quite distinct in pupae and in adults just after emergence (Pl. III fig. 4). Later on, both halves tend to fuse. The mirror-image positions of the left and right C- and E-types of NSG still illustrate this ontogenetic phenomenon. These cells mostly occupy fixed positions at the periphery of the medial group: the G-NSC (Pl. III figs. 1 and 2) lying most dorsally, the E-NSG (Pl. III figs. 4-6) more ventrally against the pons cerebri. On the other hand, the A-, $\mathrm{A}_{1}$ - and B-NSG (Pl. IV figs. 5-7) are distributed at random.

The right and left lateral groups consist of a varying number of cells, situated between neuropile and the neural lamella, caudally in the protocerebral lobes and at the level of the medial group. Two NSCtypes can be distinguished here: the relatively large L-NSC (Pl. IV figs. 1-4), somewhat flattened and forming a single layer of cells which covers a considerable area of the lobes, and the D-NSC (Pl. IV fig. 4) occupying a position between L-NSC and the neuropile.

In the ventro-medial part of the widely separated tritocerebral lobes and facing the oesophagus a right and left group of perikarya stand out against the remaining inconspicuous neurons. Since no signs of secretory activity have ever been found, these cells are not considered to be neurosecretory.

The positions, numbers, and shapes of the NSC-types mentioned are given in Fig. 2 and Table I.

The axons of the medial NSG form left and right bundles which decussate in a horizontal chiasma (Pl. II fig. 1), proceed towards the 


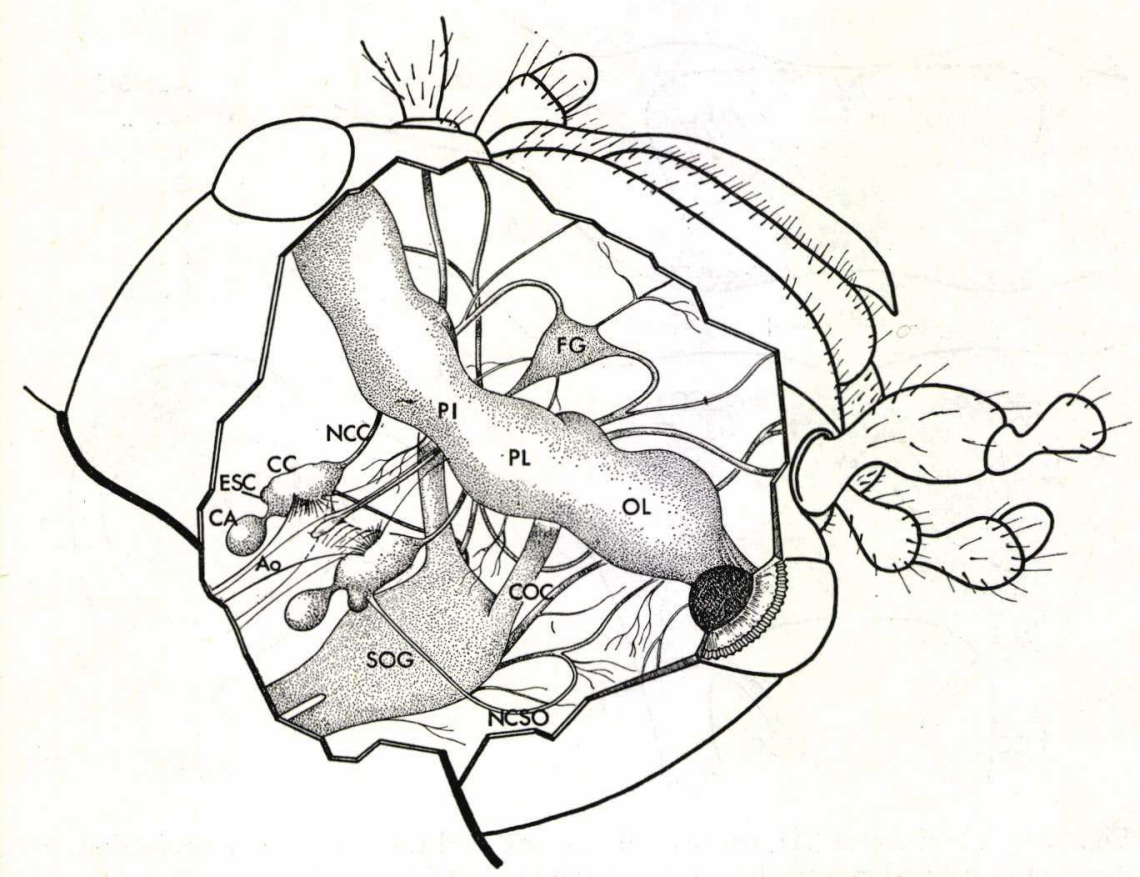

Fig. 1. The nervous system and associated retrocerebral glands in the head of the Colorado beetle (width about $2 \mathrm{~mm}$ ). The oesophagus has not been figured. Ao, aorta; CA, corpus allatum; CG, corpus cardiacum; COC, circumoesophageal connective; ESC, extrinsic secretory cells of the CG; FG, frontal ganglion; NGC, nervus corporis cardiaci; NCSO, nervus cardiaco-suboesophagealis; OL, optic lobe; PI, pars intercerebralis; PL, protocerebral lobe; SOG, suboesophagal ganglion.

(Drawing by M. P. van der Schelde).

TABLE I

Summary of topographical and morphological data on all types of NSC distinguished

\begin{tabular}{cccc}
\hline NSC-type & Number & Maximal & Shape \\
Localization & of & cell & of the \\
perikarya & dimensions & perikarya
\end{tabular}

\begin{tabular}{lllll} 
A & medial group: at random & $44-52$ & $25 \times 16$ & piriform \\
A $_{1}$ & medial group: at random & c. 50 & $25 \times 16$ & piriform \\
B & medial group: at random & c. 50 & $15 \times 10$ & piriform \\
C & medial group: dorsal & $2 \times(2-3)$ & $25 \times 25$ & spheroid \\
D & lateral group & $2 \times(1-2)$ & $13 \times 8,5$ & ellipsoid \\
E & medial group: frontal & $2 \times 2$ & $20 \times 20$ & stellate \\
L & lateral group & $2 \times(5-25)$ & $38 \times 21$ & ellipsoid \\
SOG-A & ventral suboesophageal ganglion & $2 \times 1$ & $20 \times 16$ & piriform \\
\hline
\end{tabular}




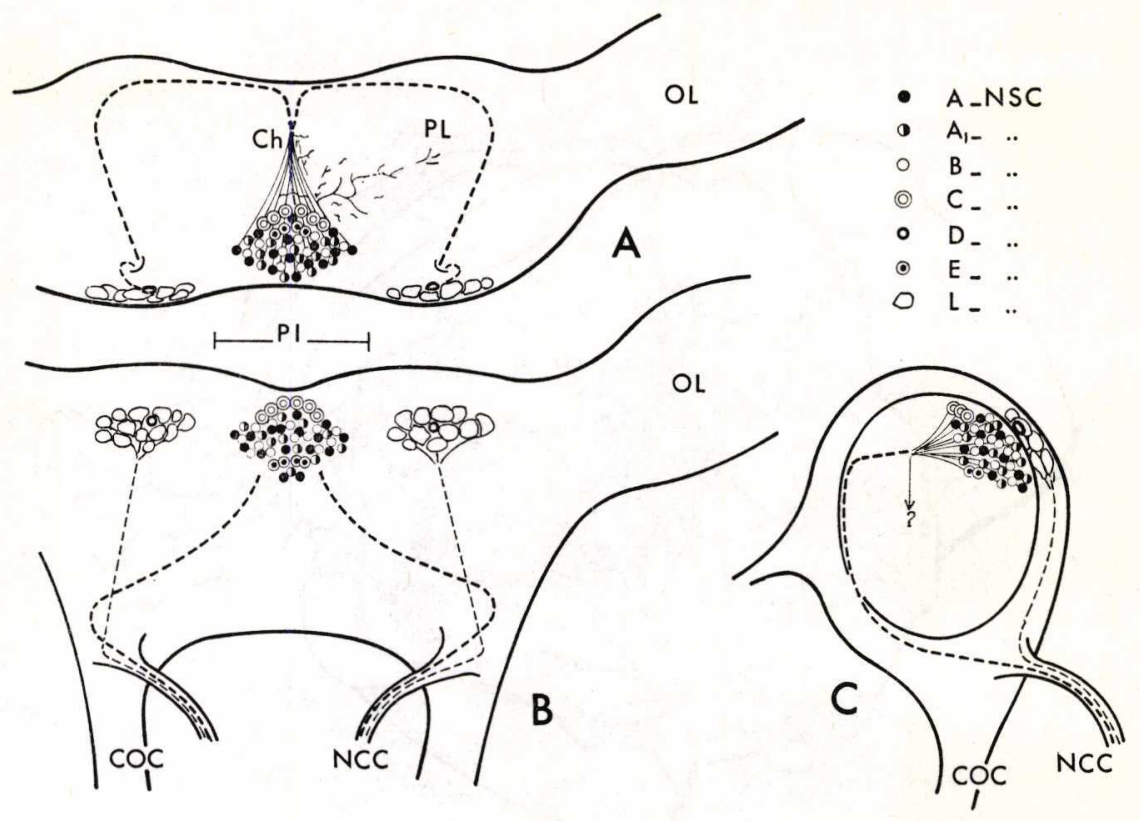

Fig. 2. In a horizontal (A), transversal (B), and sagittal (C) plane of projection, the location of cellbodies and the course of the axons of the medial and lateral neurosecretory cells are given. The groups of cells are situated in the dorso-caudal part of the brain. Ch, chiasma; COC, circumoesophageal connective; NCC, nervus corporis cardiaci; NSG, neurosecretory cell(type); OL, optic lobe.

frontal brain surface, separate, bend sharply laterally and ventrally according to the shape of the protocerebrum, and subsequently follow their own course to the corresponding nervi corporis cardiaci (NCG). The axons of the L-NSC take a quite different course. They run ventrally through the perineurium layer and ultimately also arrive at the origin of the NGC (Fig. 2). The NGC thus contain axons of contralateral medial, and ipsilateral L-NSC. In a low percentage of animals the proximal extra-cerebral course of L-axons is formed by a real NCG II, originating laterally to the NCG I. However, in all specimens examined the NCC I and II join before entering the corpora cardiaca. The length of the NCC is $100 \mu$, approximately.

The corpora cardiaca $(\mathrm{CG})$ are roughly spindle-shaped (length about $160 \mu)$ and lie close to the oesophageal musculature. Their mediocaudal ridges are connected with the sinus of the aorta (Fig. 1). At dissection the GC are easily recognized by their bluish appearance which is presumably due to their content of neurosecretory globules scattering the light (Tyndall effect) (E. Thomsen, 1954). The GC 
maintain connections with the suboesophageal ganglion (SOG) by means of the paired nervi cardiaco-suboesophagealis (NCSO) which emanate from latero-posterior regions (Fig. 3; Pl. V fig. 3). This nerve has been called nervus allato-suboesophagealis (DE WILDE, 1965; DE WILDE \& DE BOER, 1969) but in this study it could not be ascertained whether or not some of the fibres enter the CA. Within the CG the nerve ramifies, the rami run in several directions (Pl. VI fig. 1). Nervous connections with the hypocerebral ganglion or recurrent nerve, situated just over the oesophagus, could not be demonstrated with certainty. Within the GG the NCG bifurcate (Pl. VI fig. 1), the one branch providing the CG with neurosecretory material (NSM), the other forming the main connection between $\mathrm{CC}$ and corpora allata (GA): the nervi corporis allati (NCA).

The CA (approximate size $100 \mu$ ) lie close to the latero-posterior extremities of the CC and are spheroid or slightly elongated (Pl. VI figs. $3-8)$.

In the suboesophageal ganglion (SOG) two striking NSG can be found close to each other (Pl. I fig. 5) in the ventro-anterior neuron region. These closely resemble the "castration cells" in Leucophaea maderae (Scharrer, 1955). The axons run backward but their destination is unknown (see Subsection 3.3.2).

\subsubsection{DISGUSSION}

The gross anatomy of the NSS of the Colorado beetle and especially the occurrence of completely paired cardiacum-allatum complexes are fairly unusual in comparison with most insect species. These features are only shared by some other Coleoptera, Trichoptera and Lepidoptera (CAZAL, 1948). With reference to CAZAL's grouping of NSS's according to the degree of fusion of their retrocerebral glands, the NSS of Leptinotarsa belongs to the "type latéralisé".

The existence of medial and lateral groups of NSG in the protocerebrum, each with its own axonal pathway, is nowadays recognized in most insect species (cf. GABE, 1966; for exceptions, see JoHAnsson, 1958a). Little information is available, however, about the presence of NSG in other parts of the brain. FRASER (1959) described NSG in various parts of the protocerebrum in Lucilia caesar, whereas DuponTRAABE $(1956,1958)$ observed NSG in the tritocerebrum of Carausius morosus. In Leptinotarsa, in none of these regions NSC could be detected with certainty.

The fusion of NCG I and II before leaving the brain is unusual as well. This so far has only been observed in Andrena vaga (BRANDENBURG, 1956), Lucilia caesar (FrASER, 1957) and Tenebrio molitor (MoRdue, 
personal communication). No special importance should be attributed to this phenomenon, because in exceptional cases the extra-cerebral courses of NCC I and II are separate for some distance. Moreover, in electron micrographs it can clearly be seen that the axon bundles from the medial and lateral NSC are in fact strictly separated by glial sheaths. In adult Colorado beetles collected in France, ARVY \& GABE (1954) described separate NCG I and II. This discrepancy may well be due to strain differences.

In the present material the CA are only connected to the CG. Belyaeva (1967), working with the same species, in addition described nerves emanating from the CA and running to the SOG. This has never been observed in our material. In some other insects a direct nervous connection between the CA and SOG is likewise lacking: in Oncopeltus fasciatus (Johansson, 1958a), Hydrous piceus (De LeRma, 1956), and in some dytiscid species (Joly, 1945). As Johansson (1958a) pointed out, this nerve is only present in rather primitive insects.

Special attention has been paid to possible connections between the NSS and the stomatogastric nervous system. CAzAL (1948) made mention of nerves between the CC and the hypocerebral ganglion in different coleopteran species, and so did ARvy \& GABE (1954) for Leptinotarsa and HighnAm (1961a) for Schistocerca gregaria. In our histological sections no evidence for the existence of this nerve could be obtained. Yet, in some aged females neurosecretory colloids were present at the periphery of the recurrent nerve and the hypocerebral ganglion. It seems most likely that this NSM reaches these structures by way of a meshwork of tiny fibres which follow the wall of the aorta and the abundant free connective tissue strands present in the head of these animals. In contrast to the situation in Iphita limbata (NAYAR, 1956), NSM is not found within the hypocerebral ganglion of Leptinotarsa.

\subsection{HISTOLOGY}

\subsubsection{GLASSIFICATION OF NEUROSEGRETORY GELLS}

In this subsection several histological data are presented which lead to the identification of different types of NSC in the protocerebrum and suboesophageal ganglion. The positions of these NSC have been given in Subsection 3.2.1 and Fig. 2.

\subsubsection{Definition of neurosecretory cells}

The name "neurosecretory neuron" may only be given to nerve cells which fulfill several specific requirements. The fact that histologists as 
well as physiologists are interested in the phenomenon of neurosecretion has led to the formulation of definitions for NSG including both structural and functional aspects. BERN (1962) and BERN \& HAGADORN (1965), for example, suggest that the term ("definitely") "neurosecretory" be reserved for neurons that contain stainable substances and exhibit histologically detectable activity cycles that can be related to physiological activities of the organism. Furthermore, these signs of secretory activity must be related to the production of hormones.

In adopting this definition, the use of the term "NSG" should, strictly speaking, be abandoned for insects. For, although in the PI several kinds of neurons have been shown to be secretory, and overwhelming evidence exists that hormones are produced in this region, up till now it has never been demonstrated with absolute certainty which hormone is produced in a certain type of secretory neuron. VAN DER KLOOT (1960) foresaw this discrepancy when he proposed the terms "neurosecretory" and "neuro-endocrine" cells, the latter indicating an established endocrine function. In the meantime, however, the term NSG has come into common use in the literature; authors frequently relied upon the confidence that functional activities of the described NSC would eventually be found.

On that line of reasoning the term NSC will be retained in this paper, adopting GABE's (1966) definition: "neurosecretory cells (are) elements having the characteristics of neurons and also exhibiting the morphological signs of glandular activity-i.e., the intracellular elaboration and discharge from the cell of a formed, histologically detectable secretory product".

According to this definition, which is relevant for histological purposes, all cell types described in the following sections are taken to be neurosecretory. The staining reactions of these NSG have been described in Paragraph 3.3.1.3; other features which differentiate them from ordinary neurons, in Paragraph 3.3.1.4; the destination of their products, in Subsections 3.3.2 and 3.3.3. Since the course of the axons of the D- and E-NSG could not be traced (Subsection 3.3.2) and the discharge of the secretory product could therefore not be proved, the designation of these cells as neurosecretory is merely provisional.

The discharge proper of a secretory product cannot be observed with the light microscope in histological preparations, but rates of discharge can be determined in an indirect way. When it has been established that neurosecretory material (NSM) is produced in the perikarya and the NSM accumulates neither in the perikarya, nor in the axons or axon terminals (AT), it is evident that the discharge and release take place. (In this paper the terms discharge and release are defined as the 
movement of NSM from cellbody to axon, and from axon-terminal (AT) into the haemolymph, respectively.) Electron miscroscopic studies can indicate whether or not release occurs. When in the AT vesicles are found with sizes of about $500 \AA$, release is very likely to take place. These vesicles probably represent remnants of the membrane of elementary neurosecretory granules (Scharrer, 1963, 1968; NorMANN, 1965, 1969; Sмith, 1969).

\subsubsection{Terminology}

Usually, two main categories of NSG are distinguished, i.e., the Gomori-positive and -negative NSG. The former are stained intensely by staining solutions prepared on the basis of the original formula's of Gomori: a, chrome alum - haematoxylin (CHP) (GomoRI, 1941); $b$, paraldehyde-fuchsin (PAF) (GoMorI, 1950). The affinity of the stains for these NSG is based on the high concentration of cystine or cysteine in the NSM (Adams \& Sloper, 1956; Sloper, 1957). Gomorinegative cells merely fail to take up the specific stains and are mostly revealed by a counterstain.

In this paper the terminology of NAYAR (1955) will be followed: cells staining with CHP are called A-type NSG (in short, A-NSG), those staining with the phloxine counterstain B-NSC. Other NSC-types will be designated $\mathrm{A}_{1^{-}}$, B-, C-, D-, E-, L- and SOG-A-NSC. It should be stressed that this nomenclature is purely arbitrary, and valid only for Leptinotarsa.

\subsubsection{Differential staining}

Apparently as many as 8 cell types could be distinguished in the brain and SOG. In order to eliminate the possibility that some "types" might simply represent different stages in the activity cycle of one single NSG-type, a variety of staining procedures was applied, and animals in different stages of the life cycle were investigated. The main results are summarized in Table II. It may be emphasized that in none of the specimens all NSC-types could be stained according to the data in the table, simultaneously. Each type reveals an optimal colour intensity at a particular moment of the life cycle. When the sections were not oxidized before staining, no NSM in the PI or CC could be observed.

I. Chrome-haematoxylin phloxin, applied according to the original formula of GoMORI (1941) did not yield satisfactory results. Inclusions of the A-NSG were readily stained blue-black, but if only little neurosecretory material was present the A-NSM could hardly be differentiated from the grey background. 
NEUROSEGRETORY SYSTEM OF LEPTINOTARSA

163

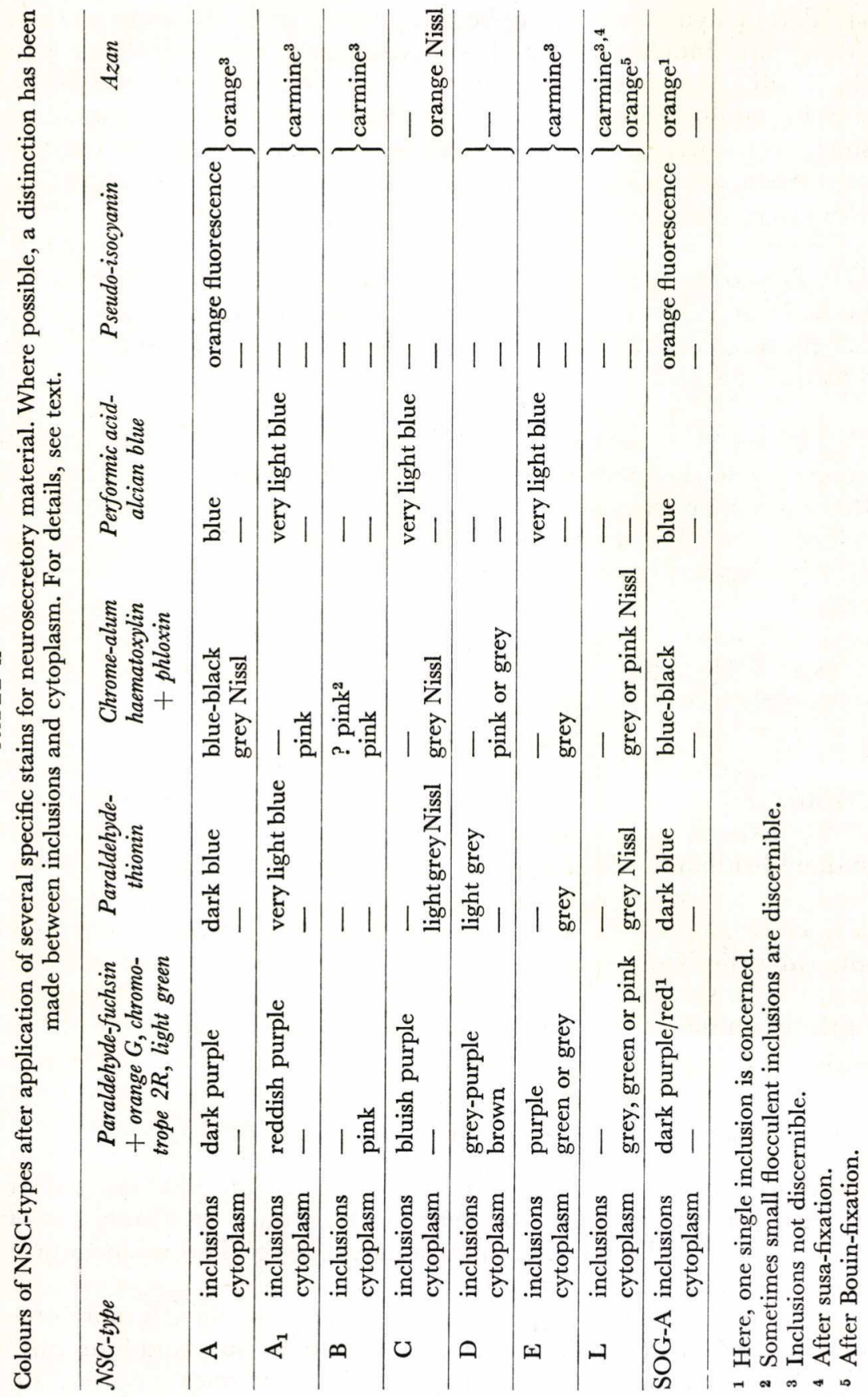


II. Paraldehyde-fuchsin, applied according to the formula of HALMI (1952) gave much better results. A-NSG could always be identified by the brilliant purple colour of the inclusions. More reproducable staining results were obtained using the modification of GABE (1953); stock and working solutions could be used for several months. After counterstaining with chromotrope $2 \mathrm{R}$, orange $\mathrm{G}$ and lightgreen, all NSG were perceptible.

III. Paraldehyde-thionin, in the formula of Huber (1963), proved to be an extremely selective stain for A-NSG. The $\mathrm{A}_{\mathbf{1}}$ - and C-NSG were hardly stained, if at all; for the purpose of routine investigations this was undesirable.

IV. In sections treated with $\mathrm{N}, \mathrm{N}^{\prime}$-diethylpseudoisocyanin-chloride, according to the method of CoAlson (1966) and examined under the fluorescence microscope, the A-NSG exhibited an intense orange fluorescence. Also their axons and axon-terminals in the CG were clearly visible. Other structures showed a very weak unspecific fluorescence. Using this method, image-fading by the ultraviolet light occurred much slower as compared with the original procedure of Sterba \& Hoheisel (1964). Examination of a given NSC was possible during about one minute.

V. The performic acid - alcian blue reaction of Adams \& Sloper (1956), used for the demonstration of protein-bound -SH groups and -S-S- linkages, gave a strong positive reaction in A-NSC; these were stained brilliantly blue. $\mathrm{A}_{1^{-}}, \mathrm{C}-$-, and E-NSC were weakly stained.

VI. Heidenhain's azan (RomeIs, 1948) was unsuitable for differentiating the NSG-types. Both $\mathrm{A}$ - and $\mathrm{A}_{1}$-NSC were stained intensely red; the former contained slightly more of the orange, the latter more of the carmine-red stain component. The G-NSG were left practically unstained.

\subsubsection{Other features of neurosecretory cells}

In addition to differences in staining properties, all NSG-types distinguished are characterized by their location, number, shape, size and content of cytoplasmic inclusions and vacuoles. The main data are summarized in Tables I and II.

As observed with the light microscope, all NSC have a more or less smooth cell membrane. Nuclei are sometimes spheroid but mostly slightly elongated. Individual large L-NSG sometimes contain 2 till 4 
nuclei (Pl. IV figs. 3 and 4). Since these differ in size and chromatine content, this situation is not thought to be the result of cell fusion.

Nucleoli are usually small and inconspicuous, and are always situated in the centre of the nucleus. They were not given further attention.

In all NSG-types, from time to time vacuoles occur which can be related either to glandular activity or degeneration, depending on the physiological state. The occurrence of possible fixation artefacts will be discussed in more detail in Paragraph 5.1.1.2.

Special attention has been paid to the occurrence of inclusions as signs for secretory activity. PAF-positive purple inclusions are the most conspicuous, particularly in the A-NSC. They may aggregate to darkly staining lumps, a few of which fill the whole perikaryon (Pl. VIII). The small reddish-purple inclusions of the $\mathrm{A}_{1}-\mathrm{NSC}$ (up to $0.5 \mu$ ) are widely dispersed (Pl. IV fig. 6) whereas those of the G-NSC are even smaller and mostly arranged in extensive cloudy aggregations situated between Nissl bodies (Pl. III fig. 2). Sometimes, in the E-NSC extremely small $(0.2 \mu)$ purple particles are present in perinuclear regions; in aged animals these particles may be abundant (Pl. III fig. 5). Very large red lumps may be present in the SOG-A-NSG (Pl. IV fig. 10). These strongly remind of the "delta granules" in neurons of Periplaneta americana (PIPA, 1961); however, these inclusions are stained green in Periplaneta.

No distinct inclusions have been found in the B- and L-NSC. Instead, in these and in the E-NSC hazy condensations of NSM occur.

\subsubsection{NEUROSEGRETORY PATHWAYS}

All described NSC-types possess distinct axons. Those of the D- and E-NSG (in short D- and E-axons) can be traced only for a short distance; they seem to join the respective lateral and medial axonal pathways. B- and L-axons are homogeneously filled with neurosecretory material (NSM); the A-, $\mathrm{A}_{\mathbf{1}^{-}}$and $\mathrm{C}$-axons contain particles similar to those in the cellbodies. The amount of NSM within the axons strongly depends on the physiological state.

When accumulation of A-NSM occurs and particularly after staining with paraldehyde-thionin, A-axons can be seen to ramify in their proximal course through the neuropile of the protocerebrum. Ramifications are most conspicuous where the axons leave the medial group of NSC (Pl. II figs. 1-3). Neurosecretory particles can be traced as far as $100 \mu$ besides the major axonal pathway. The moniliform arrangement of the NSM within the rami renders it difficult to trace the course of the rami in these regions. Other rami cross the gap between left and 
right axonal pathways. The axons of other NSC-types did not show these phenomena.

Proximal axon diameters depend on the activity of the NSC. A-, $\mathrm{A}_{1-}$ and $\mathrm{C}$-axons may measure up to $2.5 \mu$ across, other axons are much smaller. After passing the chiasma all diameters decrease; A- as well as L-axons may occasionally show swellings just before they enter the NCG.

Within the GG the NCG proceed for a considerable distance, bifurcating at last (Fig. 3). One branch carries the NSM to sites in the CC where it is temporarily stored or released into the haemolymph. The other-smaller-branch carries A-NSM straight to the CA and merely passes the dorsal area of the CG; this branch can already be called NGA, for it is isolated from the GG by a connective tissue sheath long before it emerges from the CG.

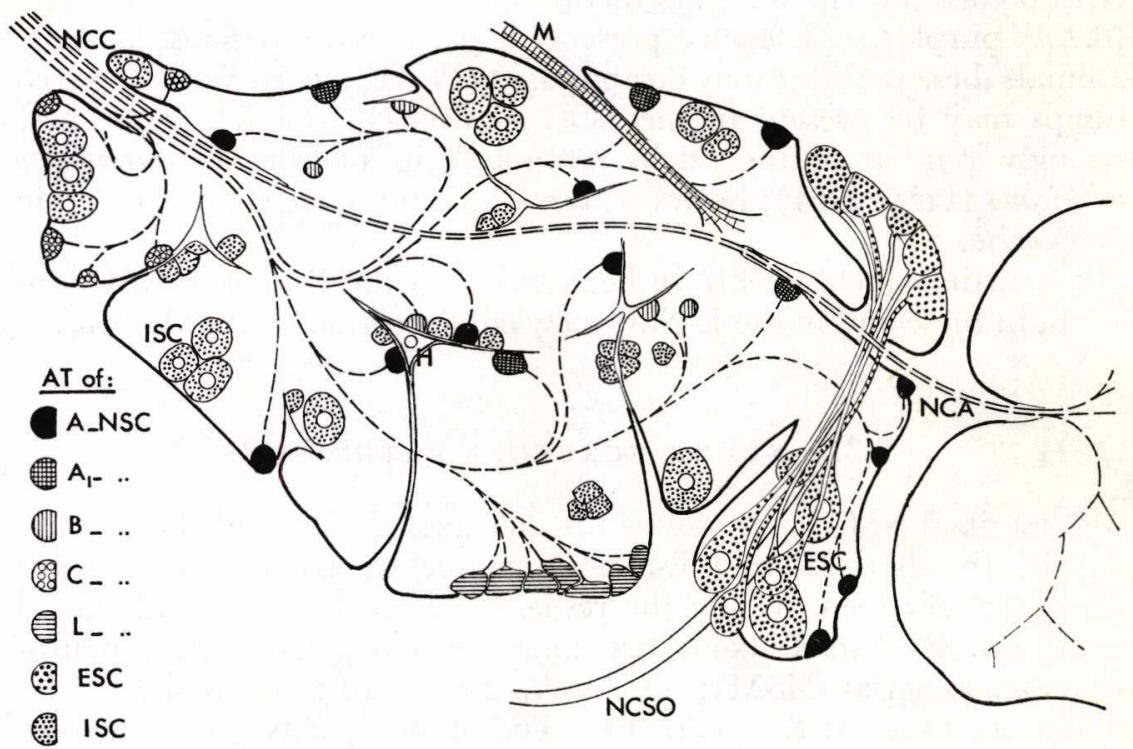

Fig. 3. Diagrammatic drawing of the structure of the corpus cardiacum and the course of the axons therein. Axons of at least 5 different types of neurosecretory cells (NSC) in the protocerebrum enter the CC by way of the nervi corporis cardiaci (NCG) (interrupted lines). Axon-terminals are scattered over the organ and usually lie close to the haemocoel, either at the periphery of the CG, or at blood-filled crevices. Axon-terminals of the C-NSG are only found in the dorso-frontal area, those of the L-NSC are sometimes grouped at the periphery. A small bundle of axons runs straight to the corpus allatum. ESC, extrinsic secretory cells; $\mathrm{H}$, haemocyte; ISC, intrinsic secretory cells; M, muscle; NCA, nervus corporis allati; NCSO, nervus cardiaco-suboesophagealis. 
The external course of the NGA is very short. The nerve which is enclosed in blue-stained connective tissue penetrates deeply into the interior of the CA; it has no real contact with the CA-tissue. Solitary fibres penetrate between the CA cells and are found throughout the organ (Fig. 3; Pl. VI fig. 2). All routine staining procedures and histochemical reactions as mentioned in Table II established the presence of A-NSM in the fibres; no other kinds of NSM were detectable.

In the suboesophageal ganglion, axons of both SOG-A-NSC can be traced running through the neuropile in caudal direction. Their ultimate destination cannot be elucidated since, after many ramifications (Pl. II fig. 4), no main axon can any longer be followed. The rami run in all directions and contain Gomori-positive NSM in a moniliform arrangement, like the rami of the A-axons in the PI.

Special attention has been paid to the phenomenon observed by GABE (1967), that the chemical composition of NSM changes along the pathway from perikaryon to CC. This was demonstrated with a histochemical procedure after Peute \& VAN de Kamer (1967). After staining with alcian blue and alcian yellow at different $\mathrm{pH}, \mathrm{NSM}$ from yellow perikarya exhibited a blue colour in the CC (and the reverse in the case of staining in a reversed order).

Using the same method, yellow, green and blue perikarya were present in the pars intercerebralis of Leptinotarsa, all in relatively large numbers. Similarly stained spots were present in the GG. Since neither in the PI, nor in the CG, any particular colour dominates, no conclusions concerning possible chemical alterations could therefore be drawn.

\subsubsection{GORPUS GARDIAGUM}

The corpora cardiaca (CC) are very complex structures (Fig. 3; Pl. V fig. 1). After staining with PAF numerous axon-terminals (AT) of the A- and $\mathrm{A}_{1}$-NSG dominate the picture. The intensity of the purple colour and the size of the AT depend on the physiological state of the animal (see Paragraph 5.1.1.4). High-quality optics are required to differentiate between purple of the A-NSM and reddish-purple of the $\mathrm{A}_{1}$-NSM. The use of an appropriate blue filter (for instance FGB 4) facilitates this differentiation. It is very peculiar that in the $\mathrm{CC}$ of ovipositing females $\mathrm{A}_{1}$-AT occur in much larger numbers than A-AT, while in the pars intercerebralis the NSM of the A-NSC dominates the picture. The axons proper are tiny and can hardly be seen in the CG.

Unlike the CG of Leucophaea (SGHARRER, 1963), those of Leptinotarsa are not compact and have no smooth surface. After staining with azan, the blue connective tissue linings of the GC prove to be very thin and are interrupted at some places. Occasionally, deep branched invagi- 
nations of the haemocoel can clearly be seen to penetrate the CG (Pl. V fig. 3), giving the CG in fact a spongy structure. This enlargement of the total surface area may effectively enhance a rapid exchange of substances between the CG and the blood. With regard to the function of the CC as a neurohaemal organ this is important. Not all the AT face the haemolymph at the periphery of the organ, many of them are apparently located at the extremely thin, blood- or connective tissuefilled crevices transversing the CG, even in its centre (Fig. 3). A- and $\mathrm{A}_{1}$-AT can also be found very distally, for instance in the glia layers surrounding the ESC (see below).

The distribution of AT of the B-, C- and L-NSC is less well understood. The small C-AT seem to occur exclusively in dorso-frontal GC areas, where lobes of the CC surround the entering NCG. B-AT are small as well; these do probably not always face the haemocoel. The L-AT, like the cellbodies stain faintly green, are large and to some extent packed together in certain peripheral areas of the CC. Taken by itself, the colour of these "L"-AT may as well indicate that the substance therein originates in the green ISC (see below). However, in $\mathrm{AT}$ in the regions mentioned the intensity of the green colour always strictly corresponds with the varying intensity in the L-NSC, and not with ISG.

Certain areas of the CG are left unstained by PAF with corresponding counterstain, or are slightly basophile, and contain dispersed nuclei. It is supposed that these regions comprise glial cells, nervous and other elements which are not revealed by bright-field and phasecontrast microscopy.

In the centre and at the periphery of the CG tens of cells show variations in size and staining capacity throughout adult life. On the analogy of similar cells in Carausius morosus (Dupont-RAABE, 1956) and Leucophaea maderae (SGHARRER, 1963) these are thought to represent intrinsic secretory cells (ISC) (Pl. V fig. 2). The cytoplasm may be faintly Gomori-positive, chromophobe or basophile. Inclusions can nicely be demonstrated in thick Epon sections, stained with toluidin blue at pH 12 (Pl. V fig. 1). The glandular nature of these cells is thus evident. It is not quite clear where the secretory material is released. As the ISC do not directly contact the haemolymph it is likely that the material is transported to places where it can be released, but cell processes cannot be found. On the other hand, many swellings-different from the AT of known origin-are scattered over the CG and contain substances which are stained like some of the ISC. Therefore, it may well be possible that these swellings are the sites where the ISCmaterial is released, the cell processes being too small to be observed with the light microscope. 
Strikingly large secretory cells (extrinsic secretory cells: ESC) are situated in a lobe of the CG extending from the latero-posterior region, and are in close association with the nervus cardiaco-suboesophagealis (NCSO) (Pl. V fig. 2). Individual cells may reach diameters up to $24 \mu$. The cluster of cells is covered by A- and $\mathrm{A}_{1}$-AT in a layer of glioplasm of varying thickness. The cellbodies are usually stained green but the produced secretion brown-red. Cell processes transport the material to the medio-caudal side of the CG where it is released (Fig. 3). Only in second instance are the ESC incorporated in the CG. In 2-day old pupae they are situated along the NCSO as well, but at some distance from the CG. In this arrangement the cluster is strikingly similar to a structure ("corpuscule jugal") with unknown function in a dytiscid species (Joly, 1945).

In the immediate vicinity of the ESG large cells with purple inclusions occur, which may sometimes possess more than one nucleus with varying size. Because they lack evident connections with the CC, these cells are not thought to be a part of the neurosecretory system. Indeed, they have much in common with the "pericardial cells" in similar locations in Aedes aegypti (BuRgess \& ReMPeL, 1966).

Depending on the physiological state, the green staining glioplasm of the CG may have developed considerably, apparently increasing the volume of the gland. The periphery is then composed of extensive green, jelly-like masses, devoid of purple NSM and clear cell membranes and containing only small pycnotic nuclei (Pl. V fig. 4). The origin of this tissue is unknown, as is its significance.

In CG that happen to be cut in a suitable orientation, a muscle can be seen running through the organ and terminating in the ventrocaudal area. Its cross-striation is evident (Pl. V fig. 5). Outside the CC it can be traced as far as the oesophagus where it joins the circular muscles. Considering its frequent occurrence it is plausible to assume that the muscle plays a role in altering the position of the CC towards the blood stream, in that way effecting the release of substances. RAABE (1965), studying the abdominal neurohaemal organs of phasmids, observed that part of the median dorso-central muscle with which these organs are connected fuses with the aliform muscles of the heart, thereby rhythmically vibrating the organ. The effect of this arrangement in Leptinotarsa may be similar. SGHARRER (1964) reported on the occasional presence of a muscle in CA of Leucophaea, whereas CAZAL (1948) in Coleoptera observed the occurrence of muscles in the basement membrane of CG. The real significance of all these phenomena remains obscure, however. 


\subsubsection{GORPUS ALLATUM}

The CA are roughly spherical. Their volumes strongly depend on the physiological condition of the animal (see Chapter 6). Their outlines, in active stages smooth and nearly round, are crumpled when the glands are small (Pl. VI). The CA are covered by a thin layer of connective tissue. In exceptional cases and only in inactive CA numerous narrow connective tissue-lined spaces divide the organ into many "islets" (Pl. VI fig. 8). Similar phenomena have been described in pupae of Pieris brassicae (KAIser, 1949). Cell boundaries are usually moderately distinct. Within large CA great differences in cell size may occur, the larger cells then lying at the periphery. In CA which are known to be very actively producing juvenile hormone, cells are very elongated; even centrally located cells may directly communicate with the haemolymph by means of cell extensions (Pl. VI fig. 3).

In large glands the nuclei have an extremely irregular shape (Pl. VI fig. 5), as they are, e.g., in Lampyris noctiluca (NAIsse, 1966), Melanoplus differentialis (MENDEs, 1948), and in some species of Lepidoptera (Kaiser, 1949; Highnam, 1958b).

After adult emergence mitotic activity has never been observed. The cytoplasm is usually stained light green by the counterstain of paraldehyde-fuchsin, the nuclei orange. As in Leucophaea maderae (SGHARRER \& VON HARNACK, 1958), in some cases numerous small intracellular vacuoles or green staining cytoplasmic condensations are present. Sometimes, in young adults, cells with translucent cytoplasm are intermingled with darkly orange-stained cells (Pl. VI fig. 6).

The structure of the CA has much in common with that in another chrysomelid beetle, Galeruca tanaceti (SIEw, 1965a). CAzAL (1948), after studying a large number of insect species, distinguished 4 morphologically different CA types; according to this arbitrary scheme the CA of Leptinotarsa belong to the "type magno-cellulaire".

A single observation concerns the presence of a supernumerary CA at one side in the animal, connected with the CG and completely isolated from the regular CA.

Usually, the NCA represents the sole nervous connection (also providing mechanical support and channeling tracheal supply) of the CA. In some cases, however, additional connections with the CG exist, which have the nature of either a true NCA (Pl. VI fig. 1) (including the presence of A-NSM) or protoplasmic strands. At present nothing is known as to their possible functional significance. 


\subsubsection{DISGUSSION}

In the protocerebrum of Leptinotarsa decemlineata as many as 7 different types of NSC have been observed which differ from ordinary neurons by their relatively large size and affinity for stains. This number seems to represent the highest record for insects which up to now have been under investigation. In most insects, A- and B-NSC have readily been found and often a third and fourth NSG-type. SiEw (1964a) found in Galeruca tanaceti 3 or 4 NSG-types in the pars intercerebralis and 2 types in the lateral region, whereas FraSer $(1957,1959)$ described 6 groups of NSC distributed over the cerebral ganglion of Lucilia caesar.

The products of 5 types of NSC (i.e., A-, A, B-, C- and L-NSC) with certainty enter the axons and are transported to the CG for temporary storage. Along the entire length of the cell processes NSM can be observed and identified. In the CC at least 2 types of secretory cells (i.e., the ISG and the ESC) produce a secretion and store it there temporarily, raising the over-all number of secretory substances (hormones?) in the CC to 7. This figure may become important for a clear understanding of possible endocrine control mechanisms in Leptinotarsa. It stresses, for example, that a term like "brain hormone" requires some specification with regard to the actual site of its production. It has to be borne in mind that the complexity of the NSS of the Colorado beetle does not seem to be representative for insects in general.

Three NSG-types have been characterized by the presence of clear paraldehyde-fuchsin positive inclusions, i.e., the A-, $\mathrm{A}_{1}$ - and G-NSG. For three reasons it is not likely that they merely represent different stages in the secretory cycle of what are in fact one or two NSG-types:

1. In all physiological stages examined all types can be observed in the numbers and locations as given in Table I.

2. Actual staining intensities may vary but not the differences in shades of the purple colours.

3. After oxidation only the A-NSG reveal the presence of noteworthy amounts of -SH groups and -S-S- linkages, C- and $\mathrm{A}_{1}-\mathrm{NSC}$ contain much less.

Because of the first-mentioned reason it is improbable that a Gomoripositive NSG may have a Gomori-negative character in another stage of the secretory cycle, as Highnam (1958a) and Girardie \& Girardie (1967) found in Mimas tiliae and Locusta migratoria, respectively.

The here-made discrimination between the Gomori-positive A-, SOG-A, $\mathrm{A}_{1^{-}}$, and C-NSC is based on-and rendered possible by-the different shades of purple revealed by these cells after staining with $\mathrm{PAF}$. It is interesting that similar phenomena have recently been ob- 
served in Schistocerca gregaria (Prentø, 1969), Agrotis segetum (Drawert, 1966), in earthworms (Teichmann et al., 1966), and in the snail Lymnaea stagnalis (BRINK \& BoER, 1967; WENDELAAR BongA, personal communication). It is not known, at present, how these apparent multiple staining properties of PAF are brought about. Aldehydefuchsin is not known to be metachromatic; it may therefore not be excluded that the commercially obtained product diamond-fuchsin in fact consists of a mixture of dyes, each component having a special affinity for one of the various kinds of NSM. On the other hand, PAF is able to react with a variety of chemical substances in the substrate, for instance aldehydes (Prentø, 1969), carboxyl groups (Teichmann et al., 1966), and sulphonates arisen by oxydation of cystine and cysteine by performic acid (AdAMs \& Sloper, 1956). Different stain-binding mechanisms are involved (PRENTø, 1969).

Our data show that chemical differences are present in the PAFpositive substrates. The pure purple A-NSM contains high concentrations of protein-bound -SH groups and -S-S- linkages, the reddish and bluish purple $\mathrm{A}_{1^{-}}$and C-NSM much less (Paragraph 3.3.1.3). DRAWERT (1966) arrived at very similar conclusions concerning two types of NSG in the moth Agrotis. These data may be useful for future chemical characterizations of neurohormones and, at least, indicate that the PAF-positive carrier proteins to which they are bound (cf. HighNAm, 1967) are chemically different.

Since staining with PAF and other specific stains are histochemical procedures, one may not simply decide on the presence of NSM when "somewhere" a structure has been stained (BERN, 1962, 1966). In Leptinotarsa, for instance, the purple colour can be observed in the neural lamella and connective tissue, chitin, aorta wall, particles in haemocytes and oenocytes, etc., structures that definitely do not contain neurosecretory granules, as followed from electron microscopic inspection. It becomes increasingly clear that the presence of many lysosomes may also give rise to Gomori-positive staining (Stutinsky et al., 1963; Boer, 1965; Hassemer \& BeGK, 1968).

In order to facilitate the comparison of physiological actions of the NSS in different insect species, Herlant-Meewis et al. (1967), RaABe (1966), and FleTcher (1969) have tried to establish a correspondence in the occurrence of NSG-types. Due to differences in histological procedures followed, individual investigators are indeed obliged to devise a vocabulary valid only for the animal under investigation. This is also true for the Colorado beetle. The A- and B-NSC are welldefined and have always been recognized in other insects, and frequent- 
ly the L-NSG as well. But the other NSG-types have not been observed frequently. The G-NSG have much in common with the " $\mathrm{C}$ "cells in Locusta migratoria (GIRARDIE \& Girardie, 1966, 1967), the "D"cells in Schistocerca gregaria (HighNAM, 1961a) and the "Riesenganglienzellen" of Galleria mellonella (REHM, 1955); the E-NSG are reminiscent of the "giant neurons" in Calliphora erythrocephala (THOMsen, 1965) and Locusta migratoria (GIRARDIE \& GiRARDIE, 1967) but these similarities may merely be accidental.

It is noteworthy that the NSS of the Colorado beetle has much in common with that of the beetles Galeruca tanaceti (SiEw, 1965a), Dytiscus marginalis (Joly, 1945), and Hydrous piceus (De Lerma, 1956).

\section{ESTIMATES OF NEUROSEGRETORY ACTIVITY: INTRODUCTION}

A histological approach to neuroendocrine activity requires means for determining whether or not neurosecretory centres are active at a given moment. As-per definition-NSC are gland cells, the study of several cytological parameters for glandular activity (cf. GABE \& ARVY, 1961) may provide the desired information.

In early investigations Weyer (1935) and ScharRer (1941) demonstrated that in the PI of the honey-bee and in the SOG of different species of cockroaches certain large cells contain colloid inclusions. The glandular nature of these NSG was derived from the variations observed in the amount of these colloids. At that time no attempt was made to give an explanation for these variations on a physiological basis. Later on, and particularly after the Gomori-stains were introduced, several authors interpreted the mere occurrence of granules as signs of secretory activity (see Highnam, 1961a, 1962b; MoRdue, 1967, for references). In contrast, REHM (1955) demonstrated that in Ephestia and Galleria NSC charged with NSM should be regarded as synthetically inactive. At present it is realized that "...by itself, the histological character of a NSS can give no indication whatsoever of the output of neurosecretory factors, i.e., of the activity of the system" (Highnam, 1965). One can imagine that the rates of synthesis, axonal transport, and release of NSM, if they are balanced, may vary within very wide limits without producing any concomitant changes in histological features of the NSS. This is possibly the reason why WIGGLESWORTH (1940) found no differences in the NSG of Rhodnius during fasting and at the height of secretion of the moulting hormone. On the other hand, if the changes which occur in the amounts of NSM are followed over a certain period, some information as to "relative" activities can sometimes be obtained. For instance, if locusts are subjected to electrical 
stimulation or enforced flying activity, NSM is rapidly released. In this case it could be concluded that the NSS was more active during and after the experiments than it was before (Highnam, 1961b).

Along similar lines of reasoning dynamic pictures of the NSS of the Colorado beetle will be interpreted. In a preliminary communication (Schooneveld, 1966) it was shown that the amounts of Gomoripositive A-NSM in the Colorado beetle vary in the course of adult life, and that the actual pattern of A-NSM accumulation depends on whether the animals are bred under long-day (LD) or short-day (SD) conditions. In the present study these patterns were analyzed in more detail. Moreover, the activity of other NSC-types was also studied.

The activity of the NSG was determined in different ways. When quantities of NSM could easily be studied, processes of accumulationas a major expression of glandular activity-were described. Otherwise, indirect signs of secretory activity were taken into account, i.e., the size of cellbodies and nuclei, and the rate of incorporation of labeled hormone precursors in NSM.

As it was considered important to look for parallels between changes in the activity of the NSS and general physiological performance, care was taken to collect the animals that were to be investigated at welltimed moments in their life cycle, preferably when visible changes in behaviour occurred (ecdysis, onset and termination of reproduction and diapause, etc.).

\section{AGTIVITY OF THE NEUROSEGRETORY SYSTEM}

The pattern of activity of the NSS throughout adult life has been analyzed by studying the NSS of animals belonging to 17 different breeding-groups:

\section{LONGDAY BREEDING GONDITIONS $a b$ ovo}

1. Pupae, 9 days after entering the soil, 1-2 days before ecdysis.

2. Adults, a few hours after ecdysis, 1-2 days before emergence; the characteristic yellow-black colour pattern of the integument had not yet developed.

3. 5-6 days after ecdysis, some hours before onset of oviposition; abdomens were largely distended by the mature eggs.

4. 1 day after the onset of oviposition.

5. 8 days oviposition.

6. 22 days oviposition.

7. Termination of oviposition at ages of 56-89 days: per day only a few eggs were deposited, or none; within 1 or 2 days the animals would probably die. 
SHORT-DAY BREEDING GONDITIONS $a b$ ovo

8. Adults, a few hours after ecdysis.

9. 6 days pre-diapause; vigorous feeding behaviour.

10. 14 days pre-diapause; strong soil-positive behaviour; digging behaviour was prohibited for 2-4 days in order to synchronize the animals for entering diapause.

11. 2 days diapause.

12. 1 week diapause.

13. 2 weeks diapause.

14. 4 weeks diapause.

BREAK OF Diapause AND POST-DiAPAUSE OVIPOSITION

15. 5 months diapause.

16. 5 months diapause, followed by 4 days exposure to light $(12$ hours $=\mathrm{SD}$ photoperiod) with abundant food.

17. $5 \frac{1}{2}$ months diapause, 7 days in the light, 1 day after the onset of post-diapause oviposition.

The animals to be investigated were taken at the same time of the year, since variations in the physiological age of the hostplant are known to modify greatly the state of activity of Leptinotarsa (DE WILDE \& FERKET, 1967). The animals of breedinggroups 1-14 were collected during late summer, 1967; those of groups 15-17 one year later.

Specimens were processed according to strictly standardized histological procedures; sections were stained with PAF and counterstained with chromotrope $2 \mathrm{R}$, orange G, and light green. Staining-racks always contained slides belonging to different breeding-group series; in that way, possible variations in staining would not severely bear upon one particular breeding-group.

The patterns of activity of the A-NSC are described in Section 5.1, those of the $\mathrm{A}_{1^{-}}, \mathrm{C}-\mathrm{-}, \mathrm{E}-, \mathrm{L}-\mathrm{,}, \mathrm{SOG}-\mathrm{A}-\mathrm{NSG}$ and the secretory cells of the $\mathrm{CC}$, in subsequent sections.

No description is given of the secretory activity of the D-NSC since the variations in stainability and size bear no relation to the age of the animals.

The B-NSC do not show clear signs of secretory activity that justify detailed examination. Suffice it to mention here that-in contrast with the more active stages-during diapause the cytoplasm is stained bright orange, indicating accumulation of B-NSM. During oviposition much NSM is found within the axons. These observations make it likely that during oviposition the B-NSC are more active than during diapause. The axon-terminals in the CG are too small and inconspicuous for being routinely investigated. 


\subsection{A-TYPE NEUROSEGRETORY GELLS}

\subsubsection{HISTOLOGY OF NSM-AGCUMULATION}

\subsubsection{Introduction}

In this subsection the pattern of accumulation of A-NSM within the NSS during adult life will be described. Since it is known in some insects that the rate of synthesis of NSM is not coupled with the rate of release from the GC (Johansson, 1958b; Highnam, 1967), amounts of NSM had to be estimated at both cell levels.

Several methods to quantify the amounts of NSM and to express the patterns of accumulation observed were considered. The patterns were too complicated to be described in a narrative manner as many authors did for other insects. Microspectrophotometric determinations of NSM-concentrations in the cellbodies, according to the method of DRAWERT (1966) were considered too time-consuming, and not applicable to the CG. The only possibility left was to devise a number of separate scoring systems by means of which the amount of NSM in cellbodies and AT could be expressed in a graphical way.

\subsubsection{Scoring systems}

It appeared that changes in the following features concerning cell morphology and NSM aggregations accompanied the changes in overall amount of NSM in the animals under investigation:

$a$, the amount of NSM within perikarya;

$b$, the degree of aggregation of the elementary neurosecretory granules (EG);

$c$, the amount of NSM within the axon-terminals (AT) in the GC;

$d$, the size of AT;

$e$, the number of AT, and

$f$, the over-all amount of NSM within the CC. In all specimens these features were studied. Those related to the transport of NSM within the NSS will be mentioned in Subsection 5.1.1.4.

In order to investigate the NSS of individuals with respect to the features mentioned, all phenomena of NSM-accumulation had to be quantified. Except for the size of the AT, however, none of the phenomena could easily be measured. The amounts of NSM observed, the numbers of AT, etc., were therefore estimated by means of scoring systems. These were composed of series of discontinuous steps, i.e., 16 for the combined features $a-b, 6$ for $c$, and 5 for $d, e$ and $f$ each. 
Details about the scoring systems are given below. The scoring systems for the number of AT is given in Section 5.2, in relation to the AT of the $\mathrm{A}_{1}$-NSG.

\section{SGORING SYSTEM 1: AGGUMULATION STAGES OF NSM IN PERIKARYA}

The staining intensities of perikarya show extreme variations throughout adult life, ranging from hardly visible up to very dark purple. Close observations of NSC at high magnification reveals that not only the total amount of NSM but also the way in which the elementary neurosecretory granules (EG) temporarily aggregate, varies, according to the physiological state of the animal. Examples of these differences are given in Pl. VIII and Fig. 4.
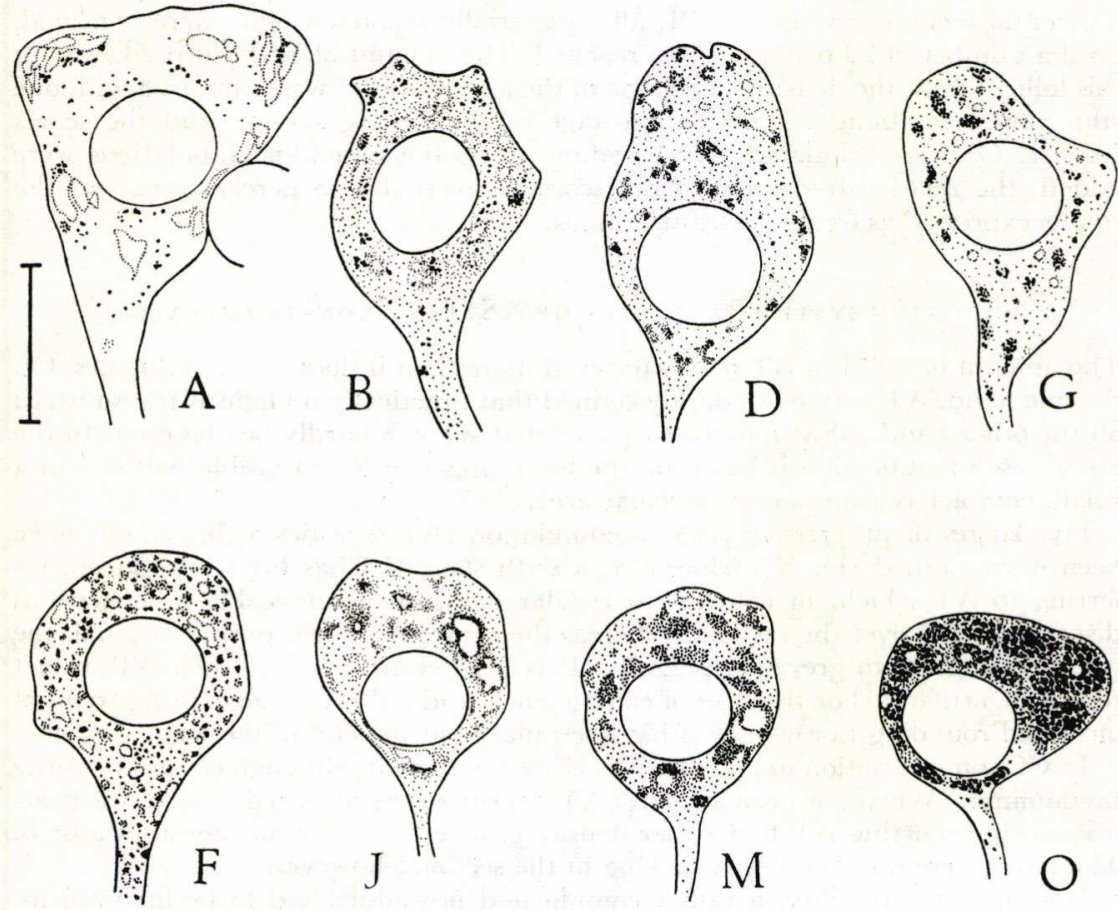

Fig. 4. Camera-lucida drawings of 8 arbitrarily distinguished stages in the accumulation of A-NSM and the degree of aggregation of elementary granules (compare with Plate VIII). For details, see text $($ scale $=10 \mu)$.

Given the fact that separate EG cannot be resolved by the light microscope, A-NSC can only be identified when the EG aggregate to some extent. Accumulation stage " $A$ " represents the minimal, accumulation stage " $O$ " the maximal amount of NSM found to be present in the perikarya. In stages of moderate accumulation, EG may aggregate in various degrees, giving rise, either to more or less compact inclusions (accumulation-stages B, D, G, H, L, N) or to hazy condensations (accumulation-stages $\mathrm{F}, \mathrm{F}^{\prime}, \mathrm{H}^{\prime}, \mathrm{J}, \mathrm{M}$ ). In the former, inclusions stand out against a more or 
less transparent background, in the latter, small clusters of EG are widely dispersed and diffusely stain cytoplasmic areas between the condensations. When perikarya are very darkly stained, a clear distinction between both patterns of NSM-accumulation cannot always be made.

Small, round vacuoles - or, at least regions devoid of NSM-have been observed in all accumulation-stages. Sometimes, however, the vacuoles are very large and irregularly shaped (accumulation-stages C, E, K), while inclusions are then very compact. In spite of the probability that these phenomena are mere artifacts, cellbodies containing this kind of vacuoles have been incorporated in the present study for the sake of completeness.

All accumulation-stages distinguished have been brought together in one single scoring system; the model cells are arranged in the sequence of increasing-visually integrated-staining intensity.

Studies on the degree of accumulation were performed as follows. In every second horizontal section through the PI, all equatorially sectioned NSC were regarded, until a number of 20 perikarya was reached. The amount of NSM in perikarya, as this follows from the density and shape of the aggregations, was compared with one (the most resembling) accumulation-stage of the scoring system, and the scores (A ..... O) were tabulated. Per breeding group the individual tabulations were added, the relative frequency of the scores converted into percentages, and the results expressed as frequency-distributions.

\section{SGORING SYSTEM 2: DENSITY OF NSM IN AXON-TERMINALS}

The amount of NSM in AT may vary even more than it does in the cellbodies. On the one hand, AT may be so darkly stained that practically no light is transmitted; on the other hand, NSM may be so scarce that AT can hardly be observed. In the latter case identification is based on the mere presence of just-visible particles in a small, completely transparent, saccular area.

Five stages of progressive NSM-accumulation (AT-densities $a, b, \ldots .$. e) have been distinguished (Pl. X). Moreover, a sixth stage (/f) has been introduced, referring to AT which, in contrast to regular ones, do not reveal a homogeneous dispersal of EG over the saccule. Whereas the centre is stained purple as usual, the colour changes into grey, peripherally. It is not certain whether such AT in fact represent artifacts. For the sake of completeness and following the existing trend of increased rounding (a-e), stage /f has been placed at the end of the scale.

In CG some variation in AT-densities is always present, although certain densities predominate. When, for instance, most AT-densities were awarded score d, the nextfrequently occurring AT had either density c, or e, certainly not densities a or b. The latter were not completely lacking in the sections, however.

Due to this variability, a rather complicated procedure had to be followed for making an inventory of the CC as to AT-densities. The CC were examined at 3 levels, i.e., in the frontal, medial and caudal regions. At each level, 3 adjacent sections were visually averaged. Four scores $(\mathrm{a} \ldots \ldots$ /f $)$ were altogether awarded for the predominant $(2$ scores $)$ and next-important AT-densities $(2 \times 1$ score). Per CC, the 12 obtained scores were tabulated and per breeding group the sum of individual tabulations was converted into frequency-distributions.

\section{SGORING SYSTEM 3: SIZE OF THE AXON-TERMINALS}

As the AT are usually more or less round, their dimensions can be measured satisfactorily with the aid of a calibrated eye-piece micrometer. However, within a given 
AT-population a large variety of diameters exists. For convenience' sake, attention has been focussed on the average size of the larger and darker AT.

Five classes of AT-size have been distinguished:

1 , smaller than $1.5 \mu ; 2,1.5-3 \mu ; 3,3-5 \mu ; 4,5-7.5 \mu ; 5$, larger than $7.5 \mu$. At each of the 3 examined levels of the CG the average AT-size was recorded. Per animal and breeding group the data were processed as mentioned above.

\section{Scoring System 4: over-All amount of NSM in the GC}

The phenomenon of accumulation is most difficult to quantify. Estimations depend exclusively on visual impression, and hence on the investigator's training and experience. With the aid of photomicrographs of a number of "standard sections", however, serious mistakes could be avoided.

In a 5 -point scale $(1 \ldots .5)$ the score 1 had been reserved for sections in which very little NSM was present, score 5 for sections in which AT (always being very dark then) occupied a considerable proportion (up to $30 \%$ and more) of the section area.

Difficulties were encountered in trying to discriminate between the purple A-NSM and the much-resembling red-purple $\mathrm{A}_{1}$-NSM. (More details are given in Section 5.2.) For that reason, the frequency-distributions for the over-all amount of NSM, as given in Fig. 5, refer to the presence of both types of NSM.

\subsubsection{Results and conclusions}

All estimates of NSM-accumulation in perikarya and AT are given in the frequency-distributions of Fig. 5.

Long-day conditions.-The graphs show that late in the pupal instar most perikarya are stained moderately dark, many of them containing compact inclusions. The AT are very large and contain extremely much NSM. Relatively low scores are awarded to the over-all amount of NSM in the CG.

One day later, a few hours after ecdysis, the compact inclusions have disappeared from the cellbodies, whereas some NSM has been released from the AT. AT-sizes have decreased.

Five to six days later, some hours before oviposition, the picture has markedly changed. Apparently, much NSM has been discharged from perikarya and released from AT, prior to the moment the animals were taken for investigation. From the fact that the over-all amount of NSM in the GG has clearly increased, it can be concluded that the NSC are synthetically active. Taken by itself, the increase in over-all amount of NSM seems paradoxical; it is in fact caused by an augmentation of the total number of AT as the result of ramification and trophic growth of the axons soon after ecdysis. Later on, this growth continues, but at a lower rate (see Sections 5.2 and 7.5 for further details).

During the entire period of oviposition the perikarya have only small amounts of NSM while compact inclusions are prevailing. In the GC AT gradually turn darker. This indicates that rates of NSM synthesis 


\begin{tabular}{|c|c|c|c|c|c|}
\hline \multicolumn{2}{|c|}{ A-NSC } & PERIKARYA & \multicolumn{3}{|c|}{ CORPUS CARDIACUM } \\
\hline & & accumulation stage & AT-density & AT-size & $\begin{array}{l}\text { over-all ammont } \\
\text { of } N M \text { M }\end{array}$ \\
\hline LONG-DAY & AGE $(n)$ & $A B C O E$ & $a b c d e: f$ & 12 & \\
\hline -day pupa & $-1 \quad(10)$ & .11. & 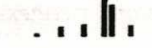 & $\cdots$ & \\
\hline ectysis & 0 (8) & "' & $\ldots I$ & 11. & \\
\hline $\begin{array}{l}\text { prae- } \\
\text { oviposition }\end{array}$ & $5-6 \quad(9)$ & IIIII & .111, & II & . . II \\
\hline $\begin{array}{l}\text { oviposition } \\
\text { of }\end{array}$ & $7 \quad(11)$ & 11. & 1111. & & \\
\hline$"(8$ days $)$ & $15 \quad 1101$ & I & II & 1 & \\
\hline "(22 days) & $29 \quad(12)$ & hl & IIII & $1 / 1$ & \\
\hline $\begin{array}{l}\text { termination } \\
\text { oviposition }\end{array}$ & 56-89 (12) & .1111 & 111 & I & \\
\hline SHORT-DA & & $A B C D E$ & $a b c$ & & \\
\hline ectysis & $0 \quad 17$ & I. I. I. I. I & .1 & & \\
\hline $\begin{array}{l}\text { praza- } \\
\text { diapause }\end{array}$ & $6 \quad(10)$ & \|\|\|\| & .11 & I & \\
\hline $\begin{array}{c}\text { proze- } \\
\text { diap unse }\end{array}$ & $14 \quad(12)$ & 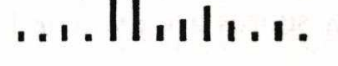 & .1111 & .11. & .11 .1 \\
\hline $\begin{array}{l}\text { diapause } \\
2 \text { days }\end{array}$ & $16 \quad$ (16) & $\ldots 1.11$, & & & \\
\hline $\begin{array}{l}\text { diapause } \\
\text { iweek } \\
\text { we }\end{array}$ & $21 \quad(10)$ & I I I & -111. & 111. & \\
\hline $\begin{array}{l}\text { diapouse } \\
2 \text { weeks }\end{array}$ & $28 \quad(13)$ & $\ldots$ & & & \\
\hline $\begin{array}{l}\text { diapause } \\
\text { sweetss }\end{array}$ & $42 \quad(10)$ & . I . li. li, I & .1 & $\| I I_{1}$ & 1 \\
\hline
\end{tabular}

Fig. 5a. For explanation see Fig. 5b.

are not quite in balance with rates of release. In most of the females which have terminated oviposition, NSM has considerably accumulated in the cellbodies and AT. At this time the CG contain much more NSM than in the younger females; this can be explained by the increase on both AT-densities and numbers of AT. In this stage the rate of synthesis exceeds the rate of release of NSM. 


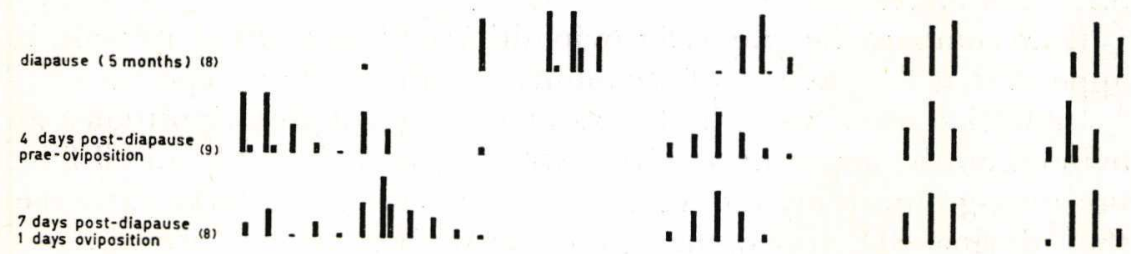

Fig. 5b. Frequency-distributions illustrating the changes in accumulation of A-NSM within perikarya and in the CG. "Over-all amount of NSM" refers to the sum of Aand $\mathrm{A}_{1}$-NSM. Numbers of specimens per breeding-group are given in brackets.

Short-day conditions.-The frequency-distributions referring to animals just after ecdysis under short-day conditions, closely resemble those of animals at long-day ecdysis.

Six days later, a noteworthy amount of NSM has been released; perikarya and AT are stained much more lightly. The overall amount of NSM in the CG has not changed. Yet, also under these conditions the number of AT has increased during the previous days. The loss of stainability of the NSC is therefore to some degree due to a re-distribution of NSM over the newly formed AT. The average size of the AT has sharply decreased.

In late pre-diapause, NSM has begun to accumulate. This process continues in the course of diapause and in 5-months diapausing animals the NSS contains the maximum amount of NSM ever observed in Leptinotarsa.

This process of accumulation is apparently interrupted in animals which have been in diapause during 4 weeks.

Break of diapause.-Four days after exposing the animals to light, most of the NSM has been released. By this time, the graphs closely resemble those of the LD pre-oviposition animals. One day after the onset of oviposition, in perikarya the amount of NSM has increased. The slight increase in over-all amount of NSM in the CG is due to an increase in the amount of $\mathrm{A}_{1}$-NSM (see Section 5.2 for further details).

Conclusions.- It appears that at the moment of ecdysis under longday and short-day conditions no large differences exist in the amounts of NSM in perikarya and AT. During the next few days and also after break of diapause NSM is largely released. Hence the NSS can be considered to be active in these stages. The mere appearance of the NSS does not provide information as to neurosecretory activities in other stages (cf. Chapter 4). Therefore, other signs of glandular activity had 
to be taken into consideration; these are dealt with in Subsections 5.1.2 and 5.1.3.

If we compare the graphs for ovipositing and diapausing animals, it appears that the patterns of accumulation differ in two respects.

In the first place, while in the examined stages of pre-oviposition and oviposition the appearance of the NSS is remarkably alike in all four breeding-groups (only the AT tend to become stained darker), we see that during SD development the NSM increasingly accumulates starting from the second half of the pre-diapause period. We may therefore conclude that during oviposition a balance exists between the rates of synthesis and release of NSM. This is not the case during diapause.

In the second place, the accumulation-stages of NSM distinguished within perikarya are not randomly distributed over the graphs for ovipositing and diapausing animals. During SD development, for instance, frequently occurring accumulation-stages are F, J, and $\mathrm{M}$, i.e., perikarya with hazy aggregations of EG (Fig. 4). These stages are nearly completely lacking in mature LD animals; instead, in these animals the accumulation-stages $\mathrm{A}, \mathrm{B}, \mathrm{D}$ and $\mathrm{G}$-with compact inclusions-are prevailing. The significance of these primarily qualitative differences is discussed in Subsection 5.1.4.

\subsubsection{Relation between accumulation of NSM in perikarya and axon-terminals of individuals}

In many insects it was observed that changes in stainability, occurring in the NSS, take place in the PI and CG simultaneously. Accumulation of NSM in the PI is implicitly held to be the result of an arrest of release from the CG. To some extent our frequency-distributions given in the previous subsection also point in that direction, particularly if changes in perikarya and over-all amount of NSM in the CG in stages of extreme accumulation are compared (aged and 5-months diapausing females). The correspondence between NSM-densities in perikarya and AT, however, is less evident. This follows most clearly from the gradually increasing AT-densities during oviposition in the absence of changes in the perikarya. It seemed therefore worth while to investigate the relations between intra-cellular accumulation of NSM by making use of the data already available on accumulation phenomena in individuals.

Advantage could be taken of the natural variation in animals belonging to a particular breeding-group. In specimens with - on the average- lighter stained perikarya on the one hand, and animals with darker stained perikarya on the other, AT-densities were investigated. For that purpose, per breeding-group an arbitrary "discrimination point" was calculated on the basis of the figures underlying the frequency-distributions of Fig. 5. With references to Fig. 6 and the animals in the stage of 5-6 days 
pre-oviposition, for example, the discrimination point is situated between accumulation-stages B and C. In 6 specimens of this breeding-group, most of the perikarya contain less NSM than-or as much NSM as - accumulation-stage B, in 3 specimens most of the perikarya contain as much NSM as - or more NSM than-stage C. For both sub-groups new frequency-distributions have been prepared; these are given in a mirror-image fashion. In this representation all upper/lower frequencydistributions for perikarya are asymmetrical. If there would indeed exist a relation between the degree of accumulation of NSM in perikarya and AT, the frequencydistributions for AT should be asymmetrical as well.

This procedure could be followed for only 6 breeding-groups. Other groups had to be discarded, either because variations in perikarya of individuals were too small, or because individuals did not differ sufficiently from each other.

As follows from Fig. 6 we may not conclude to the existence of a definite correlation between the amount of NSM in perikarya and AT. In some cases the frequency-distributions for AT show a slight tendency for upper-left/lower-right asymmetry-an indication of a positive correlation; in other cases a reverse asymmetry-a negative correlation-, or none.

Evidently, the accumulation of NSM in the PI is not the result of a decrease in the release from the CG. The question arises which mechanism is involved in this unequal distribution of NSM over perikarya and AT. Or, to put it in another way, it remains to be explained why in certain individuals the majority of NSG contain relatively little NSM, in other individuals relatively much, whereas these quantities have no bearing at all on the quantities in the AT. All individuals belonging to a particular breeding-group were bred identically and were in similar physiological stages; hence it is reasonable to assume that rates of NSM output were similar as well.

It seems most likely that the perikarya are synchronized in some way, either by a control of rates of synthesis, or rates of discharge. Arguments can be found in favour of both possibilities. On one hand, anticipating Subsection 5.1.2., some individual variations in nuclear diameters, indicating differences in synthetic activities, indeed exist. On the other hand, while axons in most animals in stages of pre-oviposition and oviposition contain small or moderate amounts of NSM, in a few animals they contain large amounts. This indicates that the discharge of NSM occurs intermittently, and that the discharge itself is completed within a rather short time.

It is very well possible that this phasic discharge gives rise to the differences observed between individuals of the here-investigated breeding-groups. Phasic discharge could, for instance, explain why the accumulation of NSM at both cell levels were not found to develop simultaneously. Just prior to the discharge, the cellbodies will contain much, the AT little NSM; just after the discharge the opposite will be 


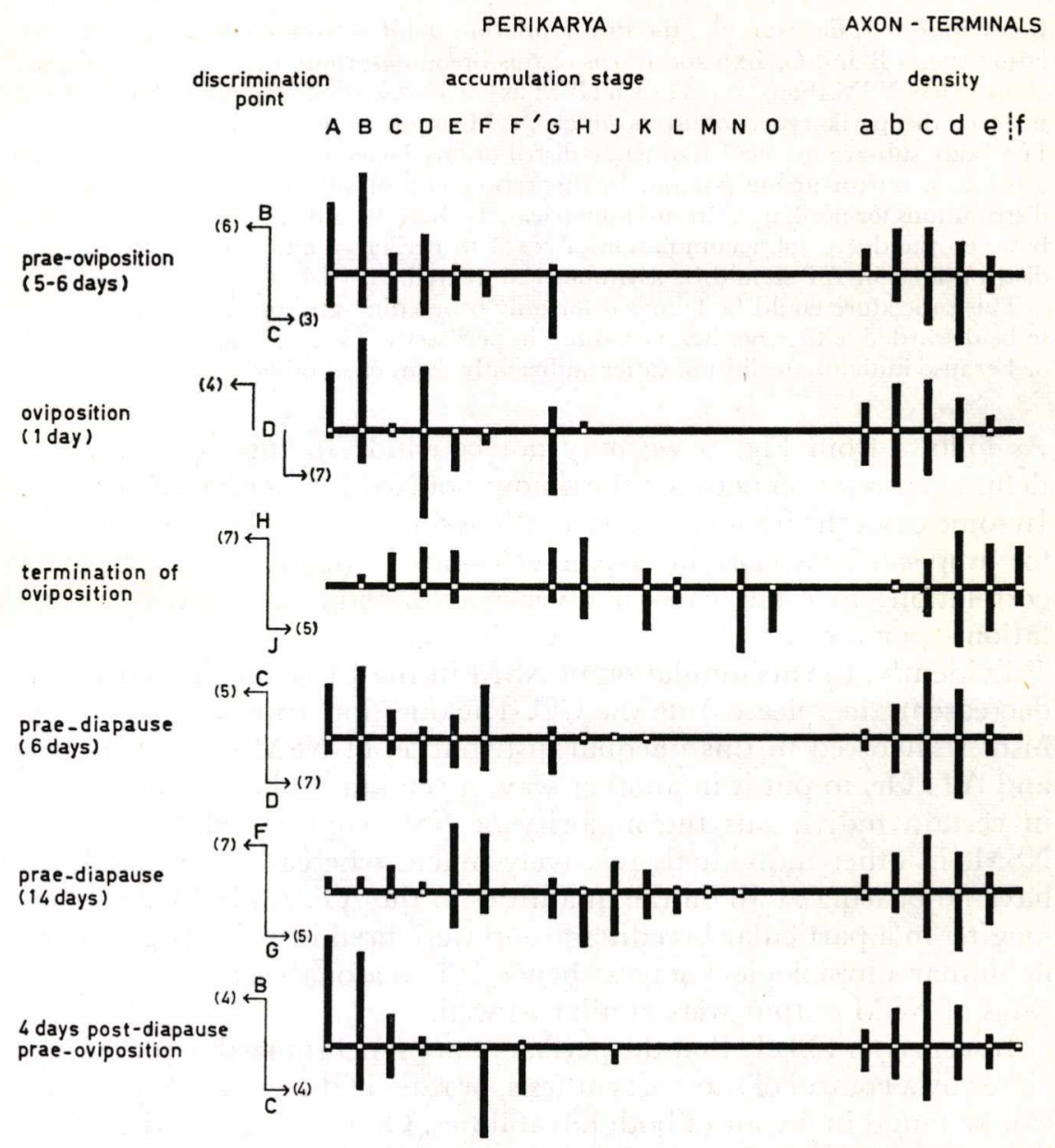

Fig. 6. Double (upper/lower) frequency-distributions which enable comparison of AT-densities of specimens with little NSM-containing perikarya with those of specimens with much NSM in the perikarya. For details, see text.

true. In between, cellbodies and AT contain moderate amounts of NSM. If, in addition, rates of synthesis and speed of axonal transport are controlled independently, the frequency-distributions for ATdensities in Fig. 6 may show any form of asymmetry, indeed.

The concept of phasic discharge of NSM is not a quite new one. In Schistocerca gregaria (Highnam, 1961a) and Iphita limbata (NAYAR, 1956) NSM was found to be located at regular intervals along the axons, suggesting that the discharge frequency is rather high, at least much higher than it seems to be in Leptinotarsa. 


\subsubsection{NUGLEUS MEASUREMENTS}

Other criteria for glandular activity are the dimensions of cellbody and nucleus (GABE \& ARvY, 1961). Although cell volumes may differ spectacularly under varying breeding conditions, this parameter for activity cannot easily be measured; therefore linear dimensions of nuclei were taken into account.

Some authors prefer to calculate actual nuclear volumes from measurements of the long and short axis in sections, including mathematic compensation for irregularities in the shape of the nucleus (cf. BRADY, 1967). In Leptinotarsa the ratio of the long and short axis seldom exceeds the value 1.4 , and is normally about 1.2 . With respect to this rather low value we have simply taken the mean of both axes as a measure for nuclear diameter.

Measurements were carried out with an accuracy of approximately $0.3 \mu$, using a calibrated eye-piece micrometer and a variable phasecontrast equipment, with an over-all magnification of $\times 1,600$. The nuclear membrane appears as a grey rim with a thickness of about $0.5 \mu$; the outer diameters have been taken into consideration.

TABLE III

Mean diameters of the A-NSG nuclei

\begin{tabular}{|c|c|c|c|c|c|c|}
\hline Breeding-group & $\begin{array}{c}\text { Age } \\
\text { (days) }\end{array}$ & $\begin{array}{c}\text { Number } \\
\text { of } \\
\text { specimens }\end{array}$ & $\begin{array}{c}\text { Mean } \\
\text { diameter }^{1} \\
(\text { in } \mu)\end{array}$ & S.E. & $\begin{array}{c}\text { Comparison } \\
\text { of the } \\
\text { means }{ }^{2}\end{array}$ & \\
\hline \multicolumn{7}{|l|}{ Long-day } \\
\hline ecdysis & 0 & 10 & 7.66 & 0.26 & \multirow{2}{*}{$\begin{array}{l}p=0.05 \\
p=0.001\end{array}$} & \multirow[b]{4}{*}{ N.S. } \\
\hline pre-oviposition & $5-6$ & 10 & 7.90 & 0.17 & & \\
\hline $\begin{array}{l}\text { oviposition } \\
\text { termination of }\end{array}$ & 29 & 12 & 8.06 & 0.25 & \multirow{2}{*}{$\mathrm{p}=0.01$} & \\
\hline oviposition & $56-89$ & 11 & 7.70 & 0.32 & & \\
\hline \multicolumn{6}{|l|}{ Short-day } & \\
\hline ecdysis & 0 & 7 & 7.43 & $0.35\}$ & \multirow{3}{*}{\multicolumn{2}{|c|}{$\begin{array}{l}\mathrm{p}=0.05 \\
\mathrm{p}=0.001\end{array}$}} \\
\hline pre-diapause & 6 & 11 & 7.67 & $0.15\}$ & & \\
\hline $\begin{array}{l}\text { pre-diapause } \\
\text { diapause }\end{array}$ & 14 & 13 & 7.05 & $0.18\}$ & & \\
\hline diapause & 28 & 13 & 6.86 & 0.22 & \multirow{3}{*}{$\mathrm{p}=0.001$} & \\
\hline $\begin{array}{l}\text { diapause } \\
\text { pre-oviposition }\end{array}$ & 42 & 12 & 6.68 & $\left.\begin{array}{l}0.24 \\
0.30\end{array}\right\}$ & & \\
\hline $\begin{array}{l}\text { pre-oviposition } \\
\text { oviposition }\end{array}$ & $\begin{array}{l}150+4 \\
173+7\end{array}$ & $\begin{array}{l}9 \\
7\end{array}$ & $\begin{array}{l}7.87 \\
8.01\end{array}$ & $\left.\begin{array}{l}0.30 \\
0.18\end{array}\right\}$ & & \\
\hline
\end{tabular}

S.E. $=$ standard error.

115 measurements per specimen.

${ }^{2}$ Student's t-test. 
In each specimen 15 A-NSG nuclei were measured. To avoid possible selection, all NSG in each third section through the PI were taken, as far as largest nucleus diameters were located in the section. Per breeding-group individual mean diameters were averaged. Results are given in Table III.

It appears that no significant differences in mean nuclear diameters - differences in synthetic activities - exist between animals at ecdysis under LD or SD conditions. During egg maturation and oviposition activities have significantly increased, whereas the termination of oviposition is accompanied by a fall in activity.

After ecdysis under SD conditions a similar initial activation occurs, which is followed, however, by a sharp decrease in activity at 14-days prae-diapause and during diapause. There are some indications that the nuclei become even smaller after 5 months of diapause but due to the presence of large amounts of NSM nuclei could not be measured accurately. After the animals are removed from the soil and exposed to light a dramatic re-activation of the NSG takes place within a few days; the mean diameters closely correspond with those of ovipositing LD specimens.

5.1.3. RATES OF INCORPORATION OF ${ }^{35}$ S-GYSTEINE INTO NEUROSECRETORY MATERIAL: AUTORADIOGRAPHIC EXPERIMENTS

\subsubsection{Introduction}

In Subsection 5.1.1 it was demonstrated that between ovipositing and diapausing females large differences exist in the amounts of NSM in cellbodies and axon-terminals. The conventional histological methods did not enable us, however, to interpret these differences in secretory activity. This could partly be overcome by measuring nuclear sizes as expressions of synthetic activity (Subsection 5.1.2), but by this method the existence of differences in neurosecretory activity could merely be established. The present study was undertaken to determine the relative rates of A-NSM synthesis in ovipositing and diapausing animals. For that purpose rates of incorporation of ${ }^{35}$ S-labeled cysteine into NSM were investigated with autoradiographic procedures.

SLOPER (1958) and co-workers (Sloper et al., 1960) demonstrated the more or less specific uptake of cysteine and other labeled sulphurcontaining amino acids by the Gomori-positive NSC in the hypothalamus of the rat. Later on, similar results were obtained in the insects Schistocerca gregaria (Highnam, 1962a; Luntz, 1968), Galeruca tanaceti (Siew, 1965c) and Anacridium aegyptium (Geldiay, 1968). The specific uptake of cysteine and related amino acids is due to the fact 
that these substances belong to the major constituents of the stainable neurosecretory substance (AdAMs \& SLOPER, 1956). This also holds for Leptinotarsa (cf. Paragraph 3.3.1.3). SGHürmann (1968), working with other labeled compounds, obtained valuable data as to protein synthesis in different brain areas of Locusta migratoria.

Since ${ }^{35} \mathrm{~S}$-cysteine was also taken up by the ordinary neurons in the brain, Highnam, Luntz, and Siew determined the ratio of labeling of NSC and neurons, as a measure for the incorporation rate in NSG. A high ratio indicated a high "relative" activity of the NSG. In the experiments on Schistocerca major metabolic differences between neurons in the breeding-groups investigated were apparently not to be expected. However, it could not be excluded that in Leptinotarsa significant differences in nervous activities during oviposition and diapause exist. For that reason the procedure of ratio determination was initially rejected and the attention was mainly focussed on the rate of incorporation of the isotope in NSG.

In preliminary experiments it was found that after injection, the ${ }^{35} \mathrm{~S}$ concentration in the haemolymph decreased very rapidly. Since the degree of labeling of neurosecretory perikarya depends on the availability of the isotope - among other factors - for the interpretation of rates of labeling the decrease in ${ }^{35} \mathrm{~S}$ concentrations were also taken into consideration.

\subsubsection{Methods}

\section{TREATMENT OF THE ANIMALS}

Animals in two different physiological stages were compared:

1. Females ovipositing since $2 \frac{1}{2}$ weeks (LD-group). The egg production, counted over 3 days, was about 50 eggs/LD-female/day for all specimens.

2. Females in diapause for 5 months (SD-group).

Via the side of the thorax the animals were injected into the caudal part of the abdomen by means of an electrolytically sharpened needle, attached to a $50 \mu \mathrm{l}$ micrometer-syringe. As some bleeding after withdrawal of the needle could not always be prevented, the needle was left in position for 45 seconds after injection; this period of time permitted a sufficient dispersal of the isotope away from the wound. Animals bleeding heavily were discarded. Care was taken that the animals were disturbed as little as possible prior to and after the injection and that they were left under normal breeding-conditions. In the case of diapausing females it has been ascertained that over a period of 24 hours the isotope injection procedure had no stimulating effect on the activity of the NSS, as compared with completely undisturbed control animals.

${ }^{35} \mathrm{~S}-1$-cysteine-HCl was obtained from the Radiochemical Centre (Amersham, England) and had a specific activity of $36 \mathrm{mCi} / \mathrm{mm}$ on November 8 th, 1968. Experiments were conducted in January (LD-group) and April 1969 (SD-group). The isotope was dissolved in Ringer-solution; each LD-specimen received $5 \mu \mathrm{Ci}$ in $4 \mu \mathrm{l}$ (Ringer), SD-specimens $1.6 \mu \mathrm{Ci}$ in $3.2 \mu \mathrm{l}$. 


\section{PREPARATION OF AUTORADIOGRAMS}

After injection of the isotope, samples were taken at varying intervals between 12 minutes and 24 hours. Heads were fixed in Bouin under reduced pressure and processed in the usual way. After dewaxing, slides were washed in ammoniacal alcohol in order to remove traces of picric acid. Neurosecretory A-cellbodies were stained with PAF to a desired extent, i.e., for LD-specimens longer, for SD-specimens shorter than usual; no counterstain was used. After washing the slides in several changes of distilled water and covering them with Kodak AR 10 stripping-film, they were thoroughly dried and stored at $4^{\circ} \mathrm{C}$ in light-tight boxes in the presence of silicagel. Exposure times were: 14 days for LD-, 31 days for SD-specimens. Films were developed in Kodak D 19 b, under standard conditions $\left(18^{\circ} \mathrm{C}\right)$.

\section{HAEMOLYMPH SAMPLES}

Just prior to decapitation two haemolymph samples of $1 \mu \mathrm{l}$ each were taken from the drop of blood arising after amputation of a hindleg, by using $1 \mu l$ microcaps (Drummond, Broomall, U.S.A.). The one sample was brought onto a strip (P) of cellulose acetate (Supraphore III, Gelman Instrument Company, Michigan, U.S.A.), airdried, and was used for the determination of over-all radioactivity. The other sample was used for the estimation of radioactivity in the precipitable fraction of the haemolymph; it was brought onto a wet strip (Q) soaked in diethyl barbiturate buffer, air-dried, fixed and washed for 60 minutes in a mixture containing $50 \mathrm{ml}$ methanol, $10 \mathrm{ml}$ acetic acid and $40 \mathrm{ml}$ water, and again air-dried. Strips $\mathbf{P}$ and $\mathbf{Q}$ of each specimen were dissolved in $12 \mathrm{ml}$ scintillation liquid (BRUNo \& Christian, 1961). The radioactivity of the samples was measured with a liquid scintillation counter (Nuclear Chicago, Mark I). The radioactivities found have been expressed in counts per minute $(\mathrm{cpm})$ since quenching apparently did not occur and the counting efficiency could not accurately be determined.

\section{GRAIN DENSITIES}

With the aid of a $\times 100$ oil-immersion objective (over-all magnification approximately $\times 2,000$ ) and dark-field illumination (substage cardioid condensor) the silver particles above A-NSC reflected light with a purple tinge. An objective diaphragm enabled a continuous transition from bright- to dark-field images, which facilitated the selection of the proper locations in the sections.

The labeling of individual NSC and other brain regions was investigated by estimating silver grain densities, rather than by grain counting. For that purpose use was made of a series of reference-density models, i.e., a varying and known number of lighted spots standing out against a dark background. Dark-field images of grains could be directly compared with one of the reference densities. These latter were prepared as follows.

A regular pattern of small black spots on white drawing paper was photographed; the negative was once, twice or repeatedly projected on different sheets of photographic paper, the sheets being displaced after each exposure. After development, random distributions of black spots were obtained. A sequence of eleven prints was made, the number of spots being increased by a factor 2 each time. This series was photographed on $35 \mathrm{~mm}$ film and the resulting strip of second-instance negatives served our purposes of grain-density determinations. It may be noted that the distribution of spots over the model area is remarkably similar to that of the silver grains; "tracts" as well as local aggregations can be observed (Fig. 7). 

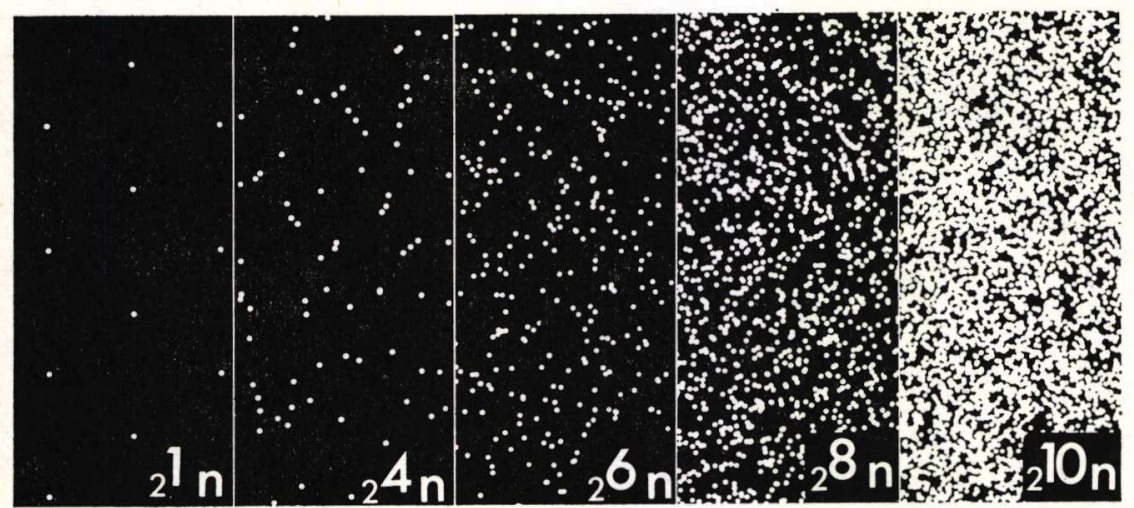

Fig. 7. Parts of 5 out of the 11 reference density models used for the estimation of grain densities in the stripping-film. For details, see text.

The strip was mounted horizontally in a small apparatus in which a beam of light illuminated the negatives from below, one at a time. By means of ground glass plates and an oblique built-in mirror the light was centered and the negative evenly illuminated. Light intensities of the transparent spots could be changed at will with a diaphragm in front of the lens system of the light source.

While studying an autoradiogram through the microscope, the images of the reference-densities were superimposed by means of a Leitz drawing tube, inserted between objectives and microscope tube. A reference-density was selected which best corresponded with the actual grain density. Grain densities covering a range of 1: 1558 (i.e., $2^{0} n-2^{1} n \ldots .2^{10} n$ ) could be determined within a few seconds. The value of "n" corresponded with 1.52 silver grains $/ 100 \mu^{2}$; this area is slightly larger than the cross-area of A-NSC in diapausing animals, but smaller than that of ovipositing females.

The background densities of silver grains were negligible as compared with the high grain-densities above neurosecretory perikarya and were not taken into account.

\subsubsection{Results}

At varying time intervals after injection of the isotope, three animals were taken for investigation.

Grain densities above the cytoplasm of A-NSC were for the first time estimated in every second section through the pars intercerebralis, for the second time in intermediate sections, and for the third time in randomly selected sections. Each time 25 different NSC were inspected. The average grain density was expressed in numbers of silver grains per $100 \mu^{2}$. This procedure could not be simplified as mean grain densities calculated after each series of estimates show rather large variations. The highest mean densities found may differ from the lowest mean density by $50 \%$. This is due to the fact that individual perikarya of a 


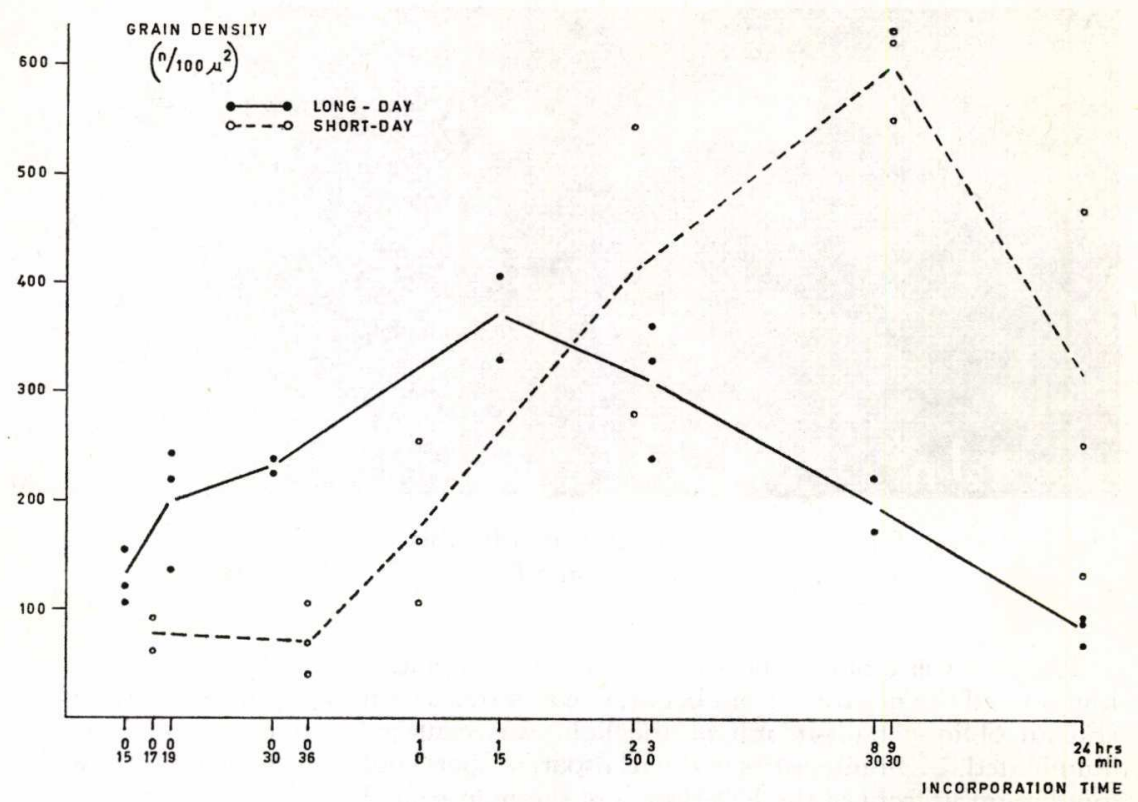

Fig. 8. Silver grain densities in the stripping-film over A-NSC, estimated after various times of incorporation of ${ }^{35} \mathrm{~S}$-cysteine in ovipositing (long-day) and diapausing (shortday) females. The amounts of isotope injected and the times of exposure of the stripping-film were for $\mathrm{LD}$ and SD beetles: $5 \mu \mathrm{Ci}-2$ weeks, and $1.6 \mu \mathrm{Ci}-4$ weeks, respectively. Individually estimated grain densities are given.

particular specimen sometimes differ in labeling by a factor 4 . Mean values of grain densities are therefore greatly influenced by the number of heavily labeled perikarya included in the series of grain density determinations. Within individuals no relation could be found between the degree of labeling and staining intensity of NSC. The pattern of ${ }^{35} \mathrm{~S}$-incorporation in $\mathrm{LD}$ and $\mathrm{SD}$ females is given in Fig. 8. It should be emphasized that: 1 , due to processing failures some slides had to be discarded, reducing some groups to only 2 specimens, and that 2 , both curves may not be compared, since different amounts of isotope have been injected and times of exposure were not equal.

The graphs clearly demonstrate that the maximum amount of isotope in $L D$ is reached at about 1 hour after injection, in SD at about 9 hours. During the shorter incorporation times the rate of labeling proceeds much faster in LD than in SD specimens, the difference being larger than could be expected on the basis of dose-response relations and differences in exposure time. The decrease in the amount of isotope incorporated after the maximum has been reached can only be in- 


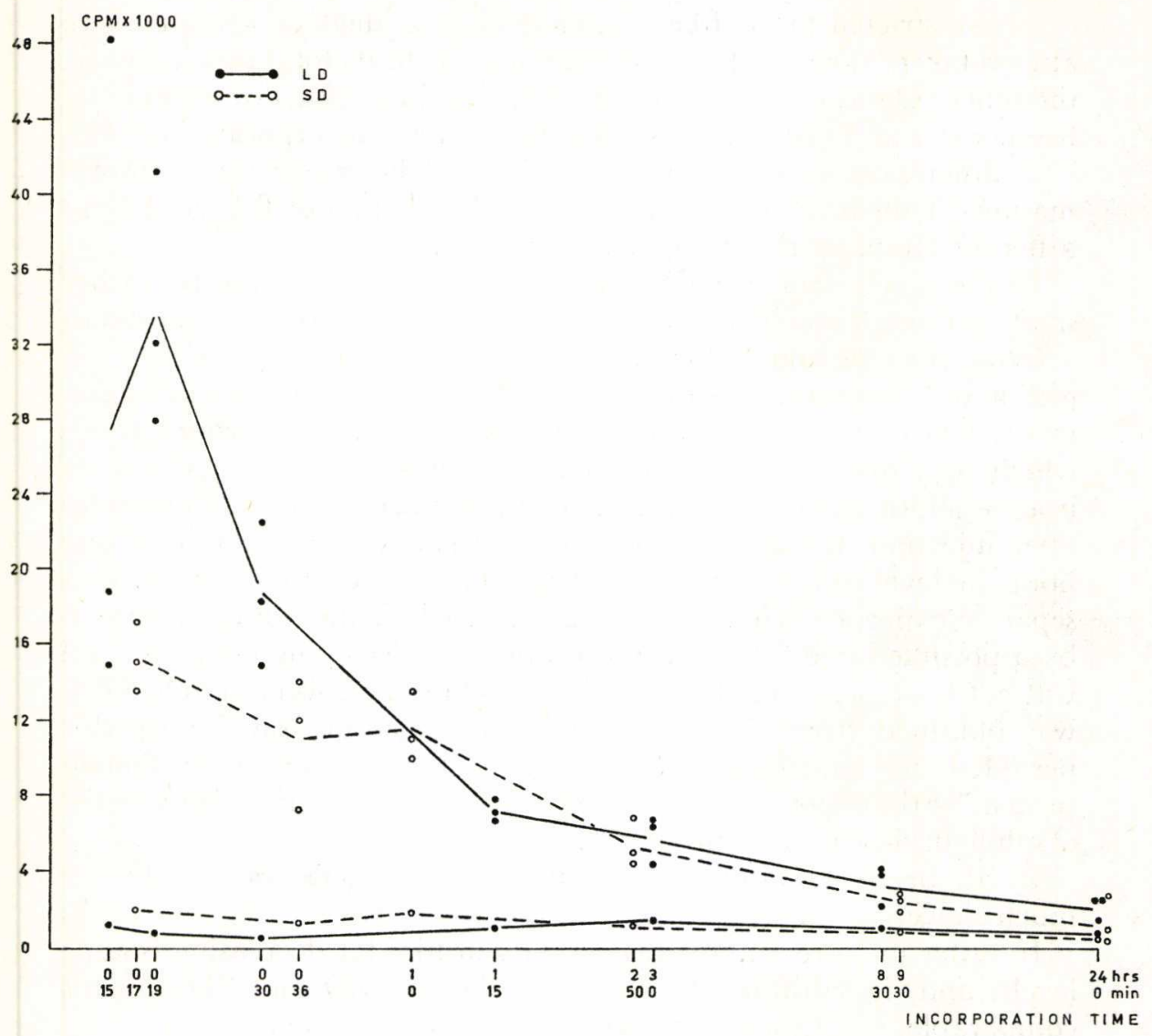

Fig. 9. Isotope concentration in the haemolymph determined at various intervals after injection. The upper curves represent the radioactivity of the non-precibitable fraction of $1 \mu \mathrm{l}$ blood samples, the lower curves, the average radioactivity of the precipitable fraction.

terpreted as an indication that the isotope supply to the NSC has decreased. For in case there would be a constant supply, we might expect that at a certain moment an equilibrium was established between the rate of isotope incorporation on the one hand and discharge of labeled protein from the perikaryon on the other. Therefore, the grain densities found must be corrected for actual isotope levels prior to the moment of fixation.

Haemolymph samples have been taken from individuals just before the heads were taken for autodiagraphic investigation. Since our inter- 
est was restricted to the free ${ }^{35} \mathrm{~S}$-amino acid, 2 identical samples were always taken, the one $(\mathrm{P})$ being examined as to its total radioactivity, the other $(\mathrm{Q})$ as to the activity in the precipitable fraction containing haemocytes and possible substances which have incorporated the ${ }^{35} \mathrm{~S}$. The differences between these samples will be reasonable approximations of the level of free ${ }^{35} \mathrm{~S}$-cysteine. The values of $\mathrm{P}-\mathrm{Q}$ and $\mathrm{Q}$ at different sampling times are given in Fig. 9.

In the precipitable fraction the amount of isotope is always rather small, although it constitutes a considerable portion of the total radioactivity, 9 to 24 hours after injection. At about 15 minutes after injection in LD specimens large variations occur; these are probably due to the fact that abdomens are heavily distended by maturing oöcytes which may offer serious circulation barriers to the small volume of isotope solutions. It is evident, however, that starting from 19 minutes after injection, the isotope level falls extremely rapidly. Within one hour the level has reached about a quarter of its original height. In a separate experiment it was investigated whether this could be caused by a possible large protein incorporation in developing oöcytes. That was not the case, as at 24 hours after injection a recovery of only $8,8 \%$ was obtained from complete ovaria and eggs deposited over this period. Later on, DE LOOF \& DE WILDE (1970) found that "female protein"- the major component of yolk proteins-contained only traces of sulphydryl-bearing amino acids.

In SD beetles the isotope level in the blood decreases as well, but much slower.

In order to correct individual grain densities for decreasing isotope levels, and, in addition, to make the data of LD and SD animals comparable, two different corrections have been made.

1. Starting from the supposition that in the case the isotope concentration in the blood was constant and equal in all animals (level X), the actually found labelling of the NSC should be multiplied by the factor: level X/actually found ${ }^{35} \mathrm{~S}$ concentration in the blood at the moment of fixation. Since level $\mathrm{X}$ was not accurately known, the highest radioactivity found in the blood samples was taken $(48,200 \mathrm{cpm})$. For the correctness of this supposition, see discussion.

2. Since for SD animals the effective duration of stripping-film exposure was twice as long as for LD animals, grain density values for the former were divided by a factor 2 .

All individually determined mean grain densities were transformed in that way. Results are given in arbitrary "corrected grain densities" in Fig. 10. 
It appears that in LD animals a balance is reached between the rates of incorporation and discharge of labeled NSM after about one hour. In SD animals this takes about 9 hours. As the result of accumulation of labeled NSM in the perikarya the amount of isotope in SD animals highly surpasses that in LD animals. It should be stressed that the labeling of NSC is in fact not related with the isotope concentration in the blood at the moment of fixation, but prior to that moment. For that reason all corrected grain densities turn out to be too low. This effect is most pronounced for the LD specimens taken after short incorporation times; in these animals the ${ }^{35} \mathrm{~S}$ content of the blood decreases particularly fast.

Since we are mainly interested in rates of incorporation, it was determined how much time elapses before a certain labeling is reached in both groups of animals. If the grain densities found after the shorter incorporation times are plotted on a linear time-scale, it appears that in SD animals it takes about 4 times as long to reach a certain (1000) corrected grain density as in LD animals (Fig. 11). This suggests that the rates of NSM production in ovipositing and diapausing females differ by a factor 4, approximately (see discussion, however).

In the second instance (see page 187) it seemed worthwhile to determine the uptake of ${ }^{35} \mathrm{~S}$ by ordinary neurons, and-after calculating the NSC/neuron ratio- to compare the situations in Leptinotarsa and Galeruca (SIEw, 1965c). Neurons situated in the dorsal PI were studied; only in this region the neuron layers were sufficiently homogeneous. Above tangential sections through these neuron layers, the distributions of grains were very regular; one or two density readings sufficed. Average grain densities are given in Fig. 12. The ratio NSC/neuron grain density was individually calculated; average ratio values are given in Fig. 13.

Only after 17 minutes of incorporation the NSC of SD specimens contain much more ${ }^{35} \mathrm{~S}$ than neurons. Between 17 and 75 minutes for both groups of animals the ratio is clearly above unity; at 24 hours the neurons contain more ${ }^{35} \mathrm{~S}$ than the NSC. In neurons, the rates of uptake and discharge of the isotope are thus lagging, as compared with NSC; similar grain densities are eventually reached, however. These data indicate that in neurons too, some protein synthesis takes place. From the observation that the neuron labeling does not further increase or decrease after certain incorporation times it follows that the labeled substance leaves the cellbody, presumably being transported to the neuropile. It is indeed observed that two different neuropile areas (i.e., in the protocerebral lobes and in the central body) are gradually labeled (Fig. 12). We may not conclude that the isotope reaches these 


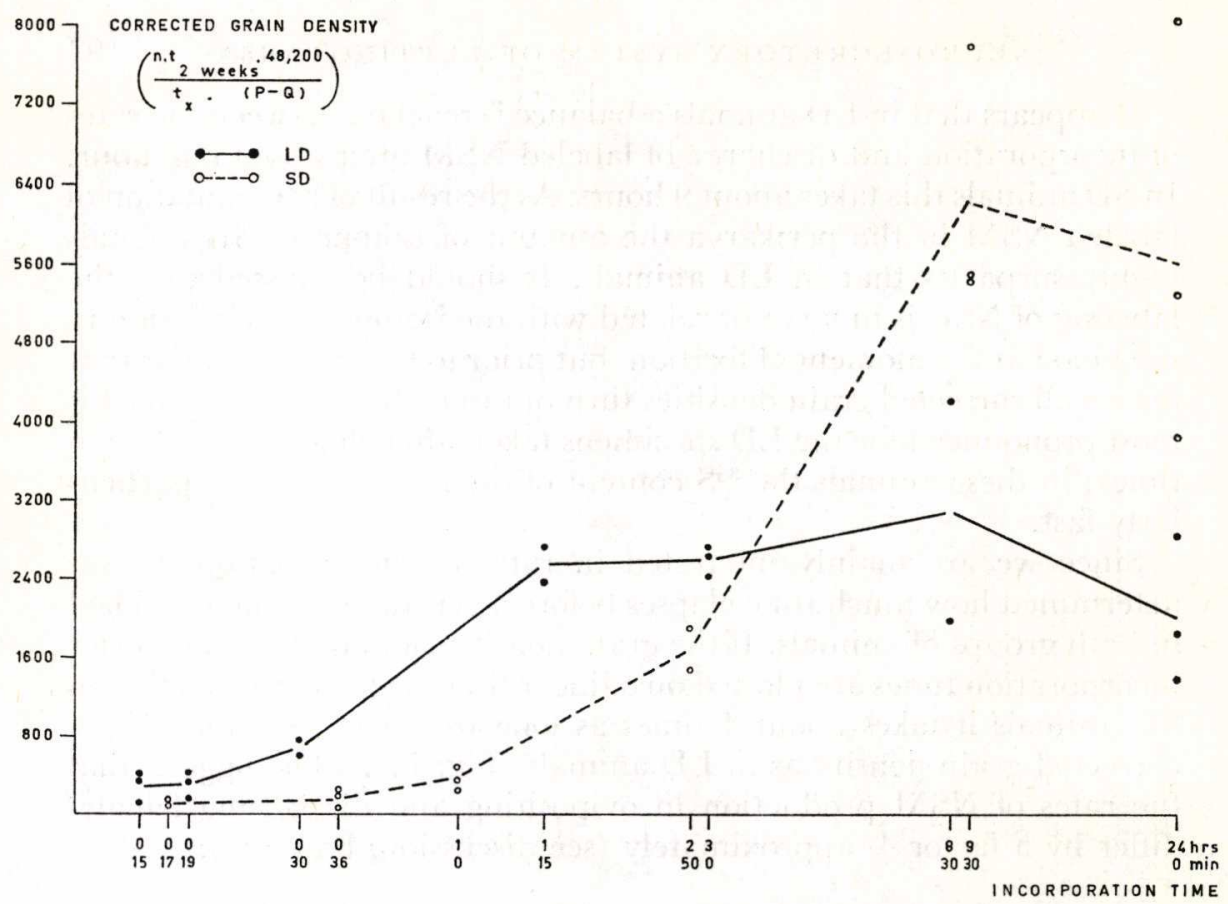

Fig. 10. Individually estimated grain densities corrected according to the formula given for differences in exposure times of the stripping-film ( $t=2$ or 4 weeks), and decreasing isotope concentration in the blood $(48,200 \mathrm{cpm}$ represents the highest radioactivity found in haemolymph samples, $\mathrm{P}-\mathrm{Q}$, the radioactivity of the non-precipitable fraction at the time of sampling).

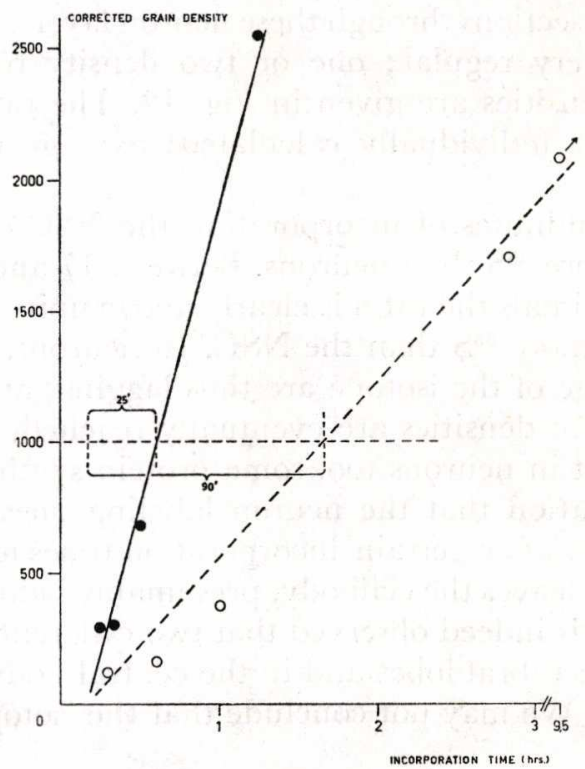

Fig. 11. Mean corrected grain densities, plotted against a linear time-scale, given for the shorter incorporation times only. (Black dots: ovipositing females; open circles: diapausing females). 
neuropile areas exclusively along the axons of the neurons under investigation. Other neuron populations bordering the neuropile also show incorporation of ${ }^{35} \mathrm{~S}$; rates are comparable to those of the neurons studied in more detail.

\subsubsection{Discussion}

With the aid of the graphs of corrected grain densities in Fig. 11 we have calculated that in $\mathrm{LD}$ animals the rate of incorporation of ${ }^{35} \mathrm{~S}$ was about 4 times higher than in SD animals. Twenty-five, respectively ninety minutes elapsed before a corrected grain density of 1000 was reached. The incorporation began about 10 minutes after injection of the isotope. It may be emphasized that these conclusions are very approximative. Some factors may well have influenced the slope of the graphs from which the conclusions were derived.

In the first place, differences between LD and SD females, leading to differences in the dilution of the isotope, have not been taken into account. According to DE KORT (1969) the weight of ovipositing and diapausing females is 183 and $142 \mathrm{mg}$, respectively. The corresponding percentages dry-weight are 30,5 \pm 0.6 and $44.5 \pm 2.1 \%$, respectively. We should therefore assume that in LD females the amount of isotope injected was diluted about twice as much as in SD females. This means that the differences in the rate of incorporation between both groups are larger than is suggested above. Irrespective of the considerations presented below, the rates of NSM synthesis differ by a factor 7, approximately.

In the second place, it is quite unknown whether the intracellular pool of free unlabeled cysteine in NSC varies in ovipositing and diapausing animals. If these pools are large, there would not be a linear relationship between isotope concentration in the blood and the rate of incorporation. In that case the grain densities found might not have been corrected for the decreasing isotope concentration in the way it has been done here. The straight lines in Fig. 11 should then be replaced by curves, and conclusions as to differences in synthetic activities in both groups could be quite different.

In the third place, the question arises which process in the NSC has in fact been investigated in these incorporation experiments. The purpose of this study was to follow the incorporation of cysteine into ANSM, but as was shown this amino acid is also utilized by ordinary neurons (Fig. 12). Possibly, this occurs after the amino acid is broken down, the ${ }^{35} \mathrm{~S}$ being used for the synthesis of non-protein substances. However, as in LD specimens the neurons are clearly labeled as early as 15 minutes after injection, it may not be ruled out that the cysteine is 


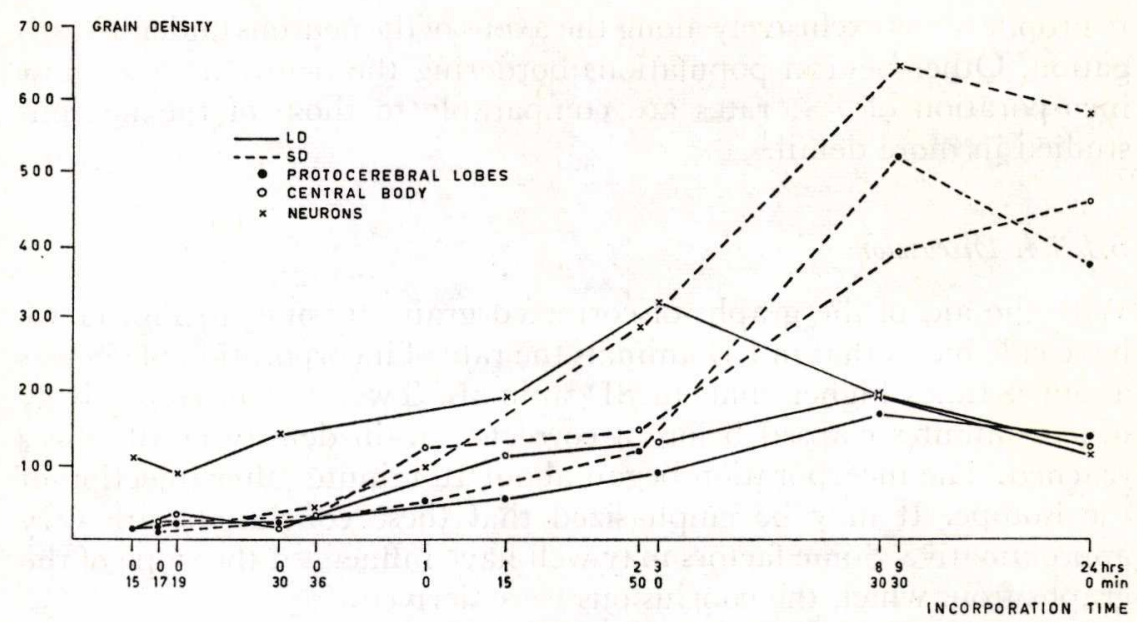

Fig. 12. Mean grain densities over ordinary neurons and two neuropile areas of the protocerebrum.

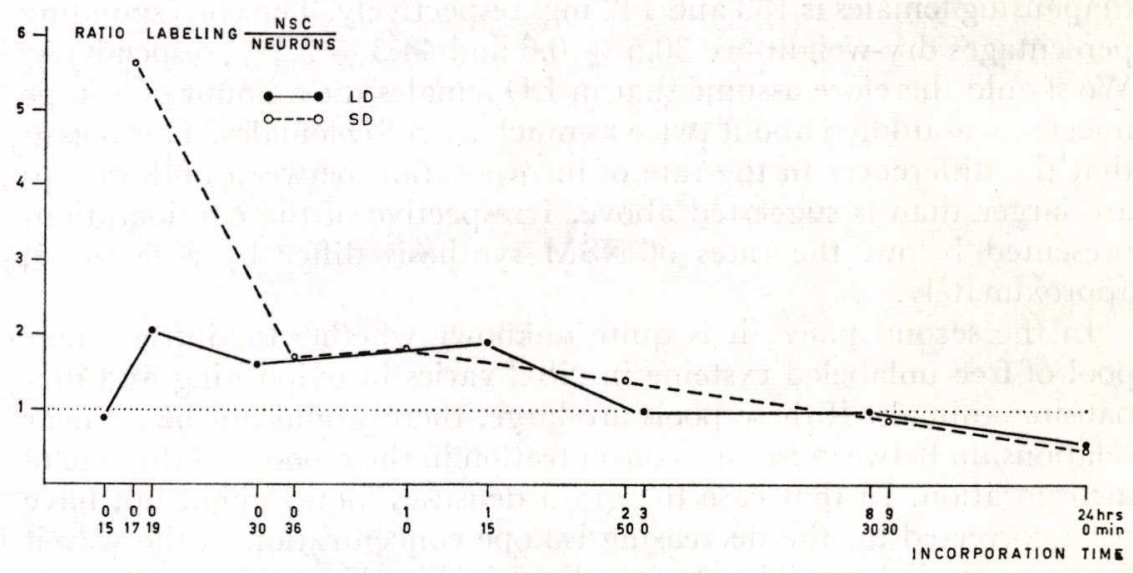

Fig. 13. Mean ratios of grain densities over NSC and neurons.

incorporated into proteins or polypeptides, in unmodified form. From the decrease in neuron labeling after longer incorporation times it follows that the labeled product is transportable. It is not impossible that the labeling of the NSC is to some extent due to similar-not specifically neurosecretory-processes. Since at present very little is known about the physiology of NSC, however, the grain densities found have not been corrected for this phenomenon. The incorporation in neurons gives rise to grain densities which are nearly similar to those 
found above NSG, but maximal values are reached later. This indicates that the rates of incorporation are much lower. For this reason, and in order to reduce the possibility that breakdown products of cysteine participate in the incorporation, the labeling of NSC after relatively short incorporation times has been especially stressed.

In the fourth place, since the isotope reaches the neurosecretory perikarya by way of the glial cells, these latter may hypothetically contribute to the grain densities above the NSC (and neurons). However, unless the isotope is highly concentrated in the glial sheaths surrounding the perikarya, this possibility seems highly unlikely as the sheaths in the PI are extremely thin (Pl. VII figs. 1 and 2). Yet the glial cells possibly play some role in another way. The low grain densities above neurons found in diapausing females at 17 minutes after injection give rise to an exceptionally high ratio value (see Fig. 13). As the neuron labeling after 36 minutes of incorporation has reached a more "normal" value, it may well be that at 17 minutes a low diffusion velocity of the isotope through glial cells was the limiting factor for incorporation by neurons. This is not necessarily so for the NSC; it is known that in the brain several kinds of glial cells occur (WIGGLesWORTH, 1960) which may be different in functional aspects. At all events, the observations demonstrate that some interference of the glial cells may not be neglected, particularly after short incorporation times.

In considering these points, the present work should be taken to be preliminary. More biochemical work remains to be done to evaluate the factors that influence the great difference we found between ovipositing and diapausing females.

The investigations were in second instance extended to the labeling of the neurons in order to see whether in Leptinotarsa the ratio NSC/ neuron grain densities found at different incorporation times followed a similar pattern as in the beetle Galeruca tanaceti (SIEw, 1965c). No correspondence could be found, however. In Galeruca, during oviposition, the ratio was relatively low (2.5) at 1 hour after the injection of ${ }^{35} \mathrm{~S}$-dl-cysteine, rose to a value of 4.5 at 3 hours, and subsequently decreased to 2.2 at 18 hours after injection. Here too the isotope concentration in the blood apparently decreased. In diapausing beetles a comparable pattern was obtained; only the maximum ratio was 2.5 and was reached at 24 hours after injection. In Leptinotarsa, on the contrary, the relation between ratio and incorporation time can be more or less depicted as a straight line (Fig. 13), both in ovipositing and diapausing females (except for very short incorporation times).

In Schistocerca a different pattern was found. The ratio of grain numbers over NSC and neurons did not vary with the incorporation time. In 7-day-old females reared with males, the ratio was 2.24, and in 
21-day-old females reared without males it was 1.39 (Highnam, 1962a). These data indicate that the NSC of the former breeding-group were more active than those of the latter. Yet, as in Leptinotarsa, in Schistocerca too the rate of labeling of NSG has been found to be a function of the isotope concentration in the haemolymph (LunTz, 1968). About two hours after the injection of ${ }^{35} \mathrm{~S}$-cysteine, the grain densities over the PI reach a maximum; due to the rapidly decreasing isotope concentration in the blood, and the discharge from the perikaryon of the labeled NSM, grain densities decrease thereafter.

In conclusion, it appears that in the three insect species mentioned above the interactions between isotope levels over the period of observation, the rates of NSM synthesis and discharge, and the uptake of isotope by ordinary neurons are different. In the present work on Leptinotarsa many uncertain factors could be avoided by relying on the relation between isotope level in the blood and rate of incorporation in NSC, exclusively.

\subsubsection{GONGLUSIONS}

The data on nuclear size and rate of incorporation of labeled cysteine as parameters for the rate of NSM synthesis contribute to an understanding of the patterns of NSM accumulation in perikarya and AT.

The frequency-distributions of Fig. 5 show that at ecdysis under both LD and SD conditions the NSG are in a similar stage of the secretory cycle; NSM that had accumulated late in the pupal instar is released. Since the nuclei are relatively small (Table III) NSM will be synthesized at a moderate rate. Some days later, the rate of synthesis and release has increased under both breeding conditions. From this moment the patterns of activity of LD and SD beetles diverge. The NSC of ovipositing animals become highly active and remain so as long as oviposition lasts; the nuclei are maximally enlarged and the autoradiographic experiments indicate that the synthesis and discharge of NSM occurs at a high rate. At the termination of oviposition the synthetic activity decreases while the NSM accumulates considerably.

During late pre-diapause and diapause, the A-NSC are gradually inactivated. Four weeks after the animals enter diapause the nuclei are very small (their volumes are about $40 \%$ smaller than during oviposition), whereas after some months of diapause the NSM production occurs at a rate of about one-seventh that of ovipositing females (cf. Paragraph 5.1.3.4.). The NSG are rapidly re-activated after the animals are exposed to light and prepare for oviposition. One day after the onset of SD oviposition nuclear diameters are similar to those during LD oviposition. 
From the changes which occur in the amounts of NSM stored in the AT in the CC, it follows that after ecdysis and after break of diapause much NSM is released. During the oviposition period the release probably remains constant and at a high level. In other stages the rates of release-i.e., the net result of neurosecretory activity-can merely be guessed on the basis of assumed NSM production; though AT show the tendency to accumulate NSM after a longer period of oviposition, this cannot be taken as an indication that the release is hampered. The autoradiographic experiments show that in these females NSM is produced in large quantities. One hour after the injection of ${ }^{35} \mathrm{~S}$-cysteine a balance is reached between the supply of the isotope and the discharge of labeled NSM. The actual average time spent in the perikaryon by the elementary granules (EG) will have the same order of magnitude. This means that once in an hour the entire A-NSM content of the PI is transported to the AT. Consequently, small changes in the amount of NSM in AT over a relatively long time are insignificant with respect to rate of output, notwithstanding the fact that the total volume of the AT in both CC probably exceeds the total volume of the perikarya. In animals which had been in diapause for 5 months AT are stained extremely dark. Yet, in this case too, some release of NSM took place, as followed from electron-microscopic investigations (ScHOoneveld, 1970). For these reasons the amount of NSM in the AT provides no information as to the rate of release of NSM from the CG.

The way in which NSM temporarily accumulates in the cellbodies can be taken as an indication of neurosecretory activity. As it has been stressed in Paragraph 5.1.1.4, the inclusions found in LD and SD animals differ in qualitative respects. In LD specimens the EG tend to aggregate into distinct inclusions (accumulation stages A, B, D and G, etc.) whereas during $\mathrm{SD}$ they are rather dispersed (stages $\mathrm{F}, \mathrm{J}$ and $\mathrm{M}$ ). In the autoradiographic experiments it was shown that the NSM in active animals left the perikaryon much more quickly than in diapausing animals. The explanation of the qualitative differences may therefore be that in the active cells EG are only observed in the immediate vicinity of the Golgi-complexes; once the EG are set free, they are rapidly transported to the axon. In contrast, in relatively inactive cells they are able to disperse, giving the perikaryon a rather homogeneously stained appearance, with hazy aggregations.

A graphic representation of the activity of the A-NSC throughout adult life is given in Fig. 16. 


\subsection{A A $_{1}$-TYPE NEUROSEGRETORY GELLS}

\subsubsection{INTRODUCTION}

Our knowledge about the activity of the $\mathrm{A}_{1}-\mathrm{NSC}$ is rather fragmentary. This is primarily due to the fact that $\mathrm{A}_{\mathbf{1}}$-NSM never accumulates in the perikarya. After staining with paraldehyde-fuchsin small and faint reddish-purple inclusions can only be found in the older ovipositing animals and sometimes after the termination of oviposition. In all other stages investigated inclusions were lacking altogether. Perikarya of the latter group of animals are frequently senescent; nuclei are then slightly pycnotic and the cytoplasm is stained bluish-purple. Measurements of nuclear diameter as a parameter of synthetic activity were cumbersome and unsuited for routine work. Nevertheless, in some ovipositing females it was found that nuclear diameters were exactly similar to those of A-NSC. In addition, the size and shape of $\mathrm{A}_{1}-\mathrm{NSC}$ very much resembled the A-NSC.

In the CG the $\mathrm{A}_{1}$-NSM is abundantly present. Within the AT the fluctuations in density of $\mathrm{A}_{1}-\mathrm{NSM}$ equal those of A-NSM. In fact, only in a rather late stage of the investigations it was realized that both kinds of NSM were present. In cases of extreme accumulation they could not, or only with difficulty, be differentiated; the use of a light blue-filter (FGB 4) and a properly selected voltage for the source of illumination proved to be essential.

Since observations of the existence of two nearly similar kinds of NSM in the CG have not been reported in the literature before, the correctness of the distinction made between $\mathrm{A}$ - and $\mathrm{A}_{1}-\mathrm{NSM}$ was investigated in several ways. In the first instance, it did not seem likely that on the mere basis of correspondence in colour the reddish-purple materials in the PI and CC were identical; as compared with A-NSC the relative lack of stainable material in $\mathrm{A}_{1}$-perikarya was somewhat peculiar. Two other explanations could be thought of for the occurrence of the reddish-purple material in the CG: 1 , it could originate from slightly Gomori-positive cells of the CG proper, or, 2, it could be ANSM which in some axons underwent a modification in chemical composition. GABE (1967) provided some evidence for similar transformations in other insects, but we were not able to confirm this for Leptinotarsa (Subsection 3.3.2).

On the other hand, the following three arguments support the idea that the reddish-purple material in the GG is produced in the PI, presumably in the $\mathrm{A}_{1}-\mathrm{NSC}$, and that it differs from A-NSM.

1. In stages during which the A-NSC are very actively secreting, sometimes large amounts of A-NSM as well as reddish-purple material 
are present in the proximal part of the axons.

2. Electron microscopically, $\mathrm{A}_{1}-\mathrm{NSC}$ are characterized by the presence of medium electron-dense EG with diameters of 1500-1800 $\AA$, A-NSG by electron-dense EG with diameters of $1200 \AA$ (Pl. VII figs. 1 and 2). In the CG, EG of similar features are present in locations which correspond well with those of the reddish-purple material and A-NSM (Pl. VII fig. 3).

3. If in just-emerged animals CG are unilaterally removed following the "neck-membrane technique" of DE WILDE \& DE BoER (1961), from the NCG-stump a GC-like structure develops (DE WILDE \& DE BoER, 1961, 1969). It appears that in early stages of regeneration no intrinsic cells have developed; yet, numerous AT are present, some of which containing A-NSM, others AT with the reddish-purple material $\left(\mathrm{A}_{1}\right.$ NSM).

\subsection{2. histology of aggumulation of $\mathrm{A}_{1}$-NSM in the GC}

Only the accumulation phenomena of $\mathrm{A}_{1}-\mathrm{NSM}$ in axon-terminals (AT) were thoroughly investigated. Attention was paid to the amounts of NSM in the AT (referred to as AT-density) and the size of the AT. The methods used were similar to those described extensively for the A-NSC (Paragraph 5.1.1.2). In fact, observations on A- and $\mathrm{A}_{1}$-AT were made simultaneously and the same scoring systems were used.

It was found that the over-all amount of NSM in one specimen consisted for a great deal of $\mathrm{A}_{1}-\mathrm{NSM}$, in other specimens only to a minor extent. As the relative amounts of $\mathrm{A}-/ \mathrm{A}_{1}-\mathrm{NSM}$ might bear some physiological information, some attention was also paid to this phenomenon. It appeared that the relations could best be investigated byvery roughly - estimating the relative numbers of AT and expressing the $\mathrm{A}-/ \mathrm{A}_{1}$-ratio in percentages. Here again, in order to get values which might be considered as representative for a given CC, this organ was "sampled" at three different levels. The ratio was determined after comparing three adjacent sections. Per animal the three percentages obtained in this way were tabulated $(10 \%, 20 \%, \ldots 90 \%)$. Per breeding-group individual tabulations were added, the frequency of the different percentages was calculated and the results were expressed as frequency-distributions. It should be mentioned that in aged pupae and at ecdysis, A- and $\mathrm{A}_{1}-\mathrm{NSM}$ are present in such a dense type of accumulations that both kinds of NSM cannot easily be distinguished in all specimens. In these cases, the main ratio was arbitrarily assumed to be about $50 \%$ (interrupted bars in Figure 14).

For convenience' sake, the frequency-distributions concerning the 
over-all amount of NSM in the CG (A- as well as $\mathrm{A}_{1}-\mathrm{NSM}$ ) are given once more.

All frequency-distributions are given in Fig. 14.

As follows from the graphs, the AT of aged pupae contain very much $\mathrm{A}_{1}$-NSM; they are large and stained extremely dark. Between the moment of ecdysis and 8 days after the beginning of oviposition in LD, and between ecdysis and 14 days pre-diapause in $\mathrm{SD}$, the content of the $\mathrm{AT}$ is largely released and AT-sizes have considerably decreased. In physiological respects the $\mathrm{A}_{1}-\mathrm{NSC}$ are active during these periods. Since accurate data as to synthetic activities of the perikarya are lacking, we know very little about the rates of output in these stages.

From 3 weeks after the beginning of oviposition onwards and from 1 week after entering diapause $\mathrm{A}_{1}$-NSM progressively accumulates in the AT. But again, we cannot conclude from the frequency-distributions whether this means that the release is hampered.

In the $\mathrm{A}_{1}$-perikarya of 14 day-old ovipositing females and in older females inclusions can be observed. As will be pointed out in the next subsection (5.2.3), from parallels which can be found between accumulation phenomena in $\mathrm{A}_{1}$ - and A-NSG it may possibly be concluded that these inclusions are signs of relatively high synthetic activities.

\subsubsection{Relation between agGumulation phenomena in $A_{1}$ - AND A-NSG}

With reference to the point raised in the previous subsection the $A_{1}$ and A-NSC are very similar in structural and functional respects. The shape and size of their cellbodies, nuclei, and axon-terminals are - on the average -identical. The ultrastructure of the cytoplasmic organelles reveals no differences between both NSG-types (SaHooneveld, 1970); only the size and electron density of the EG are slightly different (Subsection 5.2.2). When we compare the patterns of accumulation of A-NSM (Fig. 5) and $\mathrm{A}_{1}$-NSM (Fig. 14) in the CC it can be concluded that remarkable similarities exist, particularly in the AT-densities, and during LD as well as during SD breeding conditions.

Taking into account all these similarities, it is tempting to extend the parallels to the meaning of the more or less compact inclusions found in both $\mathrm{A}_{1^{-}}$and A-NSC of ovipositing females. We know that the A-NSG in these females are very active (Subsection 5.1.4) and the occurrence of compact inclusions can well be explained as resulting from the combined effects of high rates of synthesis and discharge of EG. Therefore, it is very probable that the same reasoning holds true for the $\mathrm{A}_{1}-\mathrm{NSC}$ as well, and that the presence of inclusions can be taken to indicate a high synthetic activity. 
$A_{1}-N S C$

LONG - DAY

AT-density

a b c d e : f

9-doy pupo

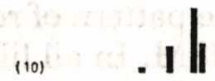

ecdysis
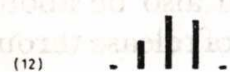

proe-oviposition (9) I|

oviposition (11) I||.

(1 day)

.. ( 8 doys $)$

(22 days)

termination

oviposition

SHORT-DAY

a b c d e! f

$\begin{array}{llll}1 & 2 & 3 & 4\end{array}$ overall amount

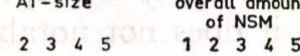

ratio number
A- $/ A_{1}-A T$
$10-30-50-70-90 \%$

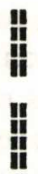

11.

11

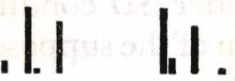

IIII.
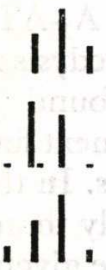

.11

.1

| I I I.

I | |. .

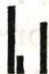

.111

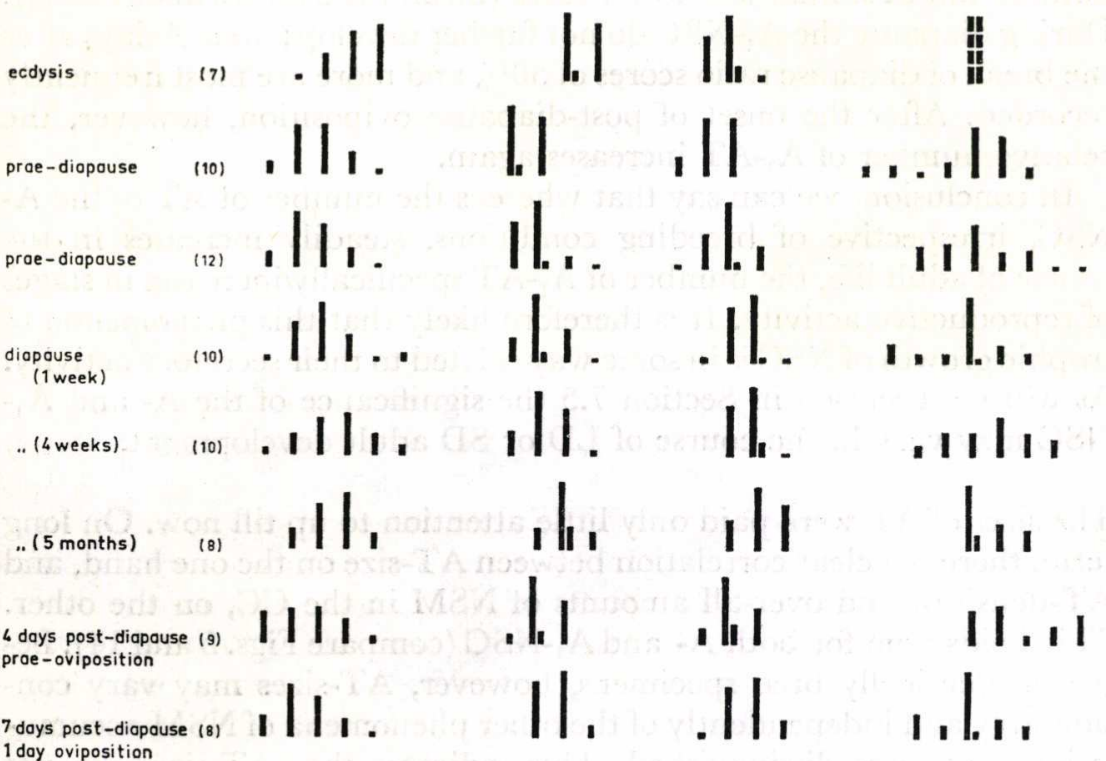

Fig. 14. Frequency-distributions illustrating the changes in accumulation of $A_{1}-N S M$ in the $\mathrm{CG}$, and the relative numbers of axon-terminals of the $\mathrm{A}-$ and $\mathrm{A}_{1}-\mathrm{NSM}$ throughout adult life. The interrupted bars indicate that ratios could not be estimated accurately. "Over-all amount of NSM" refers to the sum of A- and A - NSM.

Numbers of specimens per breeding-group are given in brackets. 
With reference to the frequency-distributions in Fig. 14 this would mean that during oviposition the $\mathrm{A}_{1}-\mathrm{NSM}$ is also released at a high rate, for in the AT it does not notably accumulate. In short, these speculations, together with the conclusions given in the above subsection, render it likely that in $L D$ females the pattern of release of $A_{1-}$ NSM has much in common with that of A-NSM. In all likelihood the patterns of release under SD conditions will also be about similar. A graphic representation of the supposed rates of release throughout adult life is given in Fig. 16.

Highly interesting observations were made with regard to the absolute and relative numbers of $\mathrm{A}$ - and $\mathrm{A}_{1}-\mathrm{AT}$ in the $\mathrm{CG}$ in the course of adult life. In the pupal stage and at ecdysis relatively few but very large and darkly stained AT have been found (Fig. 14); A- and $\mathrm{A}_{1}$-AT cannot easily be differentiated. In the next few days and under both breeding conditions the number increases. In the LD females the number of $A_{1}$ AT increases much more rapidly than that of the A-AT. This leads to the situation that low values are given for the ratio: number of $\mathrm{A}-/ \mathrm{A}_{1}-$ AT (ratio scores mostly $50 \%$ or less). In the CC of some aged females, the purple A-AT can hardly be found amongst the innumerable reddish-purple $\mathrm{A}_{1}-\mathrm{AT}$.

During pre-diapause the AT of both NSG-types also increase in number but at similar and lower rates (mean ratio scores about $50 \%$ ). During diapause the $\mathrm{A}_{1}$-NSC do not further develop; up to 4 days after the break of diapause ratio scores of $50 \%$ and more are most frequently recorded. After the onset of post-diapause oviposition, however, the relative number of $\mathrm{A}_{1}-\mathrm{AT}$ increases again.

In conclusion, we can say that whereas the number of AT of the ANSC, irrespective of breeding conditions, steadily increases in the course of adult life, the number of $\mathrm{A}_{1}-\mathrm{AT}$ specifically increases in stages of reproductive activity. It is therefore likely that this phenomenon of trophic growth of NSG is in some way related to their secretory activity. As will be discussed in Section 7.5 the significance of the A- and $\mathrm{A}_{1}$ NSC may vary in the course of LD or SD adult development.

The sizes of AT were paid only little attention to up till now. On long term, there is a clear correlation between AT-size on the one hand, and AT-densities and over-all amounts of NSM in the CC, on the other. This holds true for both A- and $\mathrm{A}_{1}-\mathrm{NSC}$ (compare Figs. 5 and 14). Between identically bred specimens, however, AT-sizes may vary considerably and independently of the other phenomena of NSM accumulation that were distinguished. This indicates that AT-sizes are not principally determined by —or adjusted to - the content of NSM. Only 
in 9-day old pupae and in adults at the moment of ecdysis one can imagine that the "pressure" of the densily packed EG (accumulation stage e) makes the AT distend, because the distensions are reduced when a few days later much of the NSM is released. In animals belonging to other breeding-groups other factors must be involved, for instance internal pressure exerted by osmosis - as a function of internal and external concentrations of substances other than the NSM proper-, or by axoplasmic flow, or by both. It is known that isolated AT ("neurosecretosomes") of vertebrates may burst and release their content of NSM as a consequence of the hypotonicity of the medium in which they are suspended (LaBella \& Sanwal, 1965). How the internal and external osmotic values vary for insect NSC remains to be investigated.

\subsection{C-TYPE NEUROSEGRETORY GELLS}

In the course of pupal and adult development the C-NSC follow a cycle of activity, as judged by the changes in staining intensity and the sizes of cellbody and nucleus. As has been mentioned in Paragraph 3.3.1.3 the C-NSC reveal a bluish-purple colour after staining with PAF. The question arose whether changes in stainability in fact represented changes in possible hormone concentrations as has been found in Aand $\mathrm{A}_{1}$-NSC. In Table II it can be seen that the inclusions of C-NSC give only a very weak positive reaction toward the performic-acid alcian-blue reaction, indicating a very low cystine or cysteine content. In this respect inclusions differ from those of the A-NSC.

It should be emphasized that as yet we do not know with certainty which cell compound actually takes up the stain. At the ultrastructural level the most striking feature of the C-NSC is the presence of numerous electron-lucent vesicles. In inactive cells, which are stained relatively dark by PAF, much less vesicles are present; instead, many small membranes which resemble vesicle fragments, occupy the cytoplasm (Schooneveld, 1970). It seems likely, therefore, that the stainability depends on the presence of these membranes. In Subsection 3.3.5 the meaning of Gomori-positive staining and the specificity of PAF have been discussed. There are indications that lysosomes may elicit a positive staining. These cell organelles are not thought to give rise to the blue colour of the G-NSG: in contrast to perikarya the axons do not contain many lysosomes; yet they contain the stainable substances.

In this study the changes in stainability of the perikarya were followed. As the AT in the CC are always small and are present in low numbers, these could not be taken into account. Changes in synthetic activities throughout the adult life cycle were studied by measuring nuclear diameters. 
Ghanges in stain ability.-On the one hand, C-perikarya may contain no stainable material at all; the cell can still be recognized by its large size and by its location in the dorsal part of the PI. On the other hand, large and intensely bluish-purple aggregations may be present which never reach a colour intensity comparable to that of the A-NSM, however. The aggregations consist of particles which can just be resolved by the light-miscroscope.

In order to express the changes in stainability the method of statistical tabulation of arbitrary accumulation-stages has once more been chosen. Nine stages $(a, b, \ldots i)$ of increasing accumulation were photographed (Pl. IX) and for each of the 4 to 6 perikarya in the PI it was determined which accumulation-stage of the scoring-system corresponded best with the appearance of the perikaryon concerned. Within a given specimen the scores were rather uniform. The scores were tabulated as explained in Paragraph 5.1.1.2. The data were converted into the frequency-distributions shown in Fig. 15.

Changes in nuclear diameters.-Nuclei of all suitably sectioned G-NSG were measured as described in Subsection 5.1.2. The mean diameters of 13 breeding-groups are given in Table IV.

At ecdysis under LD and SD conditions, nuclear diameters do not differ significantly. In the course of oviposition the diameters (hence synthetic activities) gradually decrease, but at the termination of oviposition some re-activation has taken place. In the course of diapause too, the activity decreases. Soon after the break of diapause, however, the C-NSG are completely re-activated.

From Fig. 15 it follows that the amount of stainable material increases in the course of oviposition and diapause, i.e., when synthetic activities decrease. On the other hand, 4 days after break of diapause, i.e., when the cells have been activated, relatively little material is left in the perikaryon. In this stage the axons of the C-NSG are widely distended, suggesting an active transport of substances through the axons.

As was the case in A- and $\mathrm{A}_{\mathbf{1}}-\mathrm{NSC}$, also in the C-NSG there is a reverse relation between synthetic activity and accumulation of NSM in the perikaryon. The only exception to this rule is formed by the breeding-group 5 months diapause; a possible explanation is that the animals belonging to this group were taken one year later than those belonging to the above groups; they may therefore not be strictly comparable.

A graphic representation of the cycles of activity throughout adult life is given in Fig. 16. 


\section{C-NSC}

\section{LONG-DAY}

9-day pupa

ecdysis

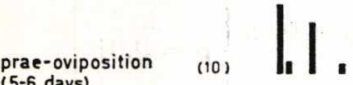

(5-6 days)

oviposition

(1 day)

" ( 8 days)

"( 22 days $)$

termination of oviposition
PERIKARYON STAINING INDEX

$a b c d e f g h$ i

$a b c d e f g h i$

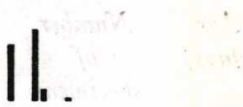

(9)

ecdysis

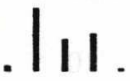

(12

prae-diapause ( 6 days)

- 111

(14 days)

1 11. (16) $\begin{array}{r}\text { diapause } \\ \text { (2 days) }\end{array}$
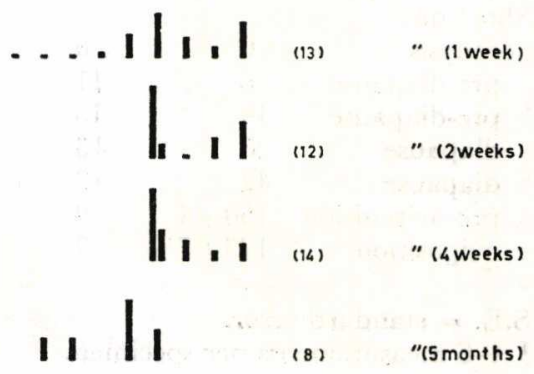

(8) "(5months)

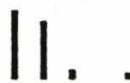

(9)

post-diapause prae-oviposition (6 days)

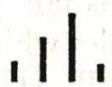

post-diapause ovipositio?

Fig. 15. Frequency-distributions illustrating the changes in staining of C-NSG perikarya. Numbers of specimens per breeding-group are given in brackets.

\subsection{E-TYPE NEUROSEGRETORY GELLS}

This cell type shows one remarkable cycle of activity. The 4 E-NSC appear only as late as in old pupae, when in the PI the left and right groups of medial NSG fuse. In 9-day old pupae they are striking by their large round nucleus, whereas cells have grown considerably at ecdysis. The cytoplasm is stained homogeneously grey then, vacuoles are either very small or absent (Pl. III fig. 4). Some days after emergence the size of the cellbody has decreased drastically and in the course of adult life the cells remain small (Pl III fig. 6). In perinuclear 
TABLE IV

Mean diameters of the G-NSG nuclei

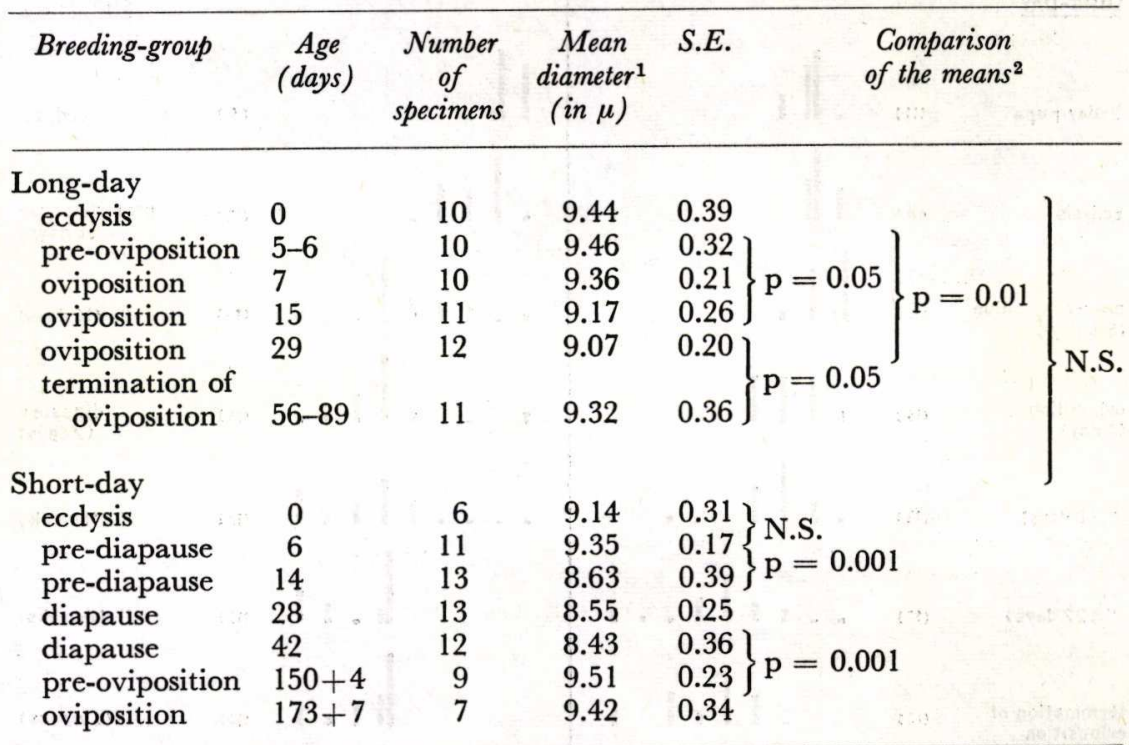

S.E. = standard error.

1 4-6 measurements per specimen.

2 Student's t-test.

cytoplasmic regions very small purple inclusions may occur which occasionally - only in females which have terminated oviposition - condense into clear inclusions (Pl. III fig. 5). The E-NSC never degenerate completely.

On the basis of these observations the secretory activity of the E-NSG seems to attain a maximum at about the moment of ecdysis or emergence. This is confirmed by the changes which take place in nuclear size. In Table $\mathrm{V}$ only the diameters in aged pupae and young adults are given.

In $\mathrm{LD}$ as well as in $\mathrm{SD}$ specimens a maximum is reached very early in the adult stage, but significant differences exist between both 0-day breeding-groups. Already in the stages pre-oviposition and late prediapause activities have decreased highly significantly.

A graphical representation of the cycle of activity is given in Fig. 16.

\subsection{L-TYPE NEUROSECRETORY GELLS}

The groups of L-NSC, in Leptinotarsa situated in the neuron layer of the 
TABLE V

Mean diameters of the E-NSC nuclei

\begin{tabular}{|c|c|c|c|c|c|c|}
\hline Breeding-group & $\begin{array}{c}\text { Age } \\
\text { (days) }\end{array}$ & $\begin{array}{l}\text { Number } \\
\text { of } \\
\text { specimens }\end{array}$ & $\begin{array}{c}\text { Mean } \\
\text { diameter }{ }^{1} \\
(\text { in } \mu)\end{array}$ & S.E. & \multicolumn{2}{|c|}{$\begin{array}{l}\text { Comparison } \\
\text { of the means }\end{array}$} \\
\hline \multicolumn{7}{|l|}{ Long-day } \\
\hline 9-day-old pupae & -1 & 10 & 9.15 & 0.41 & & \multirow{7}{*}{$\mathrm{p}=0.01$} \\
\hline ecdysis & 0 & 9 & 9.77 & 0.12 & $\left\{\begin{array}{l}p=0.001 \\
p=0.001\end{array}\right.$ & \\
\hline pre-oviposition & $5-6$ & 9 & 9.05 & 0.33 & $p=0.001$ & \\
\hline Short-day & & & & & & \\
\hline ecdysis & 0 & 7 & 9.33 & 0.41 & \multirow{3}{*}{$\begin{array}{l}\text { N.S. } \\
p=0.001\end{array}$} & \\
\hline pre-diapause & 6 & 10 & 9.43 & 0.23 & & \\
\hline pre-diapause & 14 & 13 & 8.53 & 0.26 & & \\
\hline
\end{tabular}

S.E. $=$ standard error.

1 3-4 measurements per specimen

2 Student's t-test.

left and right corpora pedunculata, are merely visible in 2-days old pupae; in 9-days old pupae the NSG are clearly larger than the surrounding normal neurons, but only in adults histological signs of secretory activity become visible. These observations are in agreement with findings in other holometabolous insects where the lateral NSC develop only late in post-embryonic life, when the primary centres corresponding to the compound eyes become differentiated (VAN DER KLoot, 1960; GABE, 1966).

Prior to the stage of maximal activity the cells are more or less spheroid, with clear and smooth cell membranes; the cytoplasm is then stained homogeneously grey. Starting from a few days after ecdysis the perikarya considerably increase in size, occasionally reaching widths of $40 \mu$ (Pl. IV fig. 1) during oviposition. In this stage the cells are flattened, cell membranes become blurred and the ratio: cytoplasm/ nuclear volume increases enormously. The cytoplasm reveals a greenish or pink colour, and refractory materials and small vacuoles are conspicuous. At examination with phase-contrast, typical short strands of the highly developed endoplasmic reticulum occupy most of the cytoplasm. Moreover, the axons of the L-NSG are distended and filled with refractory colloids. Soon after these stages of apparent activity are reached L-NSM accumulates in the peripheral regions of the CG. Judged by these criteria, the L-NSC remain active during the whole period of active reproduction.

Under SD conditions highest activities are found in early pre-diapause. During diapause the cells are inactive, as follows from their 
small size, the unstained and disorganized cytoplasm, and the inconspicuous axons. L-NSM does not accumulate in the CC, in these stages.

More objective estimations of cell activities are difficult to perform, mainly because the lateral groups do not consist of populations of identical cells. Neither the perikarya, nor the nuclei have a constant size, within a group. In addition, the larger cells do by no means always contain the larger nuclei. The impression is gained that during oviposition more L-NSG are present than during diapause, but numbers of cells may vary between individuals and even-within individualsbetween their left and right groups.

In a preliminary experiment the relation between adult maturation and nuclear size was investigated. For that purpose all nuclei of cells which could be differentiated from ordinary neurons were measured (up to 40 cells per lateral group). Per specimen, the 15 largest diameters were taken into consideration. In just-emerged animals the average diameter was $9.89 \mu$ (S.E. $=0.39 \mu ; \mathbf{n}=10$ ), in 13 to 15 -days old ovipositing females $10.57 \mu$ (S.E. $=0.54 ; \mathrm{n}=8$ ). The difference was statistically significant $(\mathrm{p}=0.01)$.

Particularly in an early stage of oviposition, but also in LD animals which showed diapause-behaviour as a consequence of inadequate food supply, phenomena of amitotic divisions of nuclei were observed. Some stages in this process could be studied with the light-microscope (Pl. IV fig. 3) and the electron microscope (Schooneveld, 1970). In the first instance, these divisions led to perikarya which contained several unequal nuclei; in the second instance cell divisions probably took place: in older specimens no cells with more than one nucleus were found. These events possibly present a mechanism by which the number of L-NSC can increase. It is assumed that amitotic divisions take place at the demand for higher secretion rates (cf. Pehlemann, 1968), which is consistent with our impressions.

In Lampyris noctiluca at the beginning discharge of their products, several NSG show an extrusion of the nucleolus from the nucleus (NAIsse, 1966). Comparable events could sometimes be observed in L-NSC of Leptinotarsa: nucleoli which showed a remarkable increase in size and a loss of their basophilia, and the budding-off of nuclear phragments (Pl. IV fig. 2). It was not ascertained that nucleoli were expelled, however.

A graphic representation of the assumed rates of synthesis and release of L-NSM is given in Fig. 16.

At the present time the role of the L-NSG is rather obscure. In two other insects, Galeruca tanaceti (SIEw, 1965b) and Adelphocoris lineolatus (EwEN, 1962) the patterns of activity throughout adult life have much 
in common with those of Leptinotarsa; in Oncopeltus fasciatus the cells were only active in young adults (Johansson, 1958a), whereas in Calliphora erythrocephala no changes in the histological appearance could be found (Thomsen, 1965). An indication of a possible function of the LNSG in Schistocerca paranensis was obtained by STRONG (1965). After cauterization of large neurosecretory (medial and lateral) brain regions growth of the GA on the same side was inhibited in young adults. According to STRONG, this would indicate that the L-NSG exert some stimulating effect on the growth of CA.

In the context of the present paper it is relevant to mention that in Leptinotarsa the reverse-i.e., an effect of CA size upon activity of the L-NSC - could not be demonstrated.

1. It was regularly observed (see Chapter 6) that the left and right CA differed considerably in size, sometimes by a factor 10 . In all cases, however, the sum of the volumes was equal to that in normal animals, which means that the larger of the two CA was strongly hypertrophied. Yet between the left and right L-NSG neither differences in cell- or nuclear size, nor differences in cell numbers could be established.

2. After unilateral allatectomy no effect on L-NSC at either side of the brain could be found.

This means that the L-NSC are not directly involved in CA growth, and also that a possible feed-back between CA activity and the NSS is not mediated via the L-NSC.

\subsection{SOG-A-TYPE NEUROSEGRETORY GELLS}

The amount of NSM in both SOG-A-perikarya revealed changes which followed a similar pattern as A-NSM in the PI, but seldom accumulated to a similar extent. Other indications as to actual rates of synthesis of NSM are largely lacking.

The nuclei are always very small. Whereas during the pupal stage and up to 29 days LD they are nicely ellipsoid, at the termination of oviposition and during diapause their shape becomes irregular and the cytoplasm vacuolates (Pl. IV fig. 9).

Under both LD and SD breeding conditions and starting from about 14 days after ecdysis, basophile material accumulates locally, giving rise to one or two large red-staining globules which may heavily distort the shape of the cell (Pl. IV fig. 10). The significance of these globules is unknown. PIPA (1961) observed very similar inclusions in several neurons of Periplaneta americana; in histochemical tests these proved to consist of glyco-lipoproteins. It is certain that the globules in Leptinotarsa do not represent secretory products since they remain unchanged 
when in post-diapause females much of the normal NSM content leaves the cellbodies.

In all breeding-groups examined fine axon branches filled with NSM are scattered over the neuropile of the SOG. Only in ovipositing females proximal axons were clearly distended and contained many tiny NSM particles.

In earlier experiments the interesting fact emerged that in aged females (52 days old) near the termination of oviposition perikarya reached unusually large dimensions due to heavy accumulations of NSM. They much resembled the "castration cells" which in Leucophaea maderae became prominent after ovariectomy (ScHARRER, 1955).

A graphic representation of the activity cycles is tentatively given in Fig. 16.

\subsection{SECRETORY GELLS OF THE GORPUS GARDIAGUM}

A least two different types of secretory cells are situated in-or are structurally related to-the CC: the "intrinsic" (ISC) and "extrinsic secretory cells" (ESG), respectively.

The ISC-"chromophile cells", according to the nomenclature of CAZAL (1948) - never reveal striking changes in staining capacity. In contrast, sizes strongly depend on the physiological stage of the animal; the cells are large during oviposition and small during diapause. In general, changes in the size of cellbody and nucleus closely follow those of the ESG which will be dealt with in more detail.

The ESG are arranged in a cluster along the origin of the NCSO. Their cell processes are most distinct during accumulation of the brownish-orange secretory product. As has already been mentioned in Subsection 3.3.3, the cells are inconspicuous in the early pupal stage and lie at some distance from the CC. In 9-day old pupae they are situated close to the junction of GC and CA, and have increased in size. Sizes reach a maximum at ecdysis-or a few days later (Pl. V fig. 2). Up to this stage the cytoplasm is usually completely chromophobe. At 6 days after ecdysis in most animals a coarse granular secretion appears in the cytoplasm and in the axons; during early oviposition it accumulates in the axon-terminals at the medial side of the CG. In LD females older than 4 weeks the cellbodies gradually turn darker by the appearance of purple inclusions; vacuoles are formed, and the nuclei lose their transparency. The amount of secretory material accumulated does not diminish in females which have terminated oviposition; furthermore, typical vacuoles are present in the axons, by this time. These features indicate that the ESG ultimately degenerate.

In SD specimens up to 6 days old the brownish material is likewise 
present in the cellbodies. During diapause, however, it disappears in part of the animals whereas the cellbodies become smaller. The secretory material does hardly accumulate in the axon-terminals. After the break of diapause signs of degeneration can be found.

A graphic representation of the cycles of activity is given in Fig. 16.

\section{AGTIVITY OF THE GORPUS ALLATUM}

\section{Volumetric growth}

In the course of adult life the CA of Leptinotarsa may show an increase in size, depending on whether the animals are bred under LD or SD conditions. It is tempting to speculate that the large GA actively produce juvenile hormone, the small CA less or none at all. It becomes increasingly clear, however, that in many insect species a relation between volume and physiological activity does not always exist. Examples of this are found in Oncopeltus fasciatus (JoHANsson, 1958a), Locusta migratoria (STAAL, 1961) and Tenebrio molitor (MoRdue, 1965). A possible explanation is that synthesis and release of juvenile hormone may be independent processes; a large CA-though possibly containing much hormone-may fail to bring it into the circulation and is hence considered to be physiologically inactive (Mordue, 1967). Naturally, the trophic growth of the gland is a separate phenomenon (Luscher \& EngelmanN, 1960).

DE WILDE and co-workers (1968) demonstrated in Leptinotarsa that the titres of juvenile hormone in the haemolymph of adults followed patterns characteristic for LD or SD development; thus we are in the unique position that changes in CA volumes can be related to changes in juvenile hormone production.

CA volumes were measured in animals belonging to different breedinggroups and, simultaneously, the histology was studied. From camera lucida drawings of every second or third section through the CA the total area of all sections (in $\mu^{2}$ ) was estimated with the use of a planimeter. The volume of the gland was calculated from the product: total area $\times$ section thickness. Per specimen both $\mathrm{CA}$ were taken into consideration.

Results are given in Table VI.

In the first place, it appears that the CA are continuously large in ovipositing females, and 2 to 3 times as large as during diapause. These data are consistent with those obtained in earlier experiments with Leptinotarsa (DE WiLde \& StegWeE, 1958; De Wilde \& DE Boer, 1961). It has long been known that the $\mathrm{CA}$ are inactive after $\mathrm{SD}$ treatment, as 
TABLE VI

Mean volumes of corpora allata of animals bred under long- and short-day conditions

\begin{tabular}{|c|c|c|c|c|c|c|}
\hline Breeding group & $\begin{array}{c}\text { Age } \\
\text { (days) }\end{array}$ & $\begin{array}{c}\text { Number } \\
\text { of } \\
\text { specimens }\end{array}$ & $\begin{array}{c}\text { Mean } \\
\text { volumes } \\
\text { (in } 10^{-6} \mathrm{~mm}^{3} \text { ) }\end{array}$ & S.E. & \multicolumn{2}{|c|}{$\begin{array}{l}\text { Comparison } \\
\text { of the means }\end{array}$} \\
\hline \multicolumn{7}{|l|}{ Long-day } \\
\hline ecdysis & 0 & 8 & 388 & $101\}$ & $p=0.001$ & \multirow{6}{*}{$\mathrm{p}=0.02$} \\
\hline pre-oviposition & $5-6$ & 10 & 671 & 155 & $p=0.05$ & \\
\hline oviposition & 7 & 14 & 555 & $72\}$ & $f^{P}-0.00$ & \\
\hline oviposition & 15 & 11 & 554 & 142 & & \\
\hline $\begin{array}{l}\text { oviposition } \\
\text { termination of }\end{array}$ & 29 & 11 & 591 & 112 & & \\
\hline oviposition & $56-89$ & 14 & 550 & 103 & & \\
\hline \multicolumn{7}{|l|}{ Short-day } \\
\hline ecdysis & 0 & 13 & 279 & 61 & & \\
\hline pre-diapause & 6 & 11 & 276 & 49 & $p=0.001$ & \\
\hline diapause & 21 & 14 & 179 & 27 & $\int^{p}=0.001$ & \\
\hline diapause & 28 & 13 & 164 & 29 & & \\
\hline diapause & 42 & 14 & 173 & 60 & $p=0.001$ & \\
\hline diapause & 150 & 9 & 273 & 40 & $\left\{\begin{array}{l}p=0.001 \\
p=0\end{array}\right.$ & \\
\hline $\begin{array}{l}\text { pre-oviposition } \\
\text { oviposition }\end{array}$ & $\begin{array}{l}150+4 \\
173+7\end{array}$ & $\begin{array}{r}10 \\
7\end{array}$ & $\begin{array}{l}807 \\
629\end{array}$ & $\begin{array}{l}185 \\
100\end{array}$ & $\left\{\begin{array}{l}p=0.05 \\
p=0\end{array}\right.$ & \\
\hline oviposition & 110 & & & & & \\
\hline
\end{tabular}

S.E. = standard error

1 Both left and right CA measured.

2 Student's t-test, after logarithmic transformation of individual values.

could be concluded from several experiments: 1, the lack of ovarian development under these conditions (DE WILDE, 1965; DE WILDE \& DE BOER, 1961, 1969); 2, the low oxygen consumption of the beetles (El-Ibrashi, 1965; DE Wilde, 1959, 1960; de Wilde \& Stegwee, 1958), whole-body homogenates (DE WiLdE \& STEGwEe, 1958), and flight muscle mitochondria (STEGWEe, 1960); 3, the degeneration of the flight muscles (STEGWEe et al., 1963; DE KorT, 1969); 4, the absence of the vitellogenic female protein (DE LOof, 1969) and 5, the absence of juvenile hormone in the haemolymph (DE WILDE et al., 1968).

On closer examination of the mean CA volumes in Table VI it can be concluded that significant differences exist between LD and SD animals at the moment of ecdysis $(p=0.02)$, probably as a consequence of different larval pretreatments. CA volumes further decrease when the animals are in diapause. Though the CA are relatively small during early pre-diapause, they are not completely inactive. DE WILDE (1958) found that in this stage germaria and primary oöcytes may 
temporarily develop to some extent. Furthermore, at the moment of SD-emergence (i.e., one day after ecdysis) the presence of some (700 Galleria Units) juvenile hormone in the blood could be demonstrated; later on, the amount fell below the detection level (DE WILDE et al., 1968). In Calliphora too, the GA showed a cycle of (low) activity after emergence, notwithstanding the fact that the animals were fed a diet (sugar) which was inadequate with respect to oöcyte growth (LEA \& Thomsen, 1962, 1969).

In Colorado beetles which have been kept in diapause for 1 to 4 weeks, the CA are very small. After 5 months of diapause, however, the volumes have slightly, though highly significantly, increased. This change in volume can possibly be related to a resumption of juvenile hormone production. As Stegwee (1964) found, the flight muscle fibrils and sarcosomes were almost completely degenerated at 6 weeks of diapause, but at the time of termination of diapause (after about 3 months) a complete regeneration was found to have occurred. This would imply that presumably under the influence of juvenile hormone this regeneration took place already before the end of diapause. The present observations that CA have increased in size during this period provide an other argument for a resumed juvenile hormone production.

One day before the onset of oviposition under both LD and SD conditions a highly significant increase in CA volume has taken place, followed after a short time by a small decrease. A similar overshoot in volume in pre-oviposition has been observed in Tenebrio (MORdue, 1965) and in Adelphocoris lineolatus (EwEN, 1966). MORDUE explained this on the assumption that the release of juvenile hormone is in fact inhibited at the moment of maximum size of the CA, although at present it is unknown how the passage of the hormone through the cell walls could be retarded. For Leptinotarsa too, some evidence in favour of MoRduE's hypothesis has been obtained. DE WILDE and co-workers (1968) have demonstrated that the juvenile hormone titre in the haemolymph increases enormously between 4 and 7 days after break of diapause, viz., from 2,000 to 18,000 Galleria Units per $\mathrm{ml}$ blood, whereas the normal value of ovipositing females is about 3,000 G.U./ml. This large increase occurs exactly at the time when the GA volumes have decreased.

Regarding these data, we can conclude that in general the size of the GA is a rough indication for, at least, the synthetic activity of the gland. The study of the histology of the CA leads to similar conclusions (see below).

\section{Histology}

In young, 2-day old pupae the CA are rounded and small and the cells 
contain round nuclei; many mitoses can be seen. In 9-day old pupae the ultimate number of cells has nearly been reached; mitotic activity is strongly reduced and is absent in later stages. At the moment of ecdysis under both LD and SD conditions the CA are spheroid, with irregular outlines, and stained orange; nuclei are small and oval or irregular, cell boundaries are inconspicuous. In the course of prediapause and diapause the shape of the CA becomes even more irregular the small nuclei are tightly packed. Cell membranes can be seen, especially in the periphery of the gland (Pl. VI fig. 7).

Soon after emergence under LD conditions, however, early signs of activation of individual cells can be observed in some cases: development of the cytoplasm, loss of the orange colour, and growth of the nuclei (Pl. VI fig. 6). At 5-6 days pre-oviposition, nearly all cells have increased in size and reveal a green colour. Nuclei are enlarged as well and have an extremely irregular shape. Cell membranes are not clearly visible (Pl. VI fig. 4). This histological picture does not change during the period of oviposition; more cells only are then more or less elongated, their apex pointing to the periphery of the CA.

Special attention was paid to the appearance of the CA at the termination of oviposition. It has already been mentioned that in this stage the volumes have not decreased as compared with ovipositing animals (Table VI). Also the histology gives no reason to assume that the arrest of oöcyte production is due to a low rate of juvenile hormone production. In females that still laid one or two eggs per day the GA were rather normal; only the amount of chromatine in the nuclei had slightly increased and cell membranes were more conspicuous as compared with 4-week old specimens (Pl. VI fig. 5). On the contrary, in females that had completely terminated oviposition some signs of degeneration could be found: cytoplasmic vacuoles, crumpled cell membranes, etc. In these animals, however, this is thought to follow from a general degeneration process since also in the brain signs of serious desintegration were found (see Pl. III fig. 3); these animals were in fact dying.

Four days after the break of diapause the CA are very similar to those during LD pre-oviposition. Only, due to their highly developed cytoplasm the cells are slightly larger. One day after the beginning of oviposition the CA are covered with a thick layer of connective tissue and in some specimens many of the CA cells are extremely elongated (Pl. VI fig. 3). The impression is gained that all cells, also those located centrally, manage to communicate directly with the haemolymph. Considering the observation that $\mathrm{CA}$ volumes have decreased in this stage (Table VI) it seems not unlikely that the formation of cell extensions is a prerequisite for a rapid release of juvenile hormone. The hypertrophy of the GA during pre-oviposition under LD and SD con- 
ditions may well be attributed to an accumulation of the secretory product as a consequence of too low release capacities of the not fully developed CA cells.

Apparently, the increases of CA volumes are primarily caused by the increase of the cytoplasmic content. Vacuoles or cytoplasmic inclusions are absent. Possible intercellular accumulations of stainable material of unknown origin (see Subsection 3.3.4) cannot be related to any physiological stage. The purple A-NSM is present in all adult stages and no marked changes in its amount occur. Only after the termination of oviposition some minor swellings of neurosecretory axons can be observed.

As has already been mentioned in Section 5.5, within certain individuals large differences in size between the left and right CA can sometimes be observed. It appears that the smaller and larger CA do not differ in histological aspects, the differences in size being exclusively dependent on the number of cells in each GA. In such cases the sum of the volumes is not different from that in animals with two equal glands. A discussion of this interesting observation exceeds the scope of this paper.

The data presented here and also those emerging from previous investigations demonstrate that the GA are continuously active during oviposition. Since oöcyte maturation is a continuous process in Leptinotarsa, a cyclic activity as found in many insects with intermittent oögenesis (cf. Engelmann, 1968) was not to be expected. There are no histological indications that the termination of oviposition is primarily due to an arrest of juvenile hormone synthesis.

A graphic representation of the patterns of activity is given in Fig. 16.

\section{GENERAL DISGUSSION}

\subsection{THE GOMPOSITE PIGTURE OF NEUROSEGRETORY AND GORPUS ALLATUM ACTIVITY}

The supposed patterns of activity of NSC and CA, as determined by various means, are given in Fig. 16 in a diagrammatic form. The largest widths of the bars refer to the highest assumed activities in the structures concerned, i.e., synthetic activity of perikarya (S), or rates of release from the cell processes or from CA cells $(R)$.

It may be mentioned that, relying on data of synthetic activities, graphs $\mathbf{S}$ were prepared first. For graphs $\mathrm{R}$, in addition, the appearance or disappearance of accumulations of materials at several time intervals has been taken into account. For that reason the graphs $\mathrm{S}$ and $\mathrm{R}$ for 

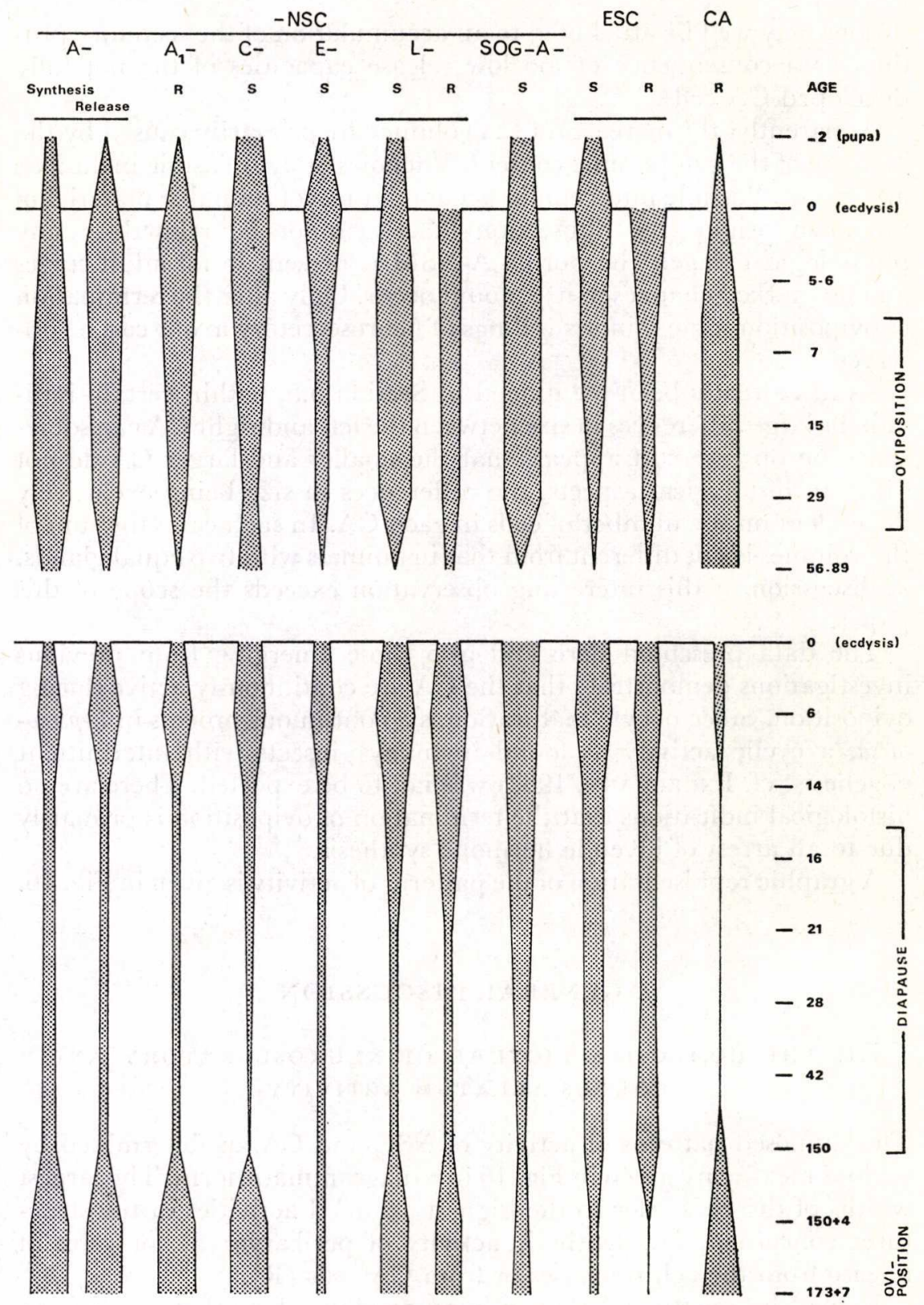

Fig. 16. Diagrammatic representation of the patterns of activity of several types of NSC, ESC, and CA in females bred under long-day and short-day conditions. The width of the bars indicates the rates of synthesis $(S)$ or release (R). For details, see Section 7.1. 
A-NSG, L-NSG, and ESC are not identical. Only the graphs S and R for L-NSC in SD animals are similar; under these conditions L-NSM does not accumulate in any of the breeding-groups examined. For the G-, E- and SOG-A-NSG only the patterns of synthetic activity are given, for the $\mathrm{A}_{1}-\mathrm{NSG}$ and the GA only the patterns of release.

A detailed discussion of possible relations between the patterns of activity found and the specific role of certain types of NSC-on the analogy of findings in other insects-exceeds the scope of this discussion. Still, certain data deserve attention; these data will be dealt with in the following Sections.

\subsection{GONTROL OF NEUROSEGRETORY ACTIVITY}

In a comprehensive review, Highnam (1967) gives many examples of environmental and intrinsic factors which in one way or another influence the activity of the NSS. But up till now, the mechanism which integrates the NSC into the central nervous system is poorly understood. It has recently been demonstrated that the NSC of Periplaneta americana are able to conduct nervous impulses (GosBeE et al., 1969). Our histological observations given in Subsection 3.3.2 render it plausible that in Leptinotarsa at least the A-NSC may be stimulated in the protocerebral neuropile. It was found that the axons of the A-NSG show some degree of arborization in their proximal course, sending numerous rami into the neuropile bordering the medial group of NSC (Pl. II figs 1-3). Very recently, ADIYODI \& BERN (1968) observed exactly similar phenomena near the PI of Periplaneta americana. Also in Aphis fabae (JoHnsson, 1963) and in Hyalophora cecropia (VAN DER KLOOT, 1960) comparable phenomena were observed. The assumption that the rami in fact represent dendrites of the NSC (BERN, 1962) is purely arbitrary at the moment. But the available indications that NSC resemble neurons in morphological respects (WIGGLESWORTH, 1965) do not $a$ priori exclude that they function like neurons as well.

The presence of NSM within rami in the neuropile has also led to the hypothesis that the "hormone" in some way or other influences synaptic transmission in these regions. BERN (1966) therefore introduced the tentative term "neurosecretory neuropile". This is in good accordance with the present concepts concerning the existence of "modulator substances" (cf. Florey, 1967) in nervous systems. Possibly, the SOG-ANSG of Leptinotarsa fit into this scheme. As has been mentioned, after the two proximal axons traverse the ganglion they ramify so frequently that no major axon tracts can be discerned ultimately. It seems likely at least that most of the NSM remains in the ganglion. For other in- 
sects too, the fate of the Gomori-positive material has been the subject of speculations. According to RaABE (1965) similar axons in Carausius morosus run into the connectives of the ventral nerve cord, while in Locusta migratoria they are supposed to run to the prothoracic gland (Chalaye, 1965, 1966).

Considering the morphology of the A-NSC it is probable that the "dendrites" subserve the transmission of nervous impulses. Up till now, however, it has not been proved that they do so indeed; nor has it become clear which event in the process of neurosecretion is controlled.

Our observations on phenomena of accumulation of A-NSM, dealt with in Paragraph 5.1.1.4, indicate that in Leptinotarsa the speed of axonal transport is under nervous control. The amount of NSM at the levels of the perikaryon and axon-terminal has been found to vary independently; the only likely explanation is that the distribution of NSM over proximal and distal parts of the NSC is determined by the rate of transport. With regard to the variable amount of NSM in the axons of identically bred individuals the speed of transport most probably changes cyclically (phasic discharge) and the A-NSC are more or less synchronized in this respect. Moreover, since the rate of transport could not be related to the amount of NSM in the axonterminals, transport and release are controlled separately.

Similar conclusions were derived from experiments on other insects. When the brain of Schistocerca is electrically stimulated, the transport of NSM through the axons is enhanced, but not the release from the axon-terminals (Highnam, 1961b). When previously starved locusts were fed, the diminution in NSM content within the NSS first becomes visible in the perikarya (Highnam et al., 1966). In Periplaneta americana, the effect of electrical brain stimulation upon the release of NSM is perceivable in the entire NSC; in contrast, when neurosecretory axons in the $\mathbf{C C}$ are depolarized by bathing the CC in a medium containing high concentrations of potassium ions, NSM is promptly released from the axon-terminals and not directly discharged from perikarya (GosBEE et al., 1969).

On the other hand, there are indications that neurosecretion may occur without the intervention of electrical impulses from the brain. Several experiments on Leptinotarsa have shown that implanted isolated $\mathrm{CC}$, in the presence of active CA, promote oviposition in pre-diapause females (DE WiLde, 1965; DE WiLde \& DE BoeR, 1969; DE Loof, 1969). As neurons are not known to occur in the CG, apparently, the release of hormones occurs independently of the nervous system. Furthermore, when young pupae of several silkworm species are injected with TTX (tetrodotoxin), a chemical that blocks synaptic transmission in a large variety of invertebrates and vertebrates (including the neuromuscular 
synapses in the moths concerned), adult development and metamorphosis take place quite normally (Williams, 1969) This means in the first place that the production and release of brain hormone continues in a normal way when the animals are paralysed, and in the second place, that neurosecretory activity in all likelihood evolves independently of the central nervous system.

The activity of NSG has in the past been causally related to the activity of the cholinergic system in the brain of Hyalophora cecropia, (VAN DER Kцоот, 1955). Also for Leptinotarsa, arguments in favour of this attractive idea of a brain-NSC interaction can be found. We know that the NSC in diapausing animals are rather inactive (cf. Subsection 5.1.4). At the same time the cholinesterase activity in the brain is strongly reduced as compared with ovipositing females (DE KORT, 1969) and electrical activity could not be demonstrated (SaHoonHoven, 1963).

However, Schoonhoven pointed out that the failure to detect electrical activity does not mean that this activity is altogether absent; it may merely be concluded that most brain areas are electrically silent in diapausing specimens. Moreover, as Smallman \& Mansingh (1969) pointed out after comparing many data in the literature, the inactivation of NSC during diapause seems to be in general independent of the cholinergic system in the brain.

In conclusion, the precise way in which insect NSC are controlled remains to be clarified. Studies concerning a possible role of biogenic amines are still in a beginning phase. It becomes increasingly clear that in vertebrates the control of neurosecretory activity in the nucleus supraopticus and nucleus paraventricularis, as well as the release of hormones from the anterior pituitary is exerted by central monoamine mechanisms (cf. KNowles, 1967), involving the catecholamines noradrenaline and dopamine (Fuxe \& HöKfELT, 1967). In brains of Periplaneta americana the presence of catecholamines has merely been demonstrated (Frontali \& Norberg, 1966; Frontali, 1968) with the aid of the histochemical fluorescence techniques of FALCK \& OWMAN (1965). Synaptoid contacts observed in the CG between neurosecretory axons belonging to different types of NSC (NormanN, 1965; SGHARRER, 1968) render it likely that the B-NSC may eventually turn out to play an important role in the control of activity of other NSG. This is also true for Leptinotarsa (Schooneveld, 1970). 


\subsection{PHOTOPERIODIC INDUCTION OF NEUROSEGRETORY AGTIVITY}

For several reasons it seems worth while to examine our data as to possible differences between the appearance of the NSS at adult ecdysis under long- or short-day breeding conditions, and shortly thereafter. For, as DE WILDE et al. (1959) showed, the effect of the photoperiod to which the older larvae are subjected is noticeable in the adults. When larvae are bred under LD conditions and the adults in constant darkness (resulting in a mild short-day effect), more eggs are produced and less animals enter diapause than when larvae are bred under SD conditions. Reversely, when adults are kept under LD-conditions, the pre-oviposition period is lengthened when they have been bred under SD conditions as larvae (DE WILDE, 1965).

It appears from our data that at the moment of LD or SD ecdysis the activity of the A-, $\mathrm{A}_{1^{-}}$, SOG-A- and C-NSC do not differ appreciably. Neither the histological appearance of the cells, nor the diameters of nuclei are significantly different. Only the nuclei of the E-NSG differ significantly; they are largest under LD-conditions (Table V). It is hardly likely, however, that this type of NSG plays a role in the divergence of adult development. For if we assume that these cells participate in inducing the specific features of $\mathrm{LD}$ conditions (development of the ovaries, composition of haemolymph proteins, etc.) we should realize that these cells are relatively active during the first week of pre-diapause. Instead, the observation that the E-NSC are exclusively active during a few days starting from the moment of ecdysis renders it most likely that they are concerned with some process during the adult moult. One is then inclined to think that they secrete, for example, bursicon-a hormone which in a large variety of insects causes the tanning of the cuticle in the newly emerged adult and which is produced in the PI, among other locations (Fraenkel \& Hsiao, 1965). C. Hsiao (1969, personal communication) was unable to demonstrate the correctness of these findings by histological investigations in Calliphora erythrocephala.

For these reasons we can conclude that in spite of the indications that lateral brain areas in Antheraea pernyi (Williams \& Adkisson, 1964; Williams, 1967) and the PI in Megoura viciae (Lees, 1964) are the site of perception of the photoperiod, the reception of photoperiodic information-somehow "stored" in the Colorado beetle pupae-does not result in an appreciable activation or inactivation of the types of NSC under investigation. It may be mentioned that in the case of Ostrinia nubilalis the NSS of last-instar larvae did not show any histological phenomena either which could be related to the effect of photoperiodic stimuli (McLeod \& BecK, 1963). 
While the activity pattern of pupal NSS is not impaired by photoperiodic treatment, the $\mathrm{CA}$ are significantly smaller at $\mathrm{SD}$ ecdysis than at LD ecdysis (Table VI). Whether these differences can be traced back to differences in activity or in mere growth, cannot be decided in this case.

\subsection{GONTROL OF GORPUS ALLATUM AGTIVITY}

In Fig. 16 it can be seen that the GA are highly active during oviposition, nearly inactive during pre-diapause, and inactive during diapause. The volume of the glands reaches a maximum at 1 day before oviposition, both under LD conditions and during post-diapause preoviposition. It may be questioned whether CA volumes may be used as criteria for activity (see Chapter 6), but when the histology of the gland is also taken into consideration the pattern of activity mentioned seems to be firmly established. It seems that two different activities of the glands can be stimulated: at LD ecdysis and at the break of diapause their synthetic activity is enhanced, while at the moment of oviposition the release of possibly stored hormone is enhanced. It has been pointed out that this latter kind of stimulation can possibly be attributed to the fact that the material produced could not readily be released before, as the consequence of an insufficient growth of CA cell processes and hence too great diffusion barriers between cells and haemolymph.

Several investigators favour the idea that the Gomori-positive NSG are involved; this is concluded from the presence of A-NSM between the cells of the GA (cf. NAyar, 1958; Highnam, 1965). De Wilde \& DE BoER $(1961,1969)$ showed that cauterization of the PI resulted in an inactivation of the CA. Our results show that the activities of A-NSG and CA are not strictly synchronized:

1. In all stages examined A-NSM was present in the CA and the amounts did not vary very much.

2. At 5 months of diapause the A-NSG are very inactive but CA volumes have increased significantly.

3. At the termination of oviposition the A-NSG seem to be inactive in many healthy specimens, while the CA remain active.

Whether the A-NSM is in some way used by the gland remains to be investigated but it should be borne in mind that intact connections with the NSS are not required for the control of CA activity by the photoperiod. When CA are implanted into SD females from which the CG-CA complexes had been removed previously, the 'glands can be repeatedly activated and inactivated by transferring the recipient animals to LD or SD conditions, alternately. It is supposed that hormones from the brain still do influence CA activity, for it is known that 
these can enter into the circulation by way of the regenerates of the NCG stump (DE WILDE \& DE BOER, 1969).

Strong (1965) and Girardie (1965) obtained evidence that in young Schistocerca paranensis adults and in fourth-stage Locusta migratoria larvae, respectively, the lateral NSC stimulate the CA. After cauterization of lateral brain regions the CA were inactivated. As follows from the pattern of activity of L-NSC (Fig. 16), it is not likely that these cells are involved in Leptinotarsa: during pre-diapause they are particularly active.

On the other hand it cannot be excluded that some material originating in the CC enters the GA. Occasionally, reddish accumulations were observed which very much resembled the staining of the large ESC, close to the CA (PI. VI fig. 7). This is particularly interesting since DE WILDE \& DE BOER (1969) have found that disruption of the NCSO retarded the inhibition of CA activity during pre-diapause: the entry of diapause was postponed after this operation. This finding was presented as evidence for an inhibitory action of the SOG, but it might also be that by this operation the possible connections between the ESG and CA were disrupted as well, since the former are intimately connected with the NCSO. Moreover, hypothetically, the activity of the ESC may be inhibited via the NCSO; disruption of this nerve then results in a removal of the inhibition. The fact that the ESC remain relatively active during diapause favours the idea that these cells in one way or another inhibit the activity of the CA, antagonizing an activating centre which is located in the brain.

Whether in Leptinotarsa the CA are controlled by other factors, for example the concentration of metabolites in the blood, feed-back mechanisms from ovaria, etc. (cf. Highnam, 1967; Engelmann, 1968), remains to be investigated.

\subsection{INVOLVEMENT OF THE NEUROSECRETORY SYSTEMIN LONG- DAY DEVELOPMENT}

The A-, $\mathrm{A}_{1^{-}}, \mathrm{C}$-,, $\mathrm{L}-$ and SOG-A-NSC seem to be involved in processes which take place during oviposition since they exhibit a high activity before and during long-day and post-diapause oviposition, and a rather low activity during diapause (Subsection 5.1.4, Fig. 16).

The necessity of neurohormones for ovarium development in other insects has frequently been stressed (for exceptions, see WIGGLESWORTH, 1964). Already before oögenesis can take place complex changes occur in neuroendocrine activity. First of all, feeding is a prerequisite for yolk formation in anautogenous species. In Calliphora erythrocephala (Тном- 
SEN \& MølleR, 1963) and Tenebrio molitor (MoRdue, 1967) it was demonstrated that the release of NSM stimulates the production of mid-gut proteases. On the contrary, in Leucophaea maderae (ENGELMANN, 1969) and Sarcophaga bullata (WILkENs, 1969) the release of NSM seems to be a secondary phenomenon, the production of gut proteases bearing a direct relationship to the quantity of food ingested. Be it as it is, in starved Leptinotarsa the act of feeding results in a sudden release of Aand $\mathrm{A}_{1}$-NSM (Schooneveld, 1966). Indeed, in three periods of adult life the onset of feeding behaviour is accompanied by a relatively high activity of the NSS: during LD and SD pre-oviposition and during early pre-diapause.

Aside from the CA hormone which acts as a gonadotropin (cf. HigHNAM, 1964), neurohormones are involved in oöcyte maturation by stimulating the fatbody to produce the proteins necessary for yolk formation (cf. EngelmanN, 1968). The high activity of the NSS of Leptinotarsa during reproductive activity fits into this scheme, but the electrophoretic analysis of haemolymph proteins shows that protein synthesis is controlled by a more complex mechanism. De Loof $(1969,1970)$ found typical SD proteins in diapausing females; these were absent in LD beetles but instead a sex-specific "female-protein" could be demonstrated. This female-protein was only synthesized by the combined actions of juvenile hormone and some factor (called here "FP-factor") elaborated in the PI, and released from the CC. Normally, this happens only in LD conditions, not-or only in minor quantities-in young SD females. Following injections of large amounts of synthetic juvenile hormone, some female-protein was formed in pre-diapause females but no fully ripe eggs were produced. For these reasons the FP-factor is released only slowly during pre-diapause.

With regard to these rather accurate data it is tempting to see whether the pattern of activity of any type of NSC in the PI corresponds with the cycle of release of the FP-factor. Some evidence can be found in favour of the hypothesis that the $\mathrm{A}_{1}-\mathrm{NSM}$ rather than A-NSM is in fact identical with the FP-factor, though at a first glance at Fig. 16 both kinds of NSM seem to be likely candidates. As has been mentioned in Section 5.2., the number of AT in the CC steadily increases in the course of adult life, but under SD conditions at a lower rate than under LD conditions. Although very speculatively, the rate of axon growth may therefore be a function of cellular activity. The frequency-distributions in Fig. 14 illustrate that in LD the $A_{1}$-AT increase much faster in number than the A-AT. In the course of diapause the reverse is true; after the onset of post-diapause oviposition the $\mathrm{A}_{1}$-AT have again relatively increased in number. This indicates that the $\mathrm{A}_{1}-\mathrm{NSC}$ are activated stronger during reproductive activity than the A-NSC. At the 
termination of oviposition the considerable accumulation of NSM in the CC is largely due to the presence of $\mathrm{A}_{\mathbf{1}}$-NSM. Since at that time the $\mathrm{A}_{1}$-perikarya show signs of degeneration, it seems not unlikely that in this stage the cessation of oviposition is due to a lack of circulating $\mathrm{A}_{1-}$ NSM rather than a decreased A-NSG or CA activity. In preliminary small-scale studies on active and diapausing male Colorado beetles no differences were found in the occurrence and distribution of $\mathrm{A}_{1^{-}}$and A-NSM in the CG.

\subsection{INDUCTION OF DIAPAUSE}

In Leptinotarsa, the state of diapause seems to be accompanied by an extremely low activity of the NSS (A-, $\mathrm{A}_{1^{-}}, \mathrm{C}-$-, L- and SOG-A-NSG) and the CA; this was also found in some other beetles with a photoperiodically controlled imaginal reproductive diapause, i.e., Galeruca tanaceti (Siew, 1965b), Hypera postica (Tombes, 1966), and some Dytiscidae (Joly, 1945). No evidence could be obtained for the possible existence of a "diapause hormone" in Leptinotarsa (DE WILDE \& DE BOER, 1969).

Since most diapause phenomena could also be induced when LD ovipositing females were allatectomized, diapause has once been considered as a special case of pseudo-allatectomy (DE WILDE \& DE BOER, 1961). However, while allatectomy diapause could easily be inversed by the implantation of active CA, this was not the case in natural SD diapause. As much as 10 to $12 \mathrm{CA}$ were needed to break diapause and to induce some oöcyte development. If, simultaneously, CG were implanted, SD beetles could be induced to oviposit (DE WILDE, 1965; DE WILDE \& DE BoER, 1961, 1969). Furthermore, diapause could be induced by cauterization of the PI in LD females. These observations indicate that diapause results from the combined effects of CA hormone deficiency and inactivity of the NSS. Our results agree with that picture.

The answer to the question which endocrine centre is primarily responsible for the initiation of diapause does not follow from our histological observations. If we consider the patterns of activity of the various types of NSC and CA under SD conditions (Fig. 16), it appears that the strongest inactivation of these structures takes place in the second half of the pre-diapause period, i.e., before the animals enter the soil. Likewise, during the same period changes in other physiological processes were found. From a week after emergence onwards the rate of oxygen consumption decreased (EL-IBRASHI, 1965). This could largely be attributed to degeneration of the flight muscles (DE KORT, 1969). 
The decrease in activity of all these processes occurs gradually when the animal prepares for, and enters, diapause. Since neither during early diapause, nor after 5 months diapause the production and release of A-NSM (and possibly also other neurohormones) has come to a complete standstill (Subsection 5.1.4), the complex physiological changes leading to diapause are presumably induced when neurohormone titres sink below critical levels.

In pupae of the moths Mimas tiliae (Highnam, 1958a) and Antheraea polyphemus (Williams, 1967) diapause may also be ascribed to subthreshold titres of brain hormone. In the latter insect the production of the hormone continues at a low rate, as in Leptinotarsa; but it is probably not released. The mechanism by which diapause in these insects is broken, however, are quite different. In the lepidopteran pupae this is effectuated by chilling the pupae for several weeks or months. This procedure enhances the elaboration and release of NSM which activates the prothoracic gland. In Leptinotarsa, diapause can only be broken when the animals have been kept in diapause for one month or longer (DE WILDE, 1957). It is possible that the temporarily increased release of A-NSM at one month of diapause (see Fig. 5) is in some way related to that critical phase. The break of diapause has not been followed closely, in this study. But it can be concluded that within four days after the animals (kept in diapause for 5 months) were exposed to light, the A-, $\mathrm{A}_{1^{-}}, \mathrm{G}-$ and L-NSC and the CA are completely activated.

\section{SUMMARY}

In this paper the gross anatomy of the neurosecretory system and the structure of neurosecretory cells (NSC), corpora cardiaca (CC), and corpora allata (CA) of the female Colorado beetle has been described in detail, and an analysis of the patterns of secretory activity throughout adult life and under short-day and long-day breeding conditions has been presented.

In the protocerebrum seven types of cells have been distinguished which differ from ordinary neurons by the cyclic changes in stainability and the dimensions of cellbodies and nuclei. These cells are therefore taken to be neurosecretory. For five of them, i.e., the so-called A-, $\mathrm{A}_{1}-$, B-, C-, and L-NSC it could be established that their neurosecretory material (NSM) is transported to, and released from, the CG; for two of them, i.e., the D- and E-NSC this could not be ascertained. NSM of the A-, $\mathrm{A}_{1}$, and C-NSC should be called Gomori-positive, but with regard to the different shades of purple revealed by these kinds of NSM, and the apparent differences in the content of sulphydryl groups, they differ in chemical respects. NSM of the Gomoripositive NSC in the suboesophageal ganglion (SOG-A-NSC) very much resembles that of the A-NSC in the brain. The other types of NSC distinguished take up one or more components of the counterstain.

The five above-mentioned kinds of NSM produced in the pars intercerebralis are temporarily stored within the axon-terminals in the CG. In addition, the CG contain materials that are elaborated by intrinsic and extrinsic secretory cells. Most of the swellings of the cell processes are clearly facing the haemocoel, either at the periphery 
of the CC, or at the numerous crevices that deeply penetrate the gland, and all "secretory" materials are eventually released. These observations demonstrate the multiple role of the CC as a neurohaemal organ.

Within the CC, some of the axons originating in the brain disentangle from the major axon bundle and run straight to the CA, where they penetrate between the cells. In all physiological stages axons of the A-NSG are discernible. It remains to be investigated whether other materials as well normally enter the CA; occasionally the material from the exterior secretory cells of the CG was found to accumulate in the CA.

In CA of ovipositing females which are known to be actively secreting juvenile hormone, cells are relatively large and nuclei have extremely irregular shapes. Many of the cells located centrally possess extensions reaching the periphery. The occurrence of a temporary overshoot in CA volume in stages of beginning activation-during the pre-oviposition periods - has been explained on the assumption that these cell processes have not yet fully developed; hence the release of the secretion is hampered, resulting in a passive hypertrophy of the CA. It seems unlikely that the cessation of oviposition in aged females is primarily caused by a cessation of juvenile hormone production. During diapause, the CA are inactive; there are some indications, however, that after five months of diapause they have been activated to some extent.

In animals of varying age and bred under long-day and short-day conditions the pattern of activity of several types of (neuro)secretory cells has been investigated. To that purpose, various parameters of glandular activity had to be taken into account.

The pattern of secretory activity of the A-NSC has been unravelled in three different ways.

1. From the study of accumulation of A-NSM in perikarya and axon-terminals it could be concluded that during the first few days after ecdysis, in long-day as well as in short-day bred animals, much of the NSM that had accumulated in the late pupal stage, is released.

2. From measurements of nuclear diameters it followed that the synthetic activity is high during oviposition and low during diapause.

3. Incorporation experiments (involving the use of ${ }^{35} \mathrm{~S}$-labeled l-cysteine as a hormone precursor, and the detection of this isotope in the NSC by means of the stripping-film technique) showed that in ovipositing females the uptake of the isotope took place at a much higher rate than in diapausing females. In an attempt to "translate" the patterns of labeling into more or less exact relative rates of NSM synthesis in both experimental groups, in addition to silver grain density the rate of decrease of the ${ }^{35} \mathrm{~S}$-concentration in the blood has been taken into account. As a preliminary result, it has been stated that the rate of NSM synthesis in ovipositing females is about seven times as high as in diapausing females. The results indicate that in diapausing females the A-NSC are by no means completely inactive and that in ovipositing animals within one hour an amount of NSM is passed to, and released from the CC, that corresponds with the amount of NSM visible within the perikarya at any given moment. In considering these figures it has been concluded that the amount of NSM temporarily accumulated in the CC bears no information as to rates of release, in general. On the other hand, the measure in which elementary neurosecretory granules aggregate in the perikarya, may be taken as a rough indication for the secretory activity of the NSC concerned: the relatively small dark inclusions occur in actively ovipositing females only, the vast hazy aggregations in diapausing females.

By making an analysis of accumulation phenomena in individuals, evidence has been obtained for the assumption that the amount of NSM in perikarya and axonterminals is primarily controlled by the rate of axonal transport, rather than by the mere rate of release from the axon-terminals. Considering the apparent synchronization of separate cells it does not seem impossible that a nervous stimulation of NSC 
is involved. At any event, the structural organization of the A-NSC (i.e., the presence of axon-collaterals and "dendrites") should enable the cell to be stimulated in the neuropile regions.

The knowledge of the other types of NSC distinguished is rather fragmentary. Attention has mainly been focussed on the appearance or disappearance of NSM accumulations (i.e., for $\mathrm{A}_{1^{-}}, \mathrm{C}-$-, L-, SOG-A-NSG and extrinsic secretory cells of the $\mathrm{CC}$ ); in some cases (i.e., for E-NSG and also for C- and L-NSC) the changes in nuclear dimensions have been taken into account. Following these direct, respectively indirect, signs of secretory activity, the patterns of activity of these types of NSC have also been resolved. All data have been brought together in a diagram given on page 218 .

All types of NSG and the CA are more active during oviposition than during diapause, but between the patterns differences exist. Some of the physiological implications have been discussed in connection with the results from pure physiological experiments on Leptinotarsa and other insects. Possibly, the $\mathrm{A}_{1}-\mathrm{NSC}$ produce a factor which in the presence of juvenile hormone is responsible for the synthesis of the sexspecific "female-protein". The E-NSC may be concerned with the tanning of the young adult cuticle, and the extrinsic secretory cells of the CG with the (inhibitory) control of corpus allatum activity.

\section{A GKNOWLEDGEMENTS}

The author is much indebted to Prof. Dr. J. de Wilde for his inspiring interest in this study and his valuable criticism and suggestions concerning the presentation of the results. Thanks are extended to staff and personnel of the Laboratory of Entomology, in particular Mr. W. Companjen for the histological training and Dr. C. A. D. de Kort for critically reading part of the manuscript. The skilful assistance of the late Mrs. M. Verbeek-Bührmann and of Miss J. van Rinsum is gratefully acknowledged. Special thanks are due to Mr. J. Ph. W. Noordink (Institute of Phytopathological Research - IPO) for his advice and help in processing the autoradiographs, to Mr. C. A. van den Anker (of the same institute) for statistical advice, to Mrs. T. H. Huisman-van Hoorn for correcting the English text, and to Mrs. A. Soutendam-Schooneveld for typing the manuscript.

The work has been made possible by grant $942-48$ of the Netherlands Organization for the Advancement of Pure Research (ZWO), and has been completed while in the service of the National Council for Agricultural Research (TNO). 


\section{REFERENCES}

Adams, C. W. M. \& J. C. Sloper, 1956. The hypothalamic elaboration of posterior pituitary principles in man, the rat and dog. Histochemical evidence derived from a performic acid-alcian blue reaction for cysteine.-J. Endocr. 13: 221-228.

Adiyodi, K. G. \& H. A. Bern, 1968. Neuronal appearance of neurosecretory cells in the pars intercerebralis of Periplaneta americana (L.).-Gen. comp. Endocr. 11 : 88-91.

Arvy, L. \&. M. GABE, 1954. Modification de la neurosécrétion protocérébrale et des glandes endocrines céphaliques de Leptinotarsa decemlineata Say au cours de la métamorphose.-C. r. Congr. Socs sav. Paris Sect. Sci.: 189-196.

Belyaeva, T. G., 1967. The secretory activity of corpora allata during sexual maturation and imaginal diapause in Gryllus domesticus L. and Leptinotarsa decemlineata Say.-Acta ent. bohemoslov. 64: 1-15.

Bergland, R. M. \& R. M. Torack, 1969. Microtubules and neurofilaments in axons of the human pituitary stalk.-Expl. Cell Res. 54: 132-134.

Bern, H. A., 1962. The properties of neurosecretory cells.-Gen. comp. Endocr. (suppl.) 1: 117-132.

- , 1966. On the production of hormones by neurons and the role of neurosecretion in neuroendocrine mechanisms. In: Nervous and hormonal mechanisms of integration.-Symp. Soc. exp. Biol. 20: 325-344.

Bern, H. A. \& I. R. HAgAdorn, 1965. Neurosecretion. In: T. H. Bullock \& G. A. Horridge, eds, Structure and function in the nervous systems of invertebrates 1: $353-429$.

Boer, H. H., 1965. A cytological and cytochemical study of neurosecretory cells in Basommatophora, with particular reference to Lymnaea stagnalis L.-Archs. néerl. Zool. 16: 313-386.

Bounhiol, J. J., 1927. Contribution à l'étude anatomique de la larve du Leptinotarsa decemlineata (Say).--Revue Zool. agric. appl. 26: 163-183.

BRADY, J., 1967. Histological observations on circadian changes in the neurosecretory cells of cockroach sub-oesophageal ganglia.-J. Insect Physiol. 13: 201-213.

Brandenburg, J., 1956. Das endocrine System des Kopfes von Andrena vaga Pz. (Ins. Hymenopt.) und Wirkung der Stylopisation (Stylops Ins. Strepsipt.).-Z. Morph. Ökol. Tiere 45: 343-364.

Brink, M. \& H. H. BoER, 1967. An electron-microscopical investigation of the follicle gland (cerebral gland) and of some neurosecretory cells in the lateral lobe of the cerebral ganglion of the pulmonate gastropod Lymnaea stagnalis L.Z. Zellforsch. mikrosk. Anat. 79: 230-243.

Bruneteau, J., 1928. Contribution de l'étude anatomique du Doryphore (Leptinotarsa decemlineata Say) à l'état d'insecte parfait.-Revue Zool. agric. appl. 27: 101110.

Bruno, G. A. \& J. E. Ghristian, 1961. Determination of carbon-14 in aqueous bicarbonate solutions by liquid scintillation counting techniques.-Analyt. Chem. 33: 1216-1218.

Burgess, L. \& J. G. Rempel, 1966. The stomodaeal nervous system, the neurosecretory system, and the gland complex in Aedes aegypti (L.). (Diptera: Culicidae).-Can. J. Zool. 44: 731-765.

CAzAL, P., 1948. Les glandes endocrines rétro-cérébrales des insectes (étude morphologique).-Bull. biol. Fr. Belg. (suppl.) 32: 1-227.

Chalaye, D., 1965. Recherches histochimiques et histophysiologiques sur la neuro- 
sécrétion dans la chaîne nerveuse ventrale du Criquet migrateur, Locusta migratoria.-C. r. hebd. Séanc. Acad. Sci., Paris (D) 260: 7010-7013.

-, 1966. Recherches sur la destination des produits de neurosécrétion de la chaîne nerveuse ventrale du Griquet migrateur, Locusta migratoria.-C. r. hebd. Séanc. Acad. Sci., Paris (D) 262: 161-164.

Coalson, R. E., 1966. Pseudoisocyanin staining of insulin and specificity of empirical islets cell stains.-Stain Technol. 41: 121-129.

De Lerma, B., 1956. Corpora cardiaca et neurosécrétion protocérébrale chez le Coleoptère Hydrous piceus L.-Annls Sci. nat., Zool. (11) 18: 235-250.

Drawert, J., 1966. Histochemische und zytophotometrische Untersuchungen an neurosekretorischen Zellen der Saateule Agrotis segetum Schiff unter besonderer Berücksichtigung der DDD-Reaktion.-Acta histochem. 24: 345-354.

Dupont-RaAbe, M., 1956. Quelques données relatives aux phénomènes de neurosécrétion chez les Phasmides.-Annls Sci. nat., Zool. (11) 18: 293-303.

-, 1958. Quelques aspects des phénomènes de neurosécrétion ches les Phasmides.2. Int. Symp. Neurosekr., Lund (W. Bargmann, B. Hanström, B. Scharrer and E. Scharrer, Eds) : 85-90.

El-Ibrashi, M. T., 1965. A comparative study of metabolic effects of the corpus allatum in two adult Coleoptera, in relation to diapause.-Meded. Landb. Hogesch. Wageningen 65 (11): 1-65.

Engelmann, F., 1968. Endocrine control of reproduction in insects.-A. Rev. Ent. 13: $1-44$.

-, 1969. Food-stimulated synthesis of intestinal proteolytic enzymes in the cockroach Leucophaea maderae.-J. Insect Physiol. 15: 217-235.

EwEN, A. B., 1962. Histophysiology of the neurosecretory system and retrocerebral endocrine glands of the Alfalfa plant bug, Adelphocoris lineolatus (Goeze) (Hemiptera: Miridae).-J. Morph. 111: 255-273.

-, 1966. The corpus allatum and oöcyte maturation in Adelphocoris lineolatus (Goeze) (Hemiptera: Miridae).-Can. J. Zool. 44: 719-727.

Falck, B. \& Ch. Owman, 1965. A detailed methodological description of the fluorescent method for the cellular demonstration of biogenic monoamines.-Acta Univ. lund. (II) 7: 1-19.

Finlayson, L. H. \& M. P. Osborne, 1968. Peripheral neurosecretory cells in the stick insect (Carausius morosus) and the blowfly larva (Phormia terrae-novae).- J. Insect Physiol. 14: 1793-1801.

FLETCHeR, B. S., 1969. The diversity of celltypes in the neurosecretory system of the beetle Blaps mucronata.-J. Insect Physiol. 15: 119-134.

FLOREY, E., 1967. Neurotransmitters and modulators in the animal kingdom.-Proc. Fedn Am. Socs exp. Biol. 26: 1164-1178.

Fraenkel, G. \& C. HsiaO, 1965. Bursicon, a hormone which mediates tanning of the cuticle in the adult fly and other insects.-J. Insect Physiol. 11: 513-556.

FRASER, A., 1957. Neurosecretory cells in the brain of the larva of Lucilia caesar L. Nature, Lond. 179: 257-258.

-, 1959. Neurosecretion in the brain of the larva of the sheep blowfly, Lucilia caesar (Diptera).-Q.Jl microsc. Sci. 100: 377-394.

Frontali, N., 1968. Histochemical localization of catecholamines in the brain of normal and drug-treated cockroaches.-J. Insect Physiol. 14: 881-886.

Frontali, N. \& K. A. Norberg, 1966. Catecholamine containing neurons in the cockroach brain.-Acta physiol. scand. 66: 243-244.

FuXe, K. \& T. Hökfelt, 1967. The influence of the central catecholamine neurons on the hormone secretion from the anterior and posterior pituitary. In: F. Stutinsky, ed., Neurosecretion: 165-177. 
GABE, M., 1953. Sur quelques applications de la coloration par la fuchsine-paraldéhyde.-Bull. Microsc. appl. (2) 3: 153-162.

-, 1966. Neurosecretion: i-xiv, 1-872, figs. 1-584, pls. I-XII.

-, 1967. Évolution du produit de neurosécrétion protocéphalique des insectes Ptérygotes au cours du cheminement axonal.-C. r. hebd. Séanc. Acad. Sci., Paris (D) 264: 943-945.

Gabe, M. \& L. Arvy, 1961. Gland cells. In: J. Brachet \& A. E. Mirsky, eds, The cell 5: 1-88.

Geldiay, S., 1968. Control of adult reproductive diapause in Anacridium aegyptium L. by direct action of photoperiod on the cerebral neurosecretory cells. Abstr. XIII Int. Congr. Ent., Moscow: 82.

Giering, R., 1959. The central nervous system of Leptinotarsa decemlineata (Say) with special consideration of the brain.-Annls Univ. Mariae Curie-Skłodowska (G) 14: $141-159$.

GrRARdie, A., 1965. Contribution à l'étude du contrôle de l'activité des corpora allata par la pars intercerebralis chez Locusta migratoria (L.).-C. r. hebd. Séanc. Acad. Sci., Paris (D) 261: 4876-4878.

Girardie, A. \& J. Girardie, 1966. Mise en évidence d'une activité neurosécrétrice des cellules C de la pars intercerebralis de Locusta migratoria L. par étude comparative histologique et ultrastructurale.-C. r. hebd. Séanc. Acad. Sci., Paris (D) 263: 1119-1122.

-, 1967. Etude histologique, histochimique et ultrastructurale de la pars intercerebralis chez Locusta migratoria L. (Orthoptère).-Z. Zellforsch. mikrosk. Anat. 78: 54-75.

Gomori, G., 1941. Observations with differential stains on human islets of Langerhans.-Am. J. Path. 17: 395-406.

-, 1950. Aldehyde-fuchsin: a new stain for elastic tissue.-Am. J. clin. Path. 20: 665-666.

Gosbee, J. L., J. V. Milligan \& B. N. Smallman, 1968. Neural properties of the protocerebral neurosecretory cells of the adult cockroach Periplaneta americana.J. Insect Physiol. 14: 1785-1792.

GraY, P., 1954. The microtomist's formulary and guide: 1-794, figs. 1-86.

HALmi, N. S., 1952. Differentiation of two types of basophils in the adenohypophysis of the rat and mouse.-Stain Technol. 27: 61-64.

Hassemer, S. M. \& S. D. BeGK, 1968. Histochemistry of the ileum of the european corn borer, Ostrinia nubilalis.-J. Insect Physiol. 14: 1233-1246.

Herlant-Meewis, H., J. Naisse \& J. Mouton, 1967. Phénomènes neurosécrétoires au niveau de la chaîne nerveuse chez les invertébrés. In: F. Stutinsky, ed., Neurosecretion: 203-218.

Highnam, K. G., 1958a. Activity of the brain/corpora cardiaca system during pupal diapause "break" in Mimas tiliae (Lepidoptera).-Q. J1 microsc. Sci. 99: 73-88.

-, 1958b. Activity of the corpora allata during pupal diapause in Mimas tiliae (Lepidoptera).-Q. J1 microsc. Sci. 99: 171-180.

-, 1961a. The histology of the neurosecretory system of the adult female desert locust, Schistocerca gregaria.-Q. J1 microsc. Sci. 102: 27-38.

-, 1961b. Induced changes in the amounts of material in the neurosecretory system of the desert locust.-Nature, Lond. 191: 199-200.

-, 1962a. Neurosecretory control of ovarian development in the desert locust. In: Neurosecretion.-Mem. Soc. Endocr. 12: 379-390.

-, 1962b. Neurosecretory control of ovarian development in Schistocerca gregaria.Q. J1 microsc. Sci. 103: 57-72. 
-, 1964. Endocrine relationships in insect reproduction. In: Insect reproduction.Symp. R. ent. Soc. Lond. 2: 26-42.

-, 1965. Some aspects of neurosecretion in arthropods.-Zool. Jb., Physiol. 71: 558-582.

-, 1967. Insect hormones.-J. Endocr. 39: 123-150.

Highnam, K. G., L. Hill \& W. Mordue, 1966. The endocrine system and oocyte growth in Schistocerca in relation to starvation and frontal ganglionectomy.- J. Insect Physiol. 12: 977-995.

Hodek, I. \& J. DE Wilde, 1969. Entomologia exp. appl. (In the press).

Huber, P., 1963. Aldehyde-thionin: ein Farbreagens mit erweiterten Anwendungsmöglichkeiten.-Mikroskopie 18: 317-338.

Johansson, A. S., 1958a. Relation of nutrition to endocrine-reproductive function in the milkweed bug Oncopeltus fasciatus (Dallas) (Heteroptera, Lygaeidae).- Nytt Mag. Zool. 7: 3-132.

-, 1958b. Neurosecretion in the milkweed bug, Oncopeltus fasciatus (Dallas). In: II Int. Symp. Neurosekr., Lund: 98-101.

Johnson, B., 1963. A histological study of neurosecretion in aphids.-J. Insect Physiol. 9: 727-739.

Joly, P., 1945. La fonction ovarienne et son contrôle humoral chez les Dytiscides.Archs Zool. exp. gén. 84: 49-164.

KAISER, P., 1949. Histologische Untersuchungen über die Corpora allata und Prothoraxdrüsen der Lepidopteren in Bezug auf ihre Funktion.-Arch. EntwMech. Org. 144: 99-131.

Knowles, F. G. W., 1967. Neuronal properties of neurosecretory cells. In: F. Stutinsky, ed., Neurosecretion: 8-19.

Kort, C. A. D., DE, 1969. Hormones and the structural and biochemical properties of the flight muscles in the Colorado beetle.-Meded. Landb. Hogesch. Wageningen 69 (2): 1-63.

LABELla, F. S. \& M. SANwAL, 1965. Isolation of nerve endings from the posterior pituitary gland.-J. Cell Biol. 25: 179-193.

LeA, A. O. \& E. Thomsen, 1962. Cycles in the synthetic activity of the medial neurosecretory cells of Calliphora erythrocephala and their regulation. In: Neurosecretion.-Mem. Soc. Endocr. 12: 345-347.

-, 1969 Size independent secretion by the corpus allatum of Calliphora erythrocephala.-J. Insect Physiol. 15: 477-482.

LeEs, A. D., 1964. The location of the photoperiodic receptors in the aphid Megoura viciae Buckton.-J. exp. Biol. 41: 119-133.

Loof, A. DE, 1969. Causale mechanismen bij de vitellogenese van de Coloradokever, Leptinotarsa decemlineata Say. Thesis, University of Ghent: 1-87, figs. 1-44.

LOOF, A. DE \& J. DE WILDE, 1970. The relation between haemolymph proteins and vitellogenesis in the Colorado beetle, Leptinotarsa decemlineata.-J. Insect Physiol. 16: 157-169.

LunTz, A. J., 1968. Neurosecretory activity and growth during reproductive development in Schistocerca gregaria Forskål. MSc thesis, University of Sheffield.

Lüscher, M. \& F. EngelmanN, 1960. Histologische und experimentelle Untersuchungen über die Auslösung der Metamorphose bei Leucophaea maderae (Orthoptera).-J. Insect Physiol. 5: 240-258.

MAdDRELl, S. H. P., 1970. Control systems - neurosecretion and transmitter substances. In: Symp. R. ent. Soc. Lond. (In the press).

MaLeod, D. G. R. \& S. D. Beck, 1963. The anatomy of the neuroendocrine complex of the european corn borer (Ostrinia nubilalis) and its relation to diapause.-Ann. ent. Soc. Am. 56: 723-727. 
Mendes, M. V., 1948. Histology of the corpus allatum of Melanoplus differentialis Orthoptera, Saltatoria).-Biol. Bull. mar. biol. Lab., Woods Hole 94: 194-207.

Mordue, W., 1965. Studies on oocyte production and associated histological changes in the neuro-endocrine system in Tenebrio molitor.-J. Insect Physiol. 11: 493-503.

-, 1967. The influence of feeding upon the activity of the neuroendocrine system during oocyte growth in Tenebrio molitor.-Gen. comp. Endocr. 9: 406-415.

Mогоноsнi, S. \& T. Oshiкi, 1969. Effect of the brain on the suboesophageal ganglion and determination of voltinism in Bombyx mori.-J. Insect Physiol. 15: 167-175.

Nayar, K. K., 1955. Studies on the neurosecretory system of Iphita limbata Stal. I.Distribution and structure of the neurosecretory cells of the nerve ring.-Biol. Bull. mar. biol. Lab., Woods Hole 108: 296-307.

-, 1956. Studies on the neurosecretory system of Iphita limbata Stal. (Hemiptera). III.- The endocrine glands and the neurosecretory pathways in the adult.-Z. Zellforsch. mikrosk. Anat. 44: 697-705.

-, 1958. Probable endocrine mechanism controlling oviposition in the insect Iphita limbata Stal. (Hemiptera). In: II Int. Symp. Neurosekr. Lund: 102-104.

NAIsse, J., 1966. Contrôle endocrinien de la différenciation sexuelle chez Lampyris noctiluca (Coleoptère, Lampyridae). II. Phenomènes neurosécrétoires et endocrines au cours du développement postembryonnaire chez le mâle et la femelle.Gen. comp. Endocr. 7: 85-104.

Normann, T. G., 1965. The neurosecretory system of the adult Calliphora erythrocephala. I. The fine structure of the corpus cardiacum with some observations on adjacent organs.-Z. Zellforsch. mikrosk. Anat. 67: 461-501.

Pehlemann, F. W., 1968. Die amitotische Zellteilung. Eine elektronen-mikroskopische Untersuchung an Interrenalzellen von Rana temporaria L.-Z. Zellforsch. mikrosk. Anat. 84: 516-548.

Peute, J. \& J. C. vAN DE KAMER, 1967. On the histochemical differences of aldehydefuchsin positive material in the fibres of the hypothalamo-hypophyseal tract of Rana temporaria.-Z. Zellforsch. mikrosk. Anat. 83: 441-448.

PIPA, R. L., 1961. Studies on the hexapod nervous system. IV. A cytological and cytochemical study of neurons and their inclusions in the brain of a cockroach, Periplaneta americana L.-Biol. Bull. mar. biol. Lab., Woods Hole 121 : 521534.

Prentø, P., 1969. Mode of action of aldehyde fuchsin as a selective stain for insect neurosecretory material. Communs V Conf. eur. comp. Endocr., Utrecht.Gen. comp. Endocr. (In the press).

RAABE, M., 1965. Etude des phénomènes de neurosécrétion au niveau de la chaîne nerveuse ventrale des Phasmides.-Bull. Soc. zool. Fr. 90: 631-654.

-, 1966. Recherches sur la neurosécrétion dans la chaîne nerveuse ventrale du Phasme, Clitumnus extradentatus: Variations d'activité des différent éléments neurosécréteurs.-C. r. hebd. Séanc. Acad. Sci., Paris 262: 303-306.

Reнм, M., 1955. Morphologische und histochemische Untersuchungen an neurosekretorischen Zellen von Schmetterlingen.-Z. Zellforsch. mikrosk. Anat. 42: $19-58$.

Rogers, A. W., 1967. Techniques of autoradiography: 1-355, figs. 1-76.

Romers, B., 1948. Mikroskopische Technik: i-xi, 1-695, figs. 1-21.

ScharRer, B., 1941. Neurosecretion. II. Neurosecretory cells in the central nervous system of cockroaches.-J. comp. Neurol. 74: 93-108.

-, 1955. Castration cells in the central nervous system of an insect (Leucophaea maderae, Blattaria).-Trans. N.Y. Acad. Sci. 17: 520-525.

-, 1963 Neurosecretion. XIII. The ultrastructure corpus cardiacum of the of the 
insect Leucophaea maderae.-Z. Zellforsch. mikrosk. Anat. 60: 761-796.

-, 1964. Histophysiological studies on the corpus allatum of Leucophaea maderae. IV. Ultrastructure during normal activity cycle.-Z. Zellforsch. mikrosk. Anat. 62: $125-148$.

-, 1968. Neurosecretion. XIV. Ultrastructural study of sites of release of neurosecretory material in blattarian insects.-Z. Zellforsch. mikrosk. Anat. 89: 1-16.

Scharrer, B. \& M. von Harnack, 1958. Histophysiological studies on the corpora allata of Leucophaea maderae. I. The normal life cycle in male and female adults.Biol. Bull. mar. biol. Lab., Woods Hole 115: 508-520.

Schooneveld, H., 1966. Some factors influencing the histological picture of the neurosecretory system of the Colorado beetle, Leptinotarsa decemlineata Say.Communs Int. Symp. Insect Endocrines, Brno.

-, 1969. Control of activity of neurosecretory " $\mathrm{A}$ "-cells in the Colorado beetle, Leptinotarsa decemlineata Say. Communs V Conf. eur. comp. Endocr., Utrecht.Gen. comp. Endocr. (In the press).

-, 1970. Ultrastructure of the neurosecretory system of the Colorado beetle (In preparation).

Schoonhoven, L. M., 1963. Spontaneous electrical activity in the brains of diapausing insects.-Science, N.Y. 141: 173-174.

Schreiner, B., 1966. Histochemistry of the A cell neurosecretory material in the milkweed bug, Oncopeltus fasciatus Dallas (Heteroptera: Lygaeidae), with a discussion of the neurosecretory materal/carrier substance.-Gen. comp. Endocr. 6: $388-400$.

SchüRmann, F.-W., 1968. Autoradiographische Untersuchungen zum Ribonucleinsäure- und Proteinstoffwechsel im Zentralnervensystem von Locusta migratoria L.-Z. Zellforsch. mikrosk. Anat. 86: 26-60.

Siew, Y. C., 1965a. The endocrine control of adult reproductive diapause in the chrysomelid beetle Galeruca tanaceti (L.). I.-J. Insect Physiol. 11: 1-10.

-, 1965b. The endocrine control of adult reproductive diapause in the chrysomelid beetle Galeruca tanaceti (L.). II.-J. Insect Physiol. 11: 463-479.

-, 1965c. The endocrine control of adult reproductive diapause in the chrysomelid beetle Galeruca tanaceti (L.). III.-J. Insect Physiol. 11: 973-981.

Sloper, J. G., 1957. Presence of a substance rich in protein-bound cystine or cysteine in the neurosecretory system of an insect.-Nature, Lond. 179: 148-149.

-, 1958. The application of newer histochemical and isotope techniques for the localization of protein-bound cystine or cysteine to the study of hypothalamic neurosecretion in normal and pathological conditions. In: II. Int. Symp. Neurosekr., Lund: 20-25.

Sloper, J. C., D. J. Arnott \& B. C. KING, 1960. Sulphur metabolism in the pituitary and hypothalamus of the rat: a study of radioisotope uptake after the injection of ${ }^{35}$ S-DL-cysteine, methionine, and sodium sulphate.-J. Endocr. 20: 9-23.

Smallman, B. N. \& A. Mansingh, 1969. The cholinergic system in insect development.-A. Rev. Ent. 14: 387-408.

Sмiтн, D. S., 1970. Links between cellular structure and function. In: Insect ultrastructure.-Symp. R. ent. Soc. Lond. (In the press).

StAAL, G. B., 1961. Studies on the physiology of phase induction in Locusta migratoria migratorioides R \& F. Thesis, Agricultural University, Wageningen: 1-125.

StegweE, D., 1960. Metabolic effect of a corpus allatum hormone in diapausing Leptinotarsa decemlineata Say.-Verh. II. Int. Kongr. Ent., Wien 3: 218-221.

-, 1964. Respiratory chain metabolism in the Colorado potato beetle.-II. Respiration and oxidative phosphorylation in "sarcosomes" from diapausing beetles.-J. Insect Physiol.10: 97-102. 
Steghee, D., E. C. Kimmel, J. A. de Boer \& S. Henstra, 1963. Hormonal control of reversible degeneration of flight muscle in the Colorado potato beetle, Leptinotarsa decemlineata Say (Coleoptera).- -J. Cell Biol. 19: 519-527.

Sterba, G. \& G. Hoheisel, 1964. Darstellung des neurosekretorischen System der Insekten mit Pseudoisocyanin.-Z. mikrosk. anat. Forsch. 72: 31-48.

Strong, L., 1965. The relationships between the brain, corpora allata and oocyte growth in the central american locust, Schistocerca sp.-II. The innervation of the corpora allata, the lateral neurosecretory complex, and oocyte growth.-J. Insect Physiol. 11: 271-280.

Stutinsky, F., A. Porte, J. P. Tranzer \& Y.Terminn, 1963. Sur la signification des inclusions colorables par l'aldéhyde-fuchsine dans les neurones du système nerveux central du rat. - C. r. hebd. Séanc. Acad. Sci., Paris 157: 2294-2296.

Teichmann, I., B. Aros \& B. Vigh, 1966. Histochemical studies on Gomori-positive substances. III. Examination of the earthworm's neurosecretory system (Lumbricus herculeus, Eisenia foetida).-Acta biol. hung. 17: 329-359.

Thomsen, E., 1954. Studies on the transport of neurosecretory material in Calliphora erythrocephala by means of ligaturing experiments.-J. exp. Biol. 31: 322-330.

Thomsen, E. \& I. Møller, 1963. Influence of neurosecretory cells and of corpus allatum on intestinal protease activity in the adult Calliphora erythrocephala Meig. -J. exp. Biol. 40: 301-321.

Thomsen, M., 1965. The neurosecretory system of the adult Calliphora erythrocephala. II. Histology of the neurosecretory cells of the brain and some related structures.-Z. Zellforsch. mikrosk. Anat. 67: 693-717.

Tombes, A. S. \& D. Bodenstein, 1966. The study of the neuroendocrine system in active and diapausing Hypera postica (Gillenhal) adults.-Communs Int. Symp. Insect Endocrines, Brno.

VAN DER KLOOT, W. G., 1955. The control of neurosecretion and diapause by physiological changes in the brain of the cecropia silkworm.-Biol. Bull. mar. biol. Lab., Woods Hole 109: 276-294.

-, 1960. Neurosecretion in insects.-A. Rev. Ent. 5: 35-52.

WEYer, F., 1935. Ueber drüsenartige Nervenzellen im Gehirn der Honigbiene, Apis mellifica L.-Zool. Anz. 112: 137-141.

Wigglesworth, V. B., 1940. The determination of characters at metamorphosis in Rhodnius prolixus (Hemiptera).-J. exp. Biol. 17: 201-222.

-, 1960. The nutrition of the central nervous system in the cockroach Periplaneta americana $\mathrm{L}$. The role of the perineurium and glial cells in the mobilization of reserves.-J. exp. Biol. 37: 500-512.

-, 1964. The hormonal regulation of growth and reproduction in insects. In: J. W. L. Beament, J. E. Treherne \& V. B. Wigglesworth, eds, Advances in Insect Physiology 2: 247-336.

-, 1965. The principles of insect physiology: i-viii, 1-741, figs. 1-407.

Wilde, J. DE, 1957. Breeding the Colorado beetle under controlled conditions.-Z. PflKrankh. PflPath. PflSchutz 64: 589-593.

-, 1958. Perception of the photoperiod by the Colorado potato beetle (Leptinotarsa decemlineata Say).-Proc. X Int. Congr. Ent., Montreal 2: 213-218.

-, 1959. Diapause in the Colorado beetle (Leptinotarsa decemlineata Say) as an endocrine deficiency syndrome of the corpora allata. In: I. Hrdy, ed., The ontogeny of insects: $226-230$.

- 1960 . Action of the juvenile hormone in the adult Colorado beetle, Leptinotarsa decemlineata Say.-Verh. XI Int. Kongr. Ent., Wien 3: 215-217.

-, 1964. Reproduction - endocrine control. In: M. Rockstein, ed., The physiology of insecta 1: 59-90. 
-, 1965. Photoperiodic control of endocrines in insects.-Archs Anat. microsc. Morph. exp. 54: 547-564.

-, 1969. Diapause and seasonal synchronization in the adult Colorado beetle (Leptinotarsa decemlineata Say). In: Dormancy and survival.-Symp. Soc. exp. Biol. 22: 263-284.

WILdE, J. DE \& J. A. DE BoeR, 1961. Physiology of diapause in the adult Colorado beetle - II. Diapause as a case of pseudo-allatectomy.-J. Insect Physiol. 6: $152-161$.

-, 1969. Humoral and nervous pathways in photoperiodic induction of diapause in Leptinotarsa decemlineata.- J. Insect Physiol. 15: 661-675.

Wilde, J. De, C. S. Duintjer \& L. Mook, 1959. Physiology of diapause in the adult Colorado beetle (Leptinotarsa decemlineata Say).-I. The photoperiod as a controlling factor.-J. Insect Physiol. 3: 75-85.

Wilde, J. DE \& P. FERKet, 1967. The hostplant as a source of seasonal information.Meded. Rijksfac. LandbWet., Gent 32: 387-392.

Wilde, J. De, G. B. Staal, C. A. D. de Kort, A. de Loof \& G. BaArd, 1968. Juvenile hormone titer in the haemolymph as a function of photoperiodic treatment in the adult Colorado beetle (Leptinotarsa decemlineata Say).-Proc. K. ned. Akad. Wet. (C) 71: 321-326.

Wilde, J. DE \& D. STEGWee, 1958. Two major effects of the corpus allatum in the adult Colorado beetle (Leptinotarsa decemlineata Say).-Archs néerl. Zool. (suppl.) 13: 277-289.

Wilkens, J. L., 1969. The endocrine control of protein metabolism as related to reproduction in the fleshfly Sarcophaga bullata.-J. Insect Physiol. 15: 1015-1024.

Williams, C. M., 1967. The present status of the brain hormone. In: J. W. L. Beament \& J. E. Treherne, eds, Insects and physiology: 133-139.

-, 1969. Photoperiodism and the endocrine aspects of insect diapause. In: Dormancy and survival.-Symp. Soc. exp. Biol. 23: 285-300.

Williams, G. M. \& P. L. Adkisson, 1964. Physiology of insect diapause. XIV. An endocrine mechanism for the photoperiodic control of pupal diapause in the oak silkworm, Antheraea pernyi.-Biol. Bull. mar. biol. Lab., Woods Hole 127: 511-525. 

PLATES I-X 
PLATE I

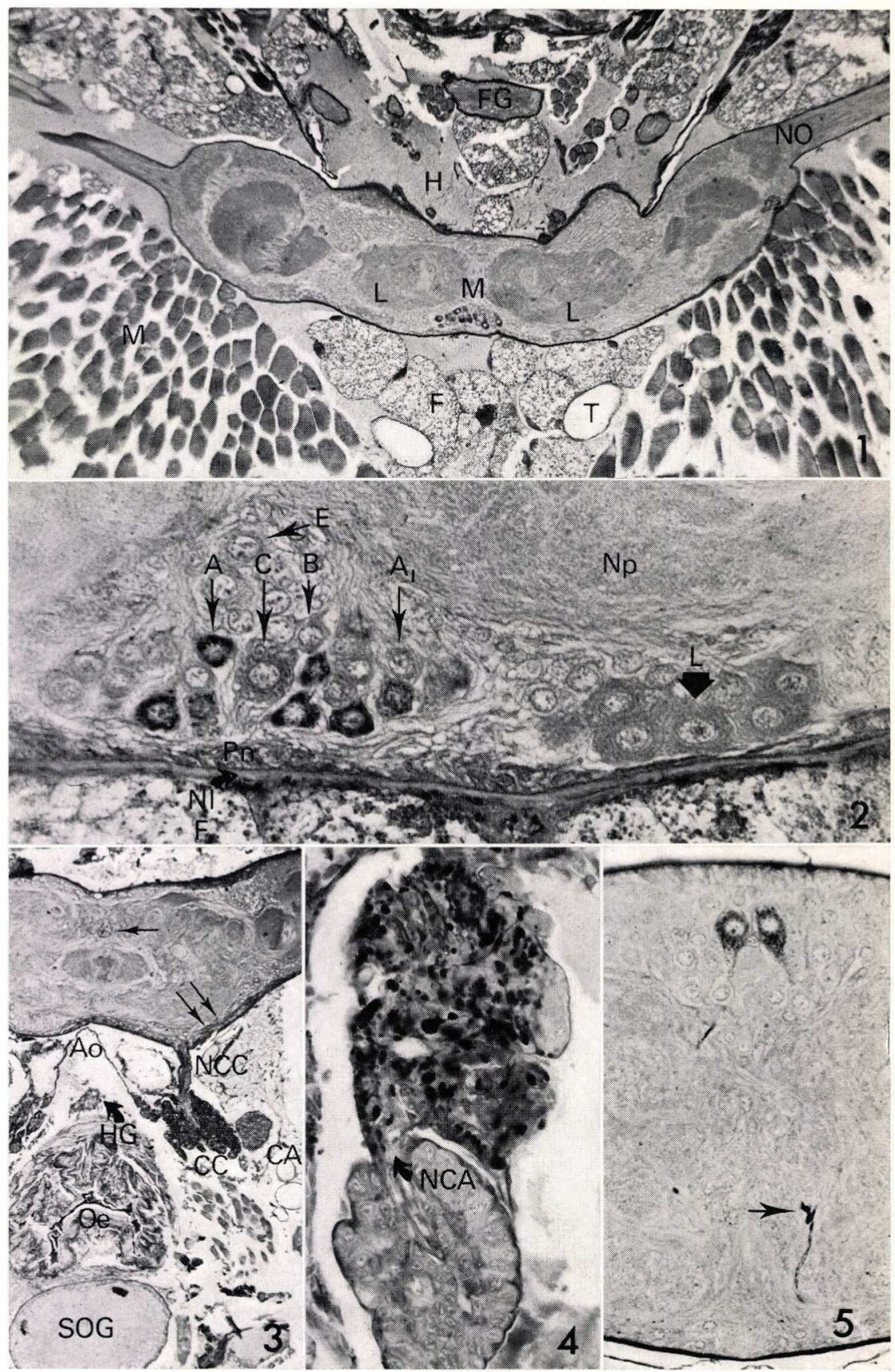




\section{PLATE II}

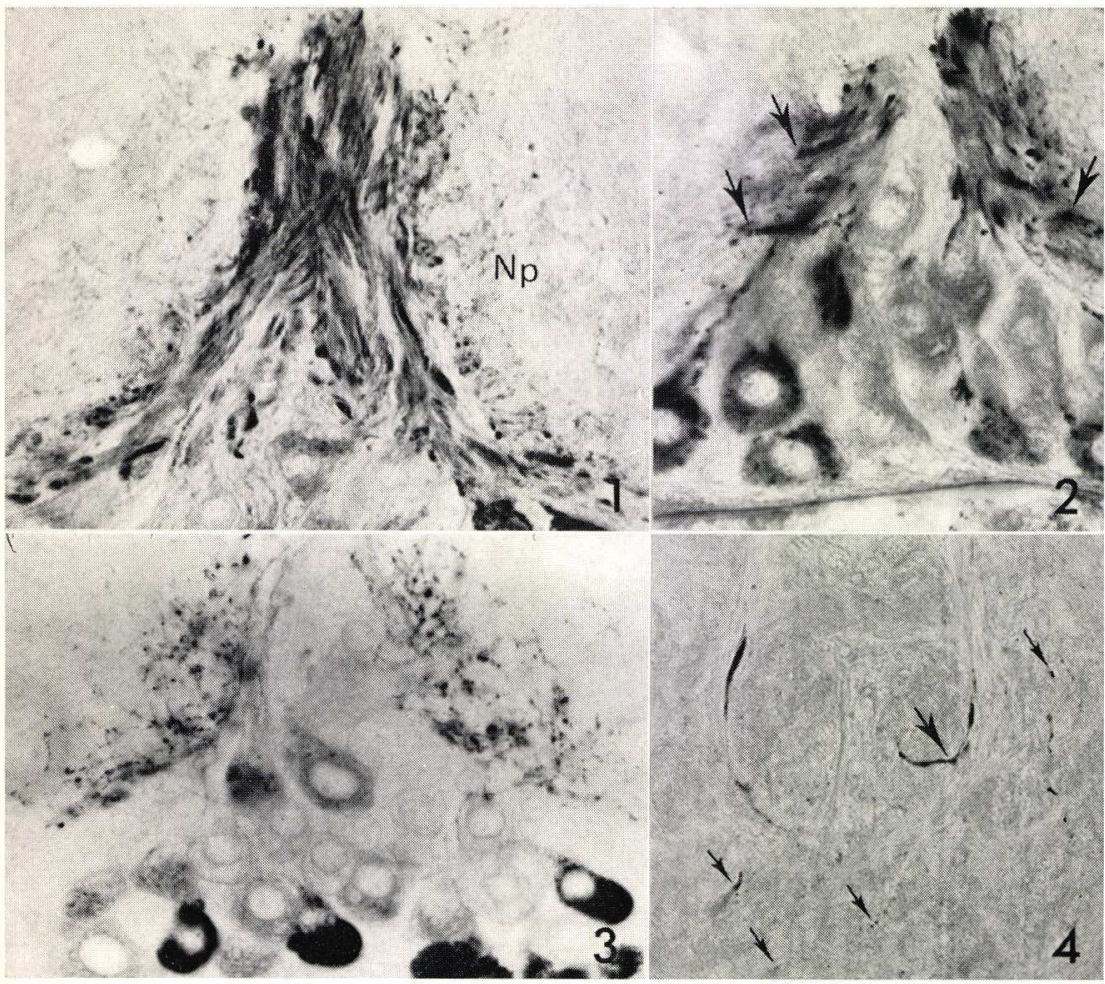

PLATE I

Fig. 1. Horizontal section through the head, showing the protocerebrum with medial (M) and lateral (L) groups of neurosecretory cells, and the nervi optici (NO), the frontal ganglion $(\mathrm{FG})$, coagulated haemolymph $(\mathbf{H})$, fatbody $(\mathrm{F})$, muscles $(\mathbf{M})$, and trachea $(\mathrm{T}) . \times 64$.

Fig. 2. The pars intercerebralis and part of the cerebral lobe at a higher magnification; several types of NSC are indicated. F, fatbody; Nl, neural lamella; Np, neuropile; Pn, perineurium layer. $\times 475$.

Fig. 3. Oblique section through the head, showing the brain with medial (arrow) and lateral (double arrows) axon bundles, one nervus corporis cardiaci (NCC), two corpora cardiaca (CG), one corpus allatum (CA), suboesophageal ganglion (SOG), hypocerebral ganglion (HG), aorta (Ao), and oesophagus (Oe). $\times 69$.

Fig. 4. Higher magnification of a corpus cardiacum-allatum complex. Note the numerous axon-terminals in the $\mathrm{CC}$ and the deep penetration of the nervus corporis allati (NCA) into the CA. $\times 336$.

Fig. 5. Horizontal section through the suboesophageal ganglion, with both SOG-ANSC. The arrow points at a bifurcation of one axon; compare with Plate II fig. $4 . \times 285$.

\section{PLATE II}

Fig. 1. Chiasma in the pars intercerebralis, lined by swollen axon collaterals in the neuropile $(\mathrm{Np}) . \times 525$.

Fig. 2. Axon branches entering the neuropile (arrows). $\times 525$.

Fig. 3. Arborization of "dendrites" of A-NSC within the neuropile (paraldehydethionin). $\times 615$.

Fig. 4. Branching of axons of the SOG-A-NSC; beaded fibres are discernible over the whole area (small arrows); the site indicated by the larger arrow corresponds with that indicated in Plate I fig. 5. $\times 336$. 


\section{PLATE III}

Fig. 1. Large C-NSC with clear vacuoles, and very darkly stained A-NSC of a female in diapause. $\times 1370$.

Fig. 2a and b. C-NSC photographed with phase-contrast (a) and bright-field (b) illumination, showing that the aggregations of NSM are located between Nissl bodies. $\times 1470$.

Fig. 3. Brain of an aged, dying, female, containing many vacuolated neuron areas. In the neuropile, no vacuolization has taken place but in the optic lobe some PAFpositive substance is present (arrow). Note the darkly stained A-NSG. $\times 97$.

Fig. 4. Pars intercerebralis of a 0-day-old beetle in which the left and right clusters of NSG are still more or less separated. Note the large and active E-NSG between the left and right axon bundles. $\times 615$.

Fig. 5. Inactive E-NSC of a female that has terminated oviposition; the perikarya contain much stainable material. $\times 810$.

Fig. 6. Inactive E-NSC of a female, during late pre-diapause; the perikarya are small and inconspicuous. $\times 810$. 
PLATE III

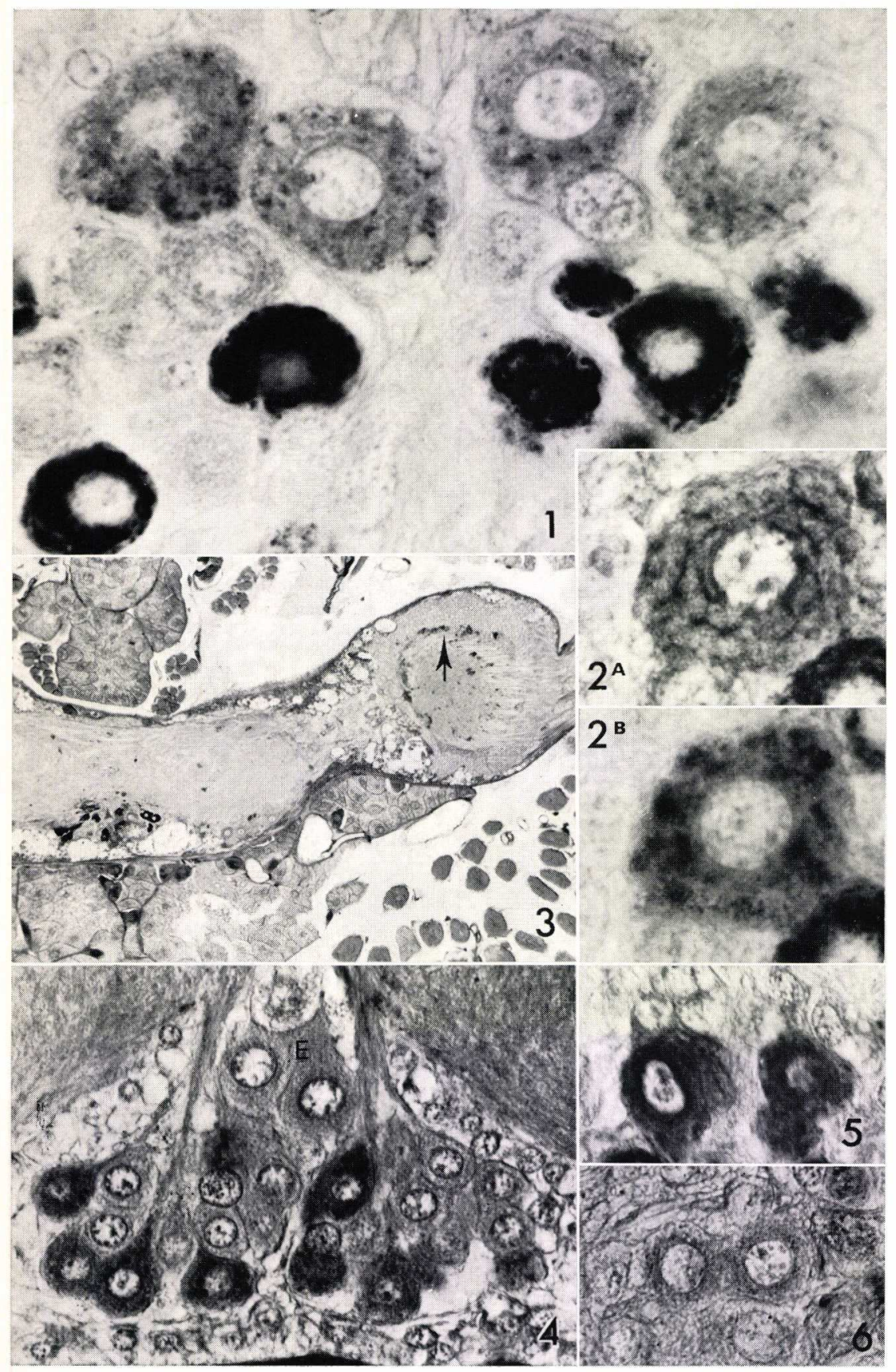




\section{PLATE IV}

Fig. 1. L-NSC, one day after the beginning of oviposition (phase-contrast). $\times 1170$.

Fig. 2. L-NSC, 5-6 days pre-oviposition, showing enlargement of the nucleolus and budding-off of the nuclear content (asterisk); the interruption of the nuclear envelope is clearly visible (phase-contrast). $\times 1470$.

Fig. 3. L-NSC, 6 days pre-diapause; the nucleus is dividing amitotically and the Nissl bodies are well-developed, indicating high secretory activity (phase-contrast). $\times 1170$.

Fig. 4. Lateral group of neurosecretory cells, with an amitotically dividing L-NSC nucleus and a D-NSC containing two unequal nuclei (oblique illumination). $\times 615$.

Fig. 5. A-NSC, with dense aggregations of NSM within the cytoplasm and axon $(\mathrm{Ax}) . \times 1290$.

Fig. 6. Two $\mathrm{A}_{1}$-NSC, containing faintly stained inclusions. $\times 1290$.

Fig. 7. Four B-NSC, stained homogeneously orange, in a diapausing specimen (dark blue filter). $\times 1290)$.

Fig. 8. Two active SOG-A-NSG of a 15-day-old ovipositing female. Note the dispersed tiny inclusions). $\times 1290$.

Fig. 9. Two inactive SOG-A-NSG of a female that had terminated oviposition. $\times 1080$.

Fig. 10. Two active SOG-A-NSC of a 15-day-old ovipositing female. In addition to fine inclusions, some large red-staining globules are present. $\times 1290$. 
PLATE IV

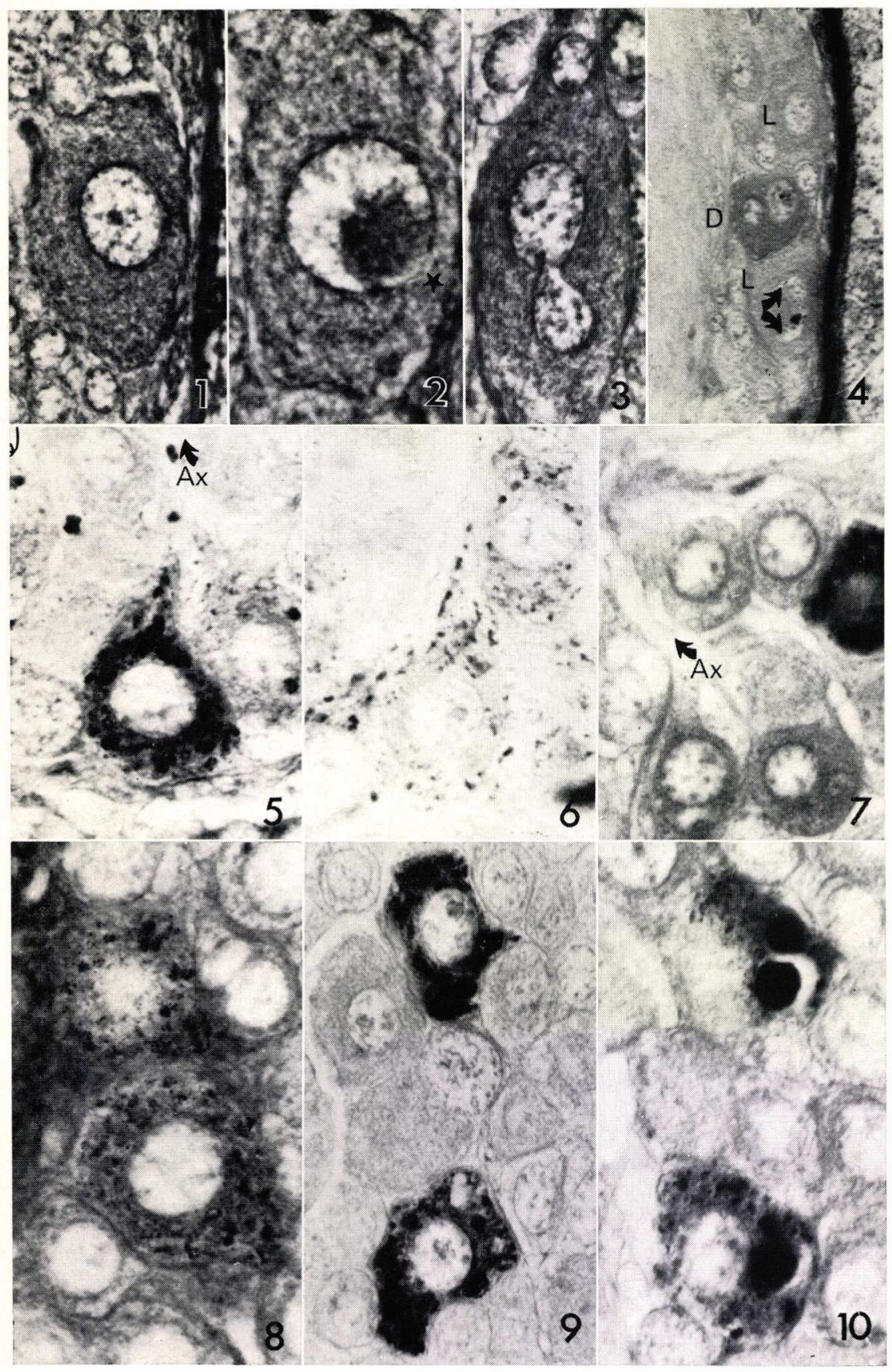




\section{PLATE V}

Fig. 1. Continuation of the NCC (centre of micrograph), comprising axons from medial (white asterisks) and lateral (black asterisks) NSC. Smaller bundles of axons have already separated from the NCG and partly surround it. Intrinsic secretory cells of varying staining intensity (arrows) contain vacuoles and inclusions (see inset in upper corner, $\times 1020)$. The periphery consists of a meshwork of axon profiles, axonterminals, and glial cells. The very dark regions presumably contain materials of the intrinsic secretory cells. $(0.5 \mu$ thick Epon section of glutaraldehyde-fixed tissue, stained with toluidine blue at $\mathrm{pH} 12) . \times 655$.

Fig. 2. NCG penetrating the CG for a considerable distance, before giving off branches (arrows), which run in all directions. Note the intrinsic (ISC) and very large extrinsic secretory cells $(\mathrm{ESC}) . \times 575$.

Fig. 3. Demonstration of the lobular character of the corpus cardiacum. At the left a cluster of ESC bordering the origin of the nervus cardiaco-suboesophagealis $(\mathrm{NCSO}) . \times 336$.

Fig. 4. Corpus cardiacum with strongly hypertrophied peripheral glial cells; in this jelly-like mass several ISC can be distinguished. $\times 336$.

Fig. 5. Muscle fibre (M) with clear cross-striation terminates in the CC. $\times 336$. 
PLATE V
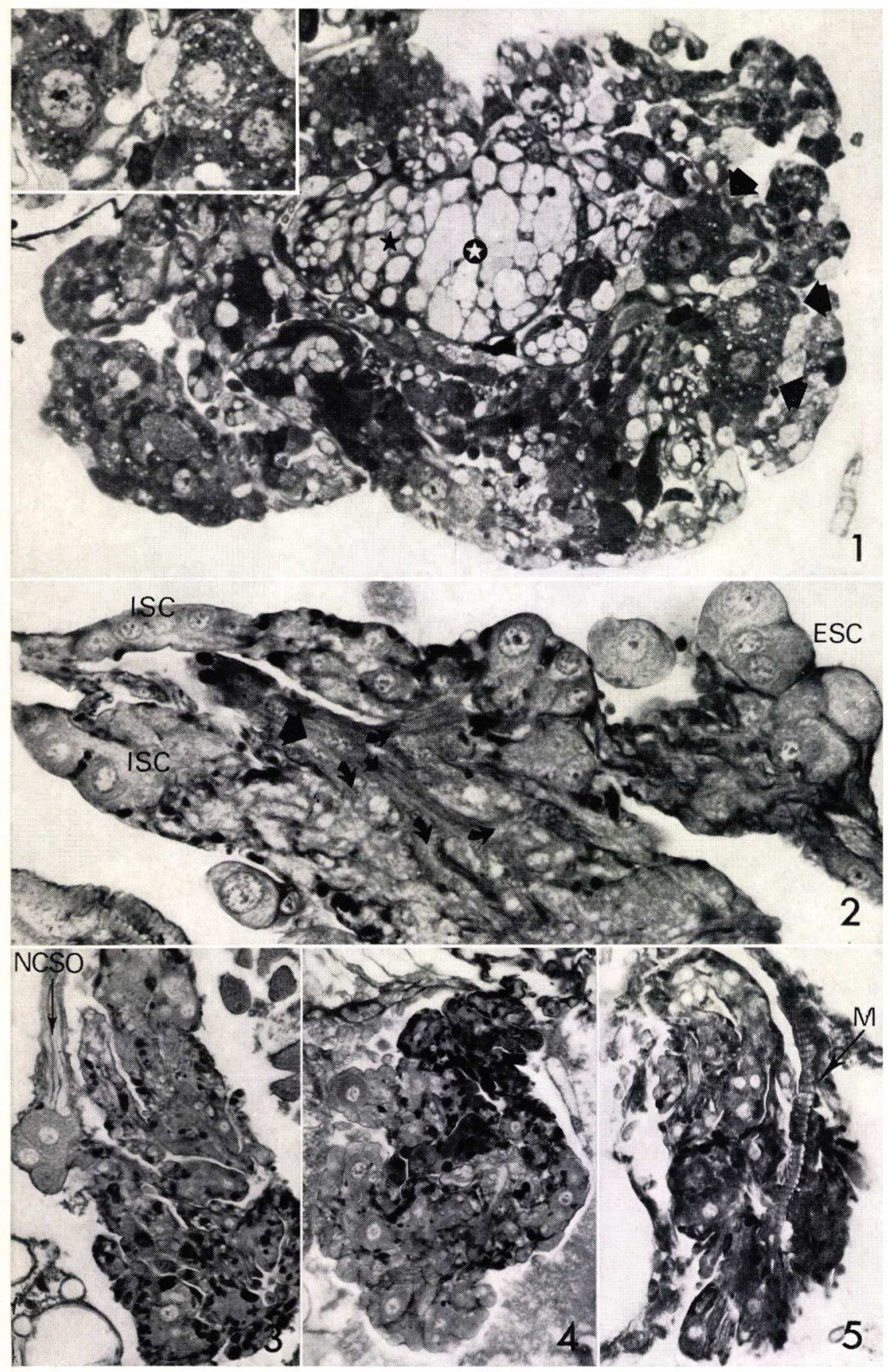


\section{PLATE VI}

Fig. 1. Cardiacum-allatum complex, showing that an axon tract (bent arrow), later on to be called NCA, branches off from the NCG (straight arrow). In this specimen, two separate NCA (asterisks) connect the CA with the CC. $\times 336$.

Fig. 2. Inactive corpus allatum of a diapausing female, with fine neurosecretory fibres that contain A-NSM (paraldehyde-thionin). $\times 525$.

Fig. 3. Active corpus allatum of female that has started post-diapause oviposition one day before. Note the extremely elongated cells, nearly all of them touching the connective tissue envelope of the CA, and the irregular shape of the nuclei. $\times 525$.

Fig. 4. Active corpus allatum in the stage 5-6 days pre-oviposition. The gland has a spheroid shape, the cytoplasm is highly developed and the cell membranes are inconspicuous. As compared with the CA at ecdysis (compare Pl. VI fig. 6), the cells have grown isometrically (dark blue-green filter). $\times 525$.

Fig. 5. Corpus allatum of a female that has terminated oviposition. The irregularly shaped nuclei are still very large and contain much chromatin. These features are indicative of a high secretory activity (dark blue-green filter) $\times 525$.

Fig. 6. Not yet active corpus allatum at the moment of ecdysis. Unstained cells and cells stained darkly orange occur simultaneously (oblique illumination). $\times 525$.

Fig. 7. Active corpus allatum of an animal that has been kept in diapause for 5 months. Note its small size, the poorly developed cytoplasm, and the striking accumulation of a substance that has been stained red like the large ESC shown at the top. $\times 525$.

Fig. 8. Active corpus allatum, divided into lobes by connective tissue-lined invaginations of the haemocoel. $\times 525$. 
PLATE VI

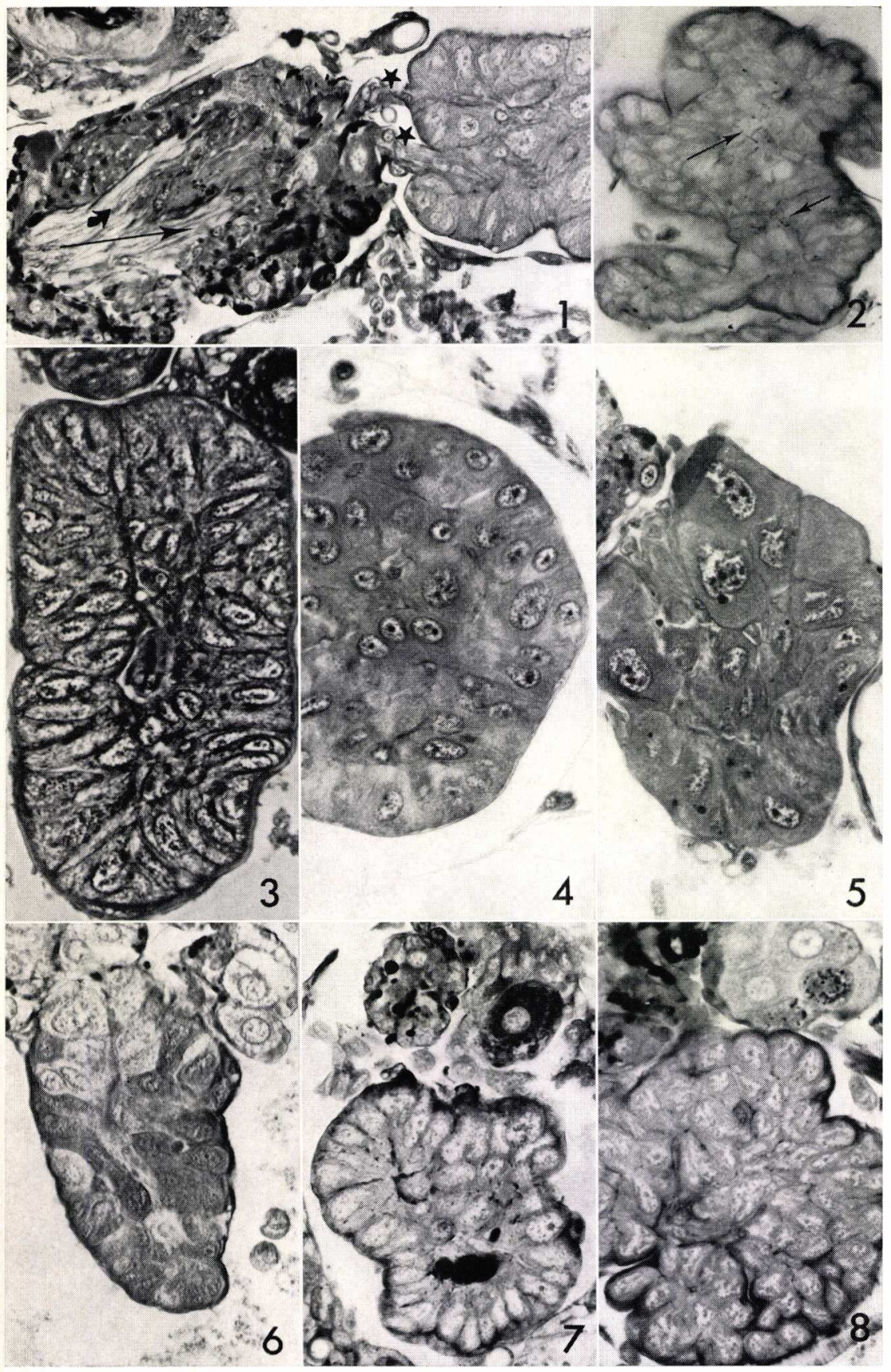


Figs. 1 and 2. Electron micrographs of an A-NSG (Fig. 1) and an $\mathrm{A}_{1}$-NSC (Fig. 2) of an actively ovipositing female. In both cells elementary neurosecretory granules (approximate diameters $1200 \AA$ in A-NSC, $1500 \AA$ in $\mathrm{A}_{1}$-NSC) and lysosomes (L) are present. In this stage, the endoplasmic reticulum is well-developed. Elementary granules are mainly found in association with Golgi complexes (Go). Note the origin of the axons $(\mathrm{Ax})$ and the thin glial sheaths $(\mathrm{Gl})$ enveloping the cellbodies. $\times 4160$.

Fig. 3. Three axon-terminals in the corpus cardiacum, containing A-NSM (on the left), $\mathrm{A}_{1}$-NSM (on the right), and B-NSM (in between). Note the differences in size and electron transparency of the elementary granules. A narrow channel, lined by connective tissue (CT), penetrates the interior of the corpus cardiacum and transports the NSM released to the body cavity (in the direction of the arrow). At the bottom, some mitochondria of a glial cell $(\mathrm{M}) . \times 25,000$.

(For all figures: brain and corpus cardiacum were fixed in $3.1 \%$ glutaraldehyde, post-fixed in 1\% osmiumtetroxide, and embedded in Epon 812; sections were stained with uranylacetate and leadcitrate, and examined in a Siemens Elmiscope I). 
PLATE VII

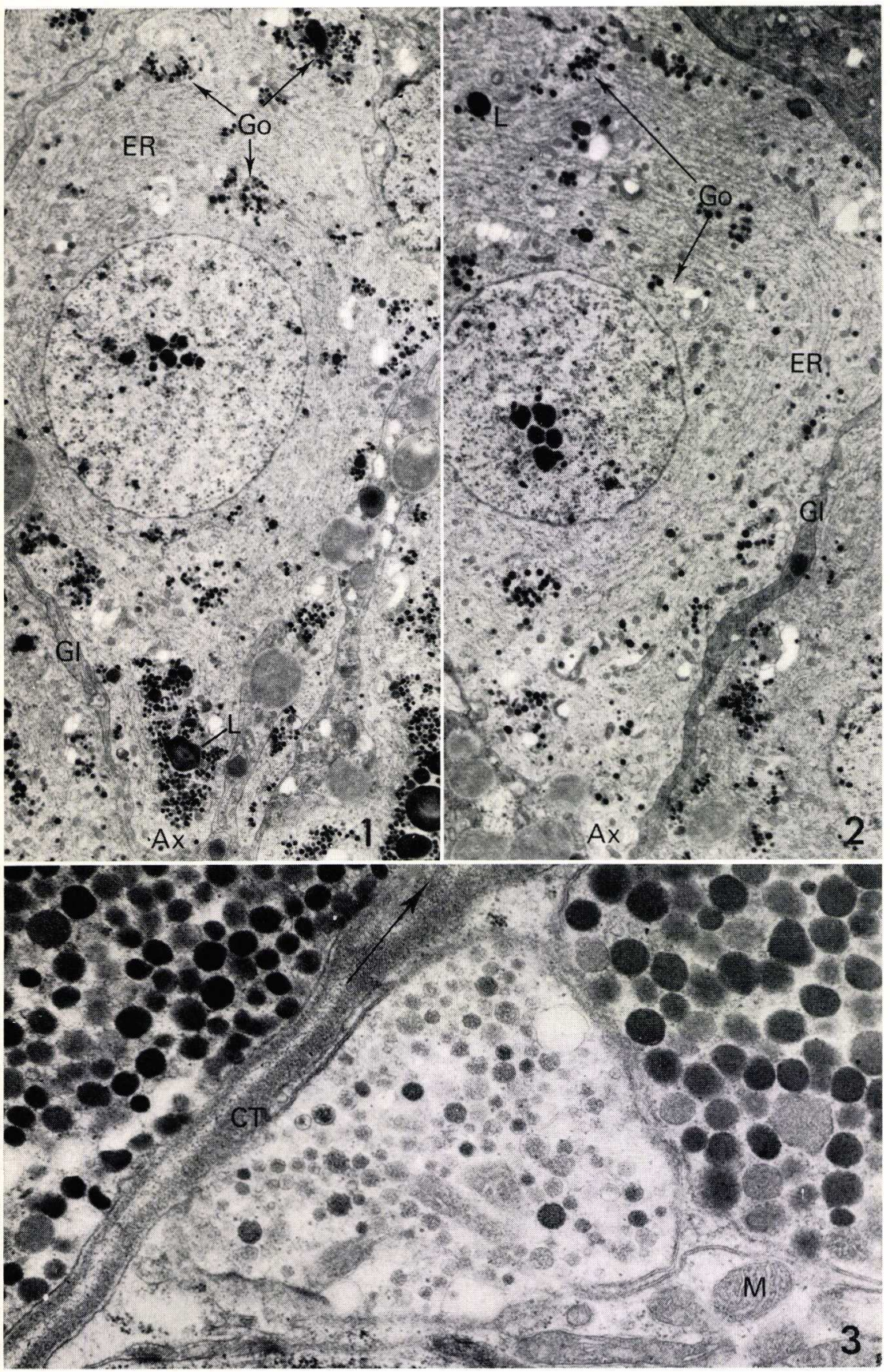


PLATE VIII
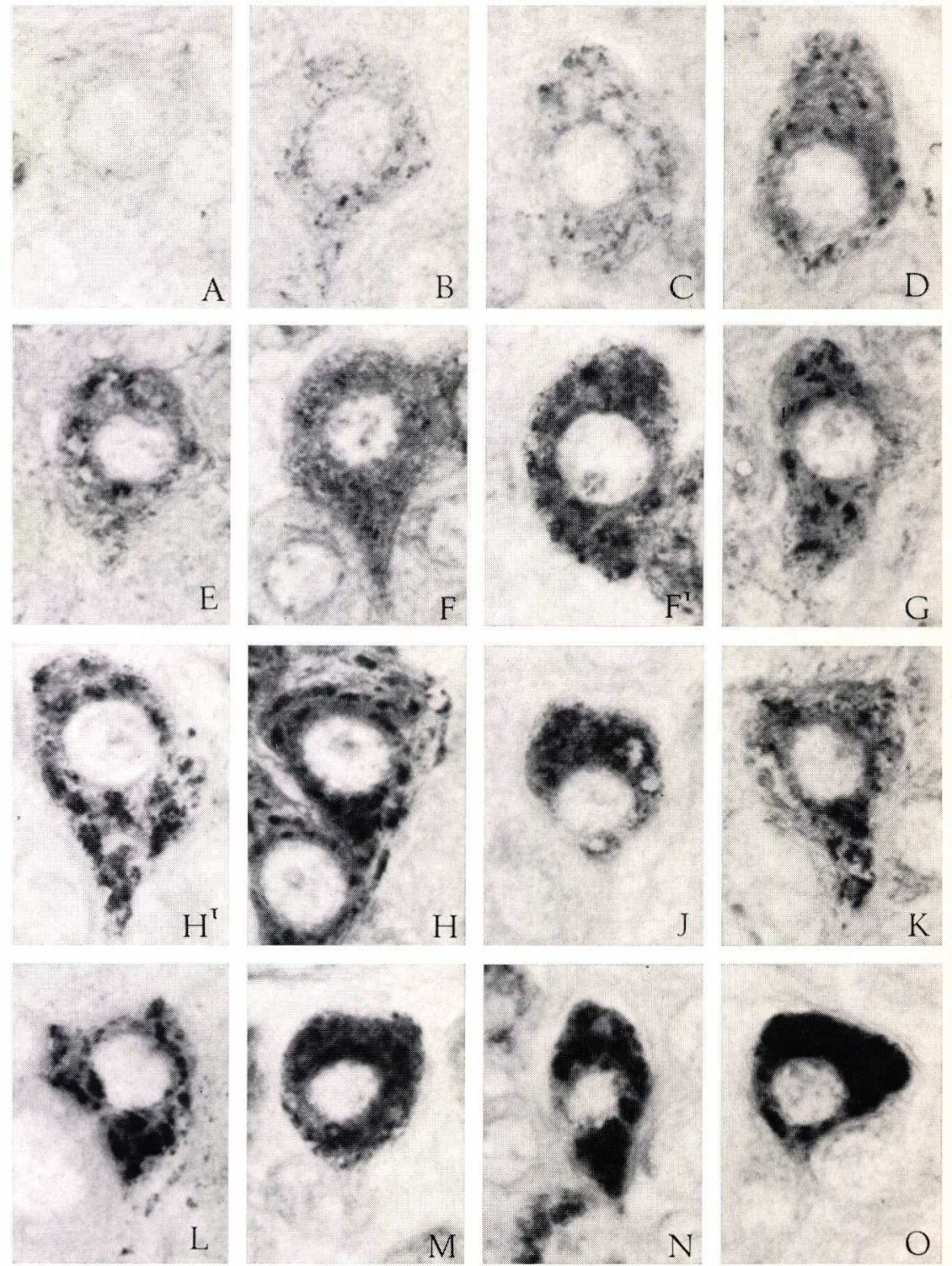

In the scoring-system used for expressing the amount of NSM and the degree of aggregation of neurosecretory particles within perikarya of the A-NSC, the above 16 stages (A... O) have been distinguished. For details, see Paragraph 5.1.1.2. $\times 1480$. 
PLATE IX
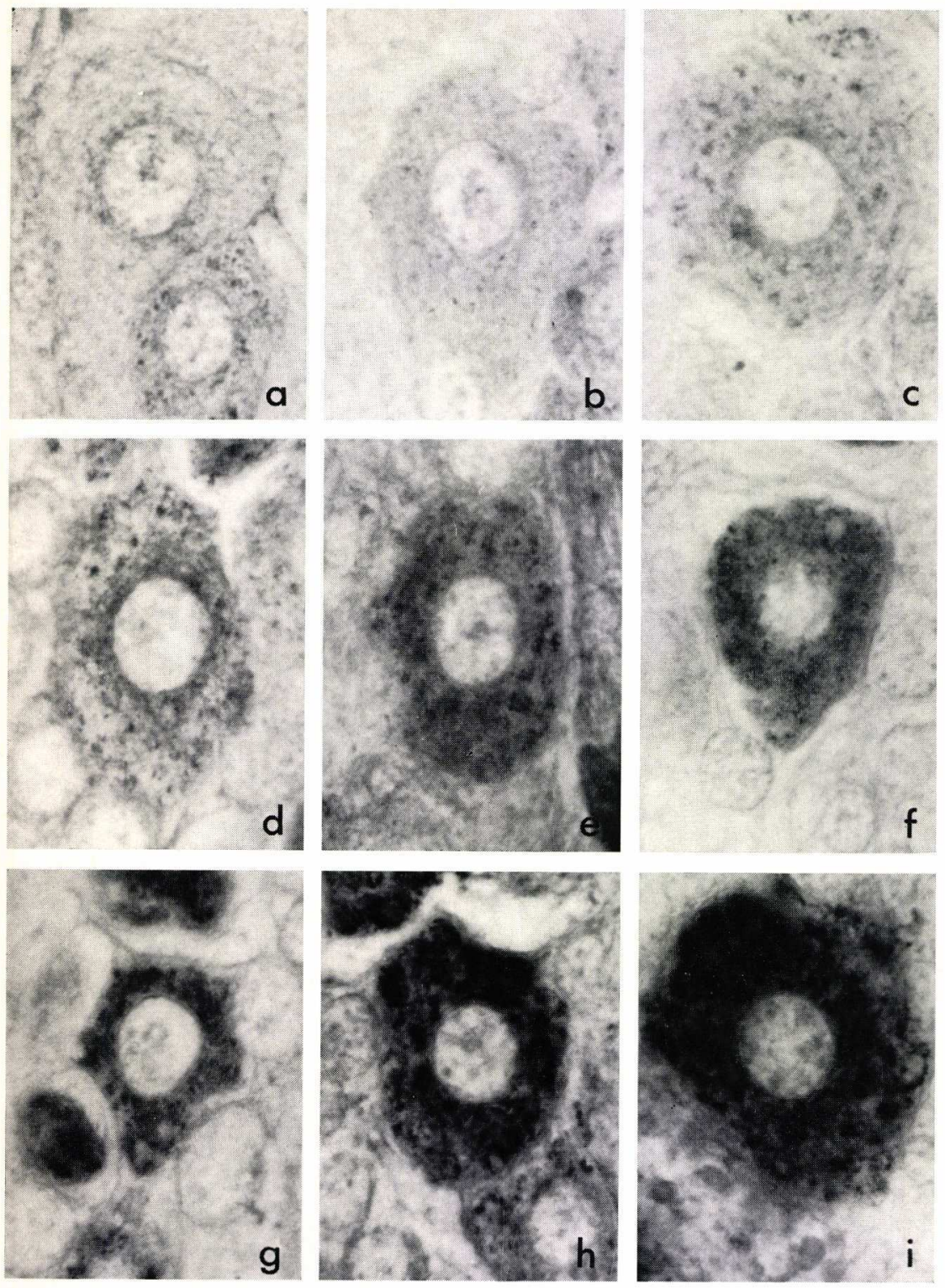

In the scoring-system used for expressing the degree of accumulation of NSM within perikarya of the C-NSC, the above 9 stages (a....i) have been distinguished. For details, see Section 5.3. × 1480 . 


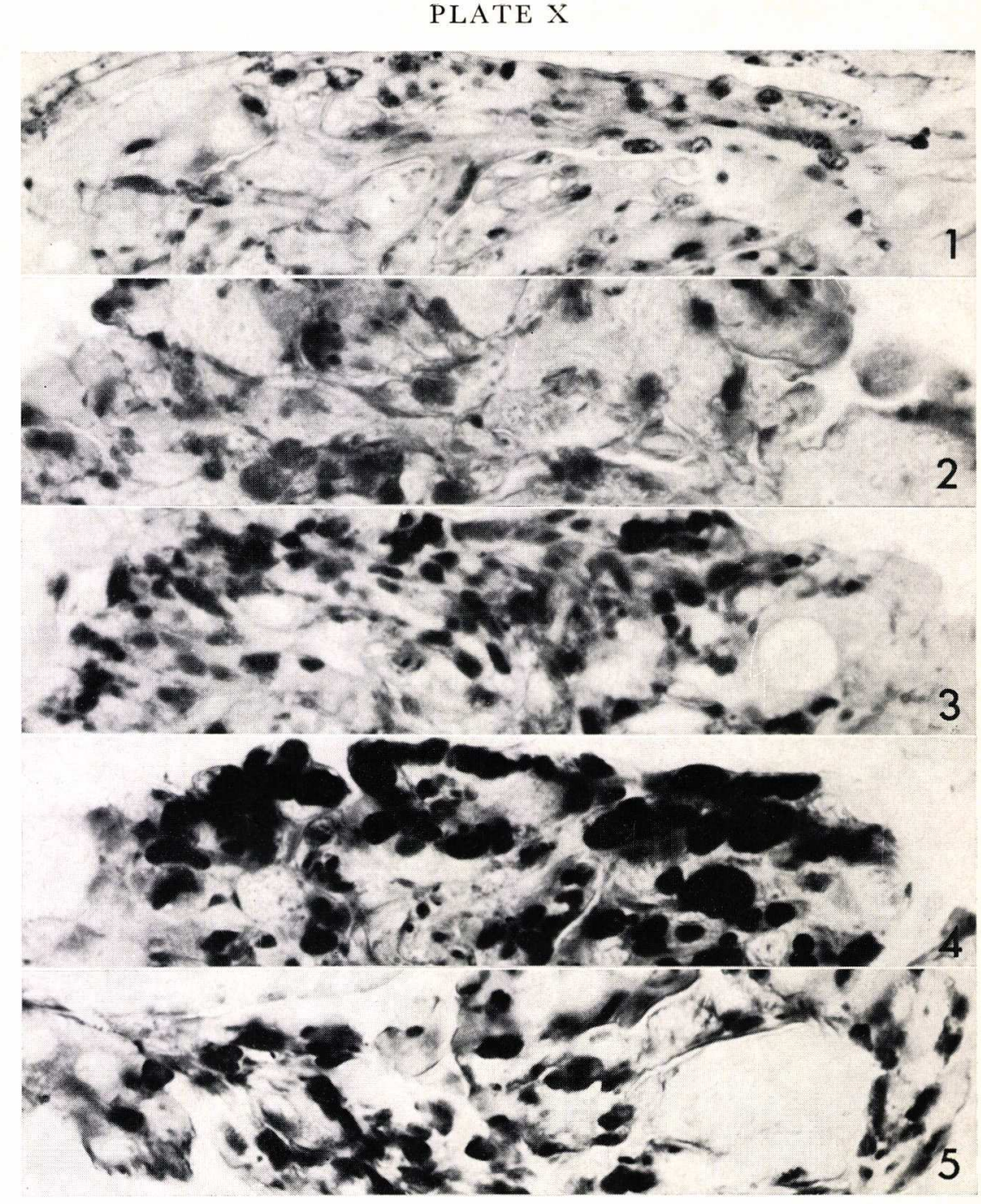

Figs. 1-5. For expressing the degree of accumulation of A- and $\mathrm{A}_{1}-\mathrm{NSM}$ in the corpus cardiacum, use has been made of three different scoring-systems, i.e., for i) the density of axon-terminals (scores a.../f), ii) the size of the axon-terminals (scores 1...5), and iii) the overall amount of NSM in the corpus cardiacum (scores 1...5). As to the area of a corpus cardiacum shown in Fig. 1, the scores for i-ii-iii are: b-2-1; Fig. 2: c-4-3; Fig. 3: d-3-3; Fig. 4: e-5-5; Fig. 5: /f-4-4. For details, see Paragraph 5.1.1.2 and Section 5.2. $\times 920$. 